FEDERAL RESERVE SYSTEM

12 CFR Parts 208 and 225

Regulations H and Y; Docket No. R-1154

FEDERAL DEPOSIT INSURANCE CORPORATION

12 CFR Part 325

RIN 3064-AC73

\author{
DEPARTMENT OF THE TREASURY \\ Office of Thrift Supervision \\ 12 CFR Part 567 \\ No. 2003-27 \\ RIN 1550-AB56
}

Risk-Based Capital Guidelines; Implementation of New Basel Capital Accord

AGENCIES: Office of the Comptroller of the Currency, Treasury; Board of Governors of the Federal Reserve System; Federal Deposit Insurance Corporation; and Office of Thrift Supervision, Treasury.

ACTION: Advance notice of proposed rulemaking.

SUMMARY: The Office of the Comptroller of the Currency (OCC), the Board of Governors of the Federal Reserve System (Board), the Federal Deposit Insurance Corporation (FDIC), and the Office of Thrift Supervision (OTS) (collectively, the Agencies) are setting forth for industry comment their current views on a proposed framework for implementing the New Basel Capital Accord in the United States. In particular, this advance notice of proposed rulemaking (ANPR) describes significant elements of the Advanced Internal Ratings-Based approach for credit risk and the Advanced Measurement Approaches for operational risk (together, the advanced approaches). The ANPR specifies criteria that would be used to determine banking organizations that would be required to use the advanced approaches, subject to meeting certain qualifying criteria, supervisory standards, and disclosure requirements. Other banking organizations that meet the criteria, standards, and requirements also would be eligible to use the advanced approaches. Under the advanced approaches, banking organizations would use internal estimates of certain risk components as key inputs in the determination of their regulatory capital requirements.

DATES: Comments must be received no later than November 3, 2003.

ADDRESSES: Comments should be directed to: 
OCC: Please direct your comments to: Office of the Comptroller of the Currency, $250 \mathrm{E}$ Street, S.W., Public Information Room, Mailstop 1-5, Washington, D.C. 20219, Attention: Docket No. 03-14; fax number (202) 874-4448; or Internet address: regs.comments@occ.treas.gov. Due to delays in paper mail delivery in the Washington area, we encourage the submission of comments by fax or e-mail whenever possible. Comments may be inspected and photocopied at the OCC's Public Information Room, 250 E Street, S.W., Washington, D.C. You may make an appointment to inspect comments by calling (202) 874-5043.

Board: Comments should refer to Docket No. R-1154 and may be mailed to Ms. Jennifer J. Johnson, Secretary, Board of Governors of the Federal Reserve System, $20^{\text {th }}$ Street and Constitution Avenue, N.W., Washington, D.C., 20551. However, because paper mail in the Washington area and at the Board of Governors is subject to delay, please consider submitting your comments by e-mail to regs.comments@federalreserve.gov., or faxing them to the Office of the Secretary at (202) 452-3819 or (202) 452-3102. Members of the public may inspect comments in Room MP-500 of the Martin Building between 9:00 a.m. and 5:00 p.m. weekdays pursuant to $\S 261.12$, except as provided by $\S 261.14$, of the Board's Rules Regarding Availability of Information, 12 CFR 261.12 and 261.14.

FDIC: Written comments should be addressed to Robert E. Feldman, Executive Secretary, Attention: Comments, Federal Deposit Insurance Corporation, $55017^{\text {th }}$ Street, N.W., Washington, D.C., 20429. Commenters are encouraged to submit comments by facsimile transmission to (202) 898-3838 or by electronic mail to Comments@FDIC.gov. Comments also may be hand-delivered to the guard station at the rear of the $55017^{\text {th }}$ Street Building (located on F Street) on business days between 8:30 a.m. and 5 p.m. Comments may be inspected and photocopied at the FDIC's Public Information Center, Room 100, $80117^{\text {th }}$ Street, N.W., Washington, D.C. between 9 a.m. and 4:30 p.m. on business days.

OTS: Send comments to Regulation Comments, Chief Counsel's Office, Office of Thrift Supervision, 1700 G Street, N.W., Washington, D.C. 20552, Attention: No. 2003-27. Delivery: Hand deliver comments to the Guard's desk, east lobby entrance, 1700 G Street, N.W., from 9:00 a.m. to 4:00 p.m. on business days, Attention: Regulation Comments, Chief Counsel's Office, Attention: No. 2003-27. Facsimiles: Send facsimile transmissions to FAX Number (202) 906-6518, Attention: No. 2003-27. E-Mail: Send e-mails to regs.comments@ots.treas.gov, Attention: No. 2003-27, and include your name and telephone number. Due to temporary disruptions in mail service in the Washington, D.C. area, commenters are encouraged to send comments by fax or e-mail, if possible.

\section{FOR FURTHER INFORMATION CONTACT:}

OCC: Roger Tufts, Senior Economic Advisor (202-874-4925 or roger.tufts@occ.treas.gov), Tanya Smith, Senior International Advisor (202-874-4735 or tanya.smith@occ.treas.gov), or Ron Shimabukuro, Counsel (202/874-5090 or ron.shimabukuro@occ.treas.gov).

Board: Barbara Bouchard, Assistant Director (202/452-3072 or barbara.bouchard@frb.gov), David Adkins, Supervisory Financial Analyst (202/452-5259 or david.adkins@,frb.gov), Division of 
Banking Supervision and Regulation, or Mark Van Der Weide, Counsel (202/452-2263 or mark.vanderweide@frb.gov), Legal Division. For users of Telecommunications Device for the Deaf (“TDD”) only, contact 202/263-4869.

FDIC: Keith Ligon, Chief (202/898-3618 or kligon@fdic.gov), Jason Cave, Chief (202/898-3548 or jcave@fdic.gov), Division of Supervision and Consumer Protection, or Michael Phillips, Counsel (202/898-3581 or mphillips@,fdic.gov).

OTS: Michael D. Solomon, Senior Program Manager for Capital Policy (202/906-5654); David W. Riley, Project Manager (202/906-6669), Supervision Policy; or Teresa A. Scott, Counsel (Banking and Finance) (202/906-6478), Regulations and Legislation Division, Office of the Chief Counsel, Office of Thrift Supervision, 1700 G Street, N.W., Washington, D.C. 20552.

\section{SUPPLEMENTARY INFORMATION:}

I. Executive Summary
A. Introduction
B. Overview of the New Accord
C. Overview of U.S. Implementation
The A-IRB Approach for Credit Risk
The AMA for Operational Risk
Other Considerations
D. Competitive Considerations

II. Application of the Advanced Approaches in the United States

A. Threshold Criteria for Mandatory Advanced Approach Organizations Application of Advanced Approaches at Individual Bank/Thrift Levels

U.S. Banking Subsidiaries of Foreign Banking Organizations

B. Implementation for Advanced Approach Organizations

C. Other Considerations

General Banks

Majority-Owned or Controlled Subsidiaries

Transitional Arrangements

III. Advanced Internal Ratings-Based Approach (A-IRB)

A. Conceptual Overview

Expected Losses versus Unexpected Losses

B. A-IRB Capital Calculations

Wholesale Exposures: Definitions and Inputs

Wholesale Exposures: Formulas

Wholesale Exposures: Other Considerations

Retail Exposures: Definitions and Inputs

Retail Exposures: Formulas

A-IRB: Other Considerations

Purchased Receivables

Credit Risk Mitigation Techniques

Equity Exposures

C. Supervisory Assessment of A-IRB Framework 
Overview of Supervisory Framework

U.S. Supervisory Review

IV. Securitization

A. General Framework

Operational Criteria

Differences Between the General A-IRB Framework and the A-IRB Approach for Securitization Exposures

B. Determining Capital Requirements

General Considerations

Capital Calculation Approaches

Other Considerations

V. AMA Framework for Operational Risk

A. AMA Capital Calculation

Overview of the Supervisory Criteria

B. Elements of an AMA Framework

VI. Disclosure

A. Overview

B. Disclosure Requirements

VII. Regulatory Analysis

A. Executive order 12866

B. Regulatory Flexibility Act

C. Unfunded Mandates Reform Act of 1995

D. Paperwork Reduction Act

List of Acronyms

\section{Executive Summary}

\section{A. Introduction}

In the United States, banks, thrifts, and bank holding companies (banking organizations or institutions) are subject to minimum regulatory capital requirements. Specifically, U.S. banking organizations must maintain a minimum leverage ratio and two minimum risk-based ratios. ${ }^{1}$ The current U.S. risk-based capital requirements are based on an internationally agreed framework for capital measurement that was developed by the Basel Committee on Banking Supervision (Basel Supervisors Committee or BSC) and endorsed by the G-10 Governors in 1988. ${ }^{2}$ The international framework (1988 Accord) accomplished several important objectives.

${ }^{1}$ The leverage ratio measures regulatory capital as a percentage of total on-balance-sheet assets as reported in accordance with generally accepted accounting principles (GAAP) (with certain adjustments). The risk-based ratios measure regulatory capital as a percentage of both on- and off-balance-sheet credit exposures with some gross differentiation based on perceived credit risk. The Agencies' capital rules may be found at 12 CFR Part 3 (OCC), 12 CFR Parts 208 and 225 (Board), 12 CFR Part 325 (FDIC), and 12 CFR Part 567 (OTS).

${ }^{2}$ The BSC was established in 1974 by the central-bank governors of the Group of Ten (G-10) countries. Countries are represented on the BSC by their central bank and also by authorities with bank supervisory responsibilities. Current member countries are Belgium, Canada, France, Germany, Italy, Japan, Luxembourg, the Netherlands, Spain, Sweden, Switzerland, the United Kingdom, and the United States. The 1988 Accord is described in a document entitled "International Convergence of Capital Measurement and Capital Standards." This document and other documents issued by the BSC are available through the Bank for International Settlements website at www.bis.org. 
It strengthened capital levels at large, internationally active banks and fostered international consistency and coordination. The 1988 Accord also reduced disincentives for banks to hold liquid, low-risk assets. Moreover, by requiring banks to hold capital against off-balance-sheet exposures, the 1988 Accord represented a significant step forward for regulatory capital measurement.

Although the 1988 Accord has been a stabilizing force for the international banking system, the world financial system has become increasingly more complex over the past fifteen years. The BSC has been working for several years to develop a new regulatory capital framework that recognizes new developments in financial products, incorporates advances in risk measurement and management practices, and more precisely assesses capital charges in relation to risk. On April 29, 2003, the BSC released for public consultation a document entitled "The New Basel Capital Accord" (New Accord) that sets forth proposed revisions to the 1988 Accord. The BSC will accept industry comment on the New Accord through July 31, 2003 and expects to issue a final revised Accord by the end of 2003. The BSC expects that the New Accord would have an effective date for implementation of December 31, 2006.

Accordingly, the Agencies are soliciting comment on all aspects of this ANPR, which is based on certain proposals in the New Accord. Comments will assist the Agencies in reaching a determination on a number of issues related to how the New Accord would be proposed to be implemented in the United States. In addition, in light of the public comments submitted on the ANPR, the Agencies will seek appropriate modifications to the New Accord.

\section{B. Overview of the New Accord}

The New Accord encompasses three pillars: minimum regulatory capital requirements, supervisory review, and market discipline. Under the first pillar, a banking organization must calculate capital requirements for exposure to both credit risk and operational risk (and market risk for institutions with significant trading activity). The New Accord does not change the definition of what qualifies as regulatory capital, the minimum risk-based capital ratio, or the methodology for determining capital charges for market risk. The New Accord provides several methodologies for determining capital requirements for both credit and operational risk. For credit risk there are two general approaches; the standardized approach (essentially a package of modifications to the 1988 Accord) and the internal ratings-based (IRB) approach (which uses an institution's internal estimates of key risk drivers to derive capital requirements). Within the IRB approach there is a foundation methodology, in which certain risk component inputs are provided by supervisors and others are supplied by the institutions, and an advanced methodology (A-IRB), where institutions themselves provide more risk inputs.

The New Accord provides three methodologies for determining capital requirements for operational risk; the basic indicator approach, the standardized approach, and the advanced measurement approaches (AMA). Under the first two methodologies, capital requirements for operational risk are fixed percentages of specified, objective risk measures (for example, gross income). The AMA provides the flexibility for an institution to develop its own individualized approach for measuring operational risk, subject to supervisory oversight. 
The second pillar of the New Accord, supervisory review, highlights the need for banking organizations to assess their capital adequacy positions relative to overall risk (rather than solely to the minimum capital requirement), and the need for supervisors to review and take appropriate actions in response to those assessments. The third pillar of the New Accord imposes public disclosure requirements on institutions that are intended to allow market participants to assess key information about an institution's risk profile and its associated level of capital.

The Agencies do not expect the implementation of the New Accord to result in a significant decrease in aggregate capital requirements for the U.S. banking system. Individual banking organizations may, however, face increases or decreases in their minimum risk-based capital requirements because the New Accord is more risk sensitive than the 1988 Accord and the Agencies' existing risk-based capital rules (general risk-based capital rules). The Agencies will continue to analyze the potential impact of the New Accord on both systemic and individual bank capital levels.

\section{Overview of U.S. Implementation}

The Agencies believe that the advanced risk and capital measurement methodologies of the New Accord are the most appropriate approaches for large, internationally active banking organizations. As a result, large, internationally active banking organizations in the United States would be required to use the A-IRB approach to credit risk and the AMA to operational risk. The Agencies are proposing to identify three types of banking organizations: institutions subject to the advanced approaches on a mandatory basis (core banks); institutions not subject to the advanced approaches on a mandatory basis, but that choose voluntarily to apply those approaches (opt-in banks); and institutions that are not mandatorily subject to and do not apply the advanced approaches (general banks). Core banks would be those with total banking (and thrift) assets of $\$ 250$ billion or more or total on-balance-sheet foreign exposure of $\$ 10$ billion or more. Both core banks and opt-in banks (advanced approach banks) would be required to meet certain infrastructure requirements (including complying with specified supervisory standards for credit risk and operational risk) and make specified public disclosures before being able to use the advanced approaches for risk-based regulatory capital calculation purposes. ${ }^{3}$

General banks would continue to apply the general risk-based capital rules. Because the general risk-based capital rules include a buffer for risks not easily quantified (for example, operational risk and concentration risk), general banks would not be subject to an additional direct capital charge for operational risk.

Under this proposal, some U.S. banking organizations would use the advanced approaches while others would apply the general risk-based capital rules. As a result, the United States would have a bifurcated regulatory capital framework. That is, U.S. capital rules would provide two distinct methodologies for institutions to calculate risk-weighted assets (the denominator of the risk-based capital ratios). Under the proposed framework, all U.S. institutions would continue to calculate regulatory capital, the numerator of the risk-based capital ratios, as they do now. Importantly, U.S. banking organizations would continue to be subject to

\footnotetext{
${ }^{3}$ The Agencies continue to reserve the right to require higher minimum capital levels for individual institutions, on a case-by-case basis, if necessary to address particular circumstances.
} 
a leverage ratio requirement under existing regulations, and Prompt Corrective Action (PCA) legislation and implementing regulations would remain in effect. ${ }^{4}$ It is recognized that in some cases, under the proposed framework, the leverage ratio would serve as the most binding regulatory capital constraint.

Implementing the capital framework described in this ANPR would raise a number of significant practical and conceptual issues about the role of economic capital calculations relative to regulatory capital requirements. The capital formulas described in this ANPR, as well as the economic capital models used by banking organizations, assume the ability to assign precisely probabilities to future credit and operational losses that might occur. The term "economic capital" is often used to refer to the amount of capital that should be allocated to an activity according to the results of such an exercise. For example, a banking organization might compute the amount of income, reserves, and capital that it would need to cover the $99.9^{\text {th }}$ percentile of possible credit losses associated with a given type of lending. The desired degree of certainty of covering losses is related to several factors including, for example, the banking organization's target credit rating. The higher the loss percentile the institution wishes to provide protection against, the less likely the capital held by the institution would be insufficient to cover losses, and the higher would be the institution's credit rating.

While the Agencies intend to move to a framework where regulatory capital is more closely aligned to economic capital, the Agencies do not intend to place sole reliance on the results of economic capital calculations for purposes of computing minimum regulatory capital requirements. Banking organizations face risks other than credit and operational risks, and the assumed loss distributions underlying banking organizations' economic capital calculations are subject to the risk of error. Consequently, the Agencies continue to view the leverage ratio tripwires contained in existing PCA and other regulations as important components of the regulatory capital framework.

\section{The A-IRB Approach for Credit Risk}

Under the A-IRB approach for credit risk, an institution's internal assessment of key risk drivers for a particular exposure (or pool of exposures) would serve as the primary inputs in the calculation of the institution's minimum risk-based capital requirements. Formulas, or risk weight functions, specified by supervisors would use the banking organization's estimated inputs to derive a specific dollar amount capital requirement for each exposure (or pool of exposures). This dollar capital requirement would be converted into a risk-weighted assets equivalent by multiplying the dollar amount of the capital requirement by 12.5 - the reciprocal of the 8 percent minimum risk-based capital requirement. Generally, banking organizations using the A-IRB approach would assign assets and off-balance-sheet exposures into one of three portfolios: wholesale (corporate, interbank, and sovereign), retail (residential mortgage, qualifying revolving, and other), and equities. There also would be specific treatments for securitization exposures and purchased receivables. Certain assets that do not constitute a direct credit exposure (for example, premises, equipment, or mortgage servicing rights) would continue to be

\footnotetext{
${ }^{4}$ Thus, for example, to be in the well-capitalized PCA category a bank must have at least a 10 percent total riskbased capital ratio, a 6 percent Tier 1 risk-based capital ratio, and a 5 percent leverage ratio. The other PCA categories also would not change.
} 
subject to the general risk-based capital rules and risk weighted at 100 percent. A brief overview of each A-IRB portfolio follows.

Wholesale (Corporate, Interbank, and Sovereign) Exposures

Wholesale credit exposures comprise three types of exposures: corporate, interbank, and sovereign. Generally, the meaning of interbank and sovereign would be consistent with the general risk-based capital rules. Corporate exposures are exposures to private-sector companies; interbank exposures are primarily exposures to banks and securities firms; and sovereign exposures are those to central governments, central banks, and certain other public-sector entities (PSEs). Within the wholesale exposure category, in addition to the treatment for general corporate lending, there would be four sub-categories of specialized lending (SL). These are project finance $(\mathrm{PF})$, object finance $(\mathrm{OF})$, commodities finance $(\mathrm{CF})$, and commercial real estate (CRE). CRE is further subdivided into low-asset-correlation CRE, and high-volatility CRE (HVCRE).

For each wholesale exposure, an institution would assign four quantitative risk drivers (inputs): (1) probability of default (PD), which measures the likelihood that the borrower will default over a given time horizon; (2) loss given default (LGD), which measures the proportion of the exposure that will be lost if a default occurs; (3) exposure at default (EAD), which is the estimated amount owed to the institution at the time of default; and (4) maturity (M), which measures the remaining economic maturity of the exposure. Institutions generally would be able to take into account credit risk mitigation techniques (CRM), such as collateral and guarantees (subject to certain criteria), by adjusting their estimates for PD or LGD. The wholesale A-IRB risk weight function would use all four risk inputs to produce a specific capital requirement for each wholesale exposure. There would be a separate, more conservative risk weight function for certain acquisition, development, and construction loans (ADC) in the HVCRE category.

\section{$\underline{\text { Retail Exposures }}$}

Within the retail category, three distinct risk weight functions are proposed for three product areas that exhibit different historical loss experiences and different asset correlations. ${ }^{5}$ The three retail sub-categories would be: (1) exposures secured by residential mortgages and related exposures; (2) qualifying revolving exposures (QRE); and (3) other retail exposures. QRE would include unsecured revolving credits (such as credit cards and overdraft lines), and other retail would include most other types of exposures to individuals, as well as certain exposures to small businesses. The key inputs to the three retail risk weight functions would be a banking organization's estimates of PD, LGD, and EAD. There would be no explicit M component to the retail A-IRB risk weight functions. Unlike wholesale exposures, for retail exposures, an institution would assign a common set of inputs (PD, LGD, and EAD) to predetermined pools of exposures, which are typically referred to as segments, rather than to

\footnotetext{
${ }^{5}$ Asset correlation is a measure of the tendency for the financial condition of a borrower in a banking organization's portfolio to improve or degrade at the same time as the financial condition of other borrowers in the portfolio improve or degrade.
} 
individual exposures. ${ }^{6}$ The inputs would be used in the risk weight functions to produce a capital charge for the associated pool of exposures.

\section{Equity Exposures}

Banking organizations would use a market-based internal model for determining capital requirements for equity exposures in the banking book. The internal model approach would assess capital based on an estimate of loss under extreme market conditions. Some equity exposures, such as holdings in entities whose debt obligations qualify for a zero percent risk weight, would continue to receive a zero percent risk weight under the A-IRB approach to equities. Certain other equity exposures, such as those made through a small business investment company (SBIC) under the Small Business Investment Act or a community development corporation (CDC) or a community and economic development entity (CEDE), generally would be risk weighted at 100 percent under the A-IRB approach to equities. Banking organizations that are subject to the Agencies' market risk capital rules would continue to apply those rules to assess capital against equity positions held in the trading book. ${ }^{7}$ Banking organizations that are not subject to the market risk capital rules would treat equity positions in the trading account as if they were in the banking book.

\section{$\underline{\text { Securitization Exposures }}$}

Under the A-IRB treatment for securitization exposures, a banking organization that originates a securitization would first calculate the A-IRB capital charge that would have been assessed against the underlying exposures as if the exposures had not been securitized. This capital charge divided by the size of the exposure pool is referred to as KIRB. If an originating banking organization retains a position in a securitization that obligates the banking organization to absorb losses up to or less than KIRB, the banking organization would deduct the retained position from capital as is currently required under the general risk-based capital rules. The general risk-based capital rules, however, require a dollar-for-dollar risk-based capital deduction for certain residual interests retained by originating banking organizations in asset securitization transactions regardless of amount. The A-IRB framework would no longer require automatic deduction of such residual interests. The amount to be deducted would be capped at KIRB for most exposures. For a position in excess of the KIRB threshold, the originating banking organization would use an external-ratings-based approach (if the position has been rated by an external rating agency or a rating can be inferred) or a supervisory formula to determine the capital charge for the position.

Non-originating banking organizations that invest in a securitization exposure generally would use an external-ratings-based approach (if the exposure has been rated by an external

\footnotetext{
${ }^{6}$ When the PD, LGD, and EAD parameters are assigned separately to individual exposures, it may be referred to as a "bottom-up" approach. When those parameters are assigned to predetermined sets of exposures (pools or segments), it may be referred to as a "top-down" approach.

${ }^{7}$ The market risk capital rules were implemented by the banking agencies in 1996. The market risk capital rules apply to any banking organization whose trading activity (on a consolidated worldwide basis) equals 10 percent or more of total assets, or $\$ 1$ billion or more. The market risk capital rules are found at 12 CFR Part 3, Appendix B (OCC), 12 CFR Parts 208 and 225, Appendix E (Board), and 12 CFR Part 325, Appendix C (FDIC). The OTS, to date, has not adopted the market risk capital rules.
} 
rating agency or a rating can be inferred). For unrated liquidity facilities that banking organizations provide to securitizations, capital requirements would be based on several factors, including the asset quality of the underlying pool and the degree to which other credit enhancements are available. These factors would be used as inputs to a supervisory formula. Under the A-IRB approach to securitization exposures, banking organizations also would be required in some cases to hold regulatory capital against securitizations of revolving exposures that have early amortization features.

\section{$\underline{\text { Purchased Receivables }}$}

Purchased receivables, that is, those that are purchased from another institution either through a one-off transaction or as part of an ongoing program, would be subject to a two-part capital charge: one part is for the credit risk arising from the underlying receivables and the second part is for dilution risk. Dilution risk refers to the possibility that contractual amounts payable by the underlying obligors on the receivables may be reduced through future cash payments or other credits to the accounts made by the seller of the receivables. The framework for determining the capital charge for credit risk permits a purchasing organization to use a topdown (pool) approach to estimating PDs and LGDs when the purchasing organization is unable to assign an internal risk rating to each of the purchased accounts. The capital charge for dilution risk would be calculated using the wholesale risk weight function with some additional specified risk inputs.

\section{The AMA for Operational Risk}

Under the A-IRB approach, capital charges for credit risk would be directly calibrated solely for such risk and, thus, unlike the 1988 Accord, would not implicitly include a charge for operational risk. As a result, the Agencies are proposing that banking organizations operating under the A-IRB approach also would have to hold regulatory capital for exposure to operational risk. The Agencies are proposing to define operational risk as the risk of losses resulting from inadequate or failed internal processes, people, and systems, or external events. Under the AMA, each banking organization would be able to use its own methodology for assessing exposure to operational risk, provided the methodology is comprehensive and results in a capital charge that is reflective of the operational risk experience of the organization. The operational risk exposure would be multiplied by 12.5 to determine a risk-weighted assets equivalent, which would be added to the comparable amounts for credit and market risk in the denominator of the risk-based capital ratios. The Agencies will be working closely with institutions over the next few years as operational risk measurement and management techniques continue to evolve.

\section{Other Considerations}

\section{$\underline{\text { Boundary Issues }}$}

With the introduction of an explicit regulatory capital charge for operational risk, an issue arises about the proper treatment of losses that can be attributed to more than one risk factor. For example, where a loan defaults and the banking organization discovers that the collateral for the loan was not properly secured, the banking organization's resulting losses would be attributable 
to both credit and operational risk. The Agencies recognize that these types of boundary issues are important and have significant implications for how banking organizations would compile loss data sets and compute regulatory capital charges.

The Agencies are proposing the following standard to govern the boundary between credit and operational risk: A loss event that has characteristics of credit risk would be incorporated into the credit risk calculations for regulatory capital (and would not be incorporated into operational risk capital calculations). This would include credit-related fraud losses. Thus, in the above example, the loss from the loan would be attributed to credit risk (not operational risk) for regulatory capital purposes. This separation between credit and operational risk is supported by current U.S. accounting standards for the treatment of credit risks.

With regard to the boundary between the trading book and the banking book, for institutions subject to the market risk rules, positions currently subject to those rules include all positions held in the trading account consistent with GAAP. The New Accord proposed additional criteria for positions includable in the trading book for purposes of market risk capital requirements. The Agencies encourage comment on these additional criteria and whether the Agencies should consider adopting such criteria (in addition to the GAAP criteria) in defining the trading book under the Agencies' market risk capital rules. The Agencies are seeking comment on the proposed treatment of the boundaries between credit, operational, and market risk.

\section{Supervisory Considerations}

The advanced approaches introduce greater complexity to the regulatory capital framework and would require a high level of sophistication in the banking organizations that implement the advanced approaches. As a result, the Agencies propose to require core and optin banks to meet certain infrastructure requirements and comply with specific supervisory standards for credit risk and for operational risk. In addition, banking organizations would have to satisfy a set of public disclosure requirements as a prerequisite for approval to using the advanced approaches. Supervisory guidance for each credit risk portfolio type, as well as for operational risk, is being developed to ensure a sufficient degree of consistency within the supervisory framework, while also recognizing that internal systems will differ between banking organizations. The goal is to establish a supervisory framework within which all institutions must develop their internal systems, leaving exact details to each institution. In the case of operational risk in particular, the Agencies recognize that measurement methodologies are still evolving and flexibility is needed.

It is important to note that supervisors would not look at compliance with requirements, or standards alone. Supervisors also would evaluate whether the components of an institution's advanced approaches are consistent with the overall objective of sound risk management and measurement. An institution would have to use appropriately the advanced approaches across all material business lines, portfolios, and geographic regions. Exposures in non-significant business units as well as asset classes that are immaterial in terms of size and perceived risk profile may be exempted from the advanced approaches with supervisory approval. These immaterial portfolios would be subject to the general risk-based capital rules. 
Proposed supervisory guidance for corporate credit exposures and for operational risk is provided separately from this ANPR in today's Federal Register. The draft supervisory guidance for corporate credit exposures is entitled "Supervisory Guidance on Internal-Ratings-Based Systems for Corporate Credit." The guidance includes specified supervisory standards that an institution's internal rating system for corporate exposures would have to satisfy for the institution to be eligible to use the A-IRB approach for credit risk. The draft operational risk guidance is entitled "Supervisory Guidance on Operational Risk Advanced Measurement Approaches for Regulatory Capital." The operational risk guidance includes identified supervisory standards for an institution's AMA framework for operational risk. The Agencies encourage commenters to review and comment on the draft guidance pieces in conjunction with this ANPR. The Agencies intend to issue for public comment supervisory guidance on retail credit exposures, equity exposures, and securitization exposures over the next several months.

\section{Supervisory Review}

As mentioned above, the second pillar of the New Accord focuses on supervisory review to ensure that an institution holds sufficient capital given its overall risk profile. The concepts of Pillar 2 are not new to U.S. banking organizations. U.S. institutions already are required to hold capital sufficient to meet their risk profiles, and supervisors may require that an institution hold more capital if its current levels are deficient or some element of its business practices suggest the need for more capital. The Agencies also have the right to intervene when capital levels fall to an unacceptable level. Given these long-standing elements of the U.S. supervisory framework, the Agencies are not proposing to introduce specific requirements or guidelines to implement Pillar 2. Instead, existing guidance, rules, and regulations would continue to be enforced and supplemented as necessary as part of this proposed new regulatory capital framework. However, all institutions operating under the advanced approaches would be expected by supervisors to address specific assumptions embedded in the advanced approaches (such as diversification in credit portfolios), and would be evaluated for their ability to account for deviations from the underlying assumptions in their own portfolios.

\section{Disclosure}

An integral part of the advanced approaches is enhanced public disclosure practices and improved transparency. Under the Agencies' proposal, specific disclosure requirements would be applicable to all institutions using the advanced approaches. These disclosure requirements would encompass capital, credit risk, equities, credit risk mitigation, securitization, market risk, operational risk, and interest rate risk in the banking book.

\section{Competitive Considerations}

It is essential that the Agencies gain a full appreciation of the possible competitive equity concerns that may be presented by the establishment of a new capital framework. The creation of a bifurcated capital framework in the United States -- one set of capital standards applicable to large, internationally active banking organizations (and those that choose to apply the advanced approaches), and another set of standards applicable to all other institutions -- has created concerns among some parties about the potential impact on competitive equity between the two sets of banking organizations. Similarly, differences in supervisory application of the advanced 
approaches (both within the United States and abroad) among large, internationally active institutions may pose competitive equity issues among such institutions.

The New Accord relies upon compliance with certain minimum operational and supervisory requirements to promote consistent interpretation and uniformity in application of the advanced approaches. Nevertheless, independent supervisory judgment will be applied on a case-by-case basis. These processes, albeit subject to detailed and explicit supervisory guidance, contain an inherent amount of subjectivity and must be assessed by supervisors on an ongoing basis. This supervisory assessment of the internal processes and controls leading to an institution's internal ratings and other estimates must maintain the high level of internal risk measurement and management processes contemplated in this ANPR.

The BSC's Accord Implementation Group (AIG), in which the Agencies play an active role, will seek to ensure that all jurisdictions uniformly apply the same high qualitative and quantitative standards to internationally active banking institutions. However, to the extent that different supervisory regimes implement these standards differently, there may be competitive dislocations. One concern is that the U.S. supervisory regime will impose greater scrutiny in its implementation standards, particularly given the extensive on-site presence of bank examiners in the United States.

Quite distinct from the need for a level playing field among internationally active institutions are the competitive concerns of those institutions that do not elect to adopt or may not qualify for the advanced approaches. Some banking organizations have expressed concerns that small or regional banks would become more likely to be acquired by larger organizations seeking to lever capital efficiencies. There also is a qualitative concern about the impact of being considered a "second tier" institution (one that does not implement the advanced approaches) by the market, rating agencies, or sophisticated customers such as government or municipal depositors and borrowers. Finally, there is the question of what, if any, competitive distortions might be introduced by differences in regulatory capital minimums between the advanced approaches and the general risk-based capital rules for loans or securities with otherwise similar risk characteristics, and the extent to which such distortions may be mitigated in an environment in which well-managed banking organizations continue to hold excess capital. ${ }^{8}$

Because the advanced framework described in this ANPR is more risk-sensitive than the 1988 Accord and the general risk-based capital rules, banking organizations under the advanced approaches would face increases in their minimum risk-based capital charges on some assets and decreases on others. The results of a Quantitative Impact Study (QIS3) the BSC conducted in late 2002 indicated the potential for the advanced approaches described in this document to produce significant changes in risk-based capital requirements for specific activities; the results

\footnotetext{
${ }^{8}$ The Agencies note that under the general risk-based capital rules some institutions currently are able to hold less capital than others on some types of assets (for example, through innovative financing structures or use of credit risk mitigation techniques). In addition, some institutions may hold lower amounts of capital because the market perceives them as highly diversified, while others hold higher amounts of capital because of concentrations of credit risk or other factors.
} 
also varied on an institution-by-institution basis. The results of QIS3 can be found at www.bis.org and various results of QIS3 are noted at pertinent places in this ANPR.

The Agencies do not believe the results of QIS3 are sufficiently reliable to form the basis of a competitive impact analysis, both because the inputs to the study were provided on a bestefforts basis and because the proposals in this ANPR are in some cases different than those that formed the basis of QIS3. The Agencies are nevertheless interested in views on how changes in regulatory capital (for the total of credit and operational risk) of the magnitude described in QIS3, if such changes were in fact realized, would affect the competitive landscape for domestic banking organizations.

The Agencies plan to conduct at least one more QIS, and potentially other economic impact analyses, to better understand the potential impact of the proposed framework on the capital requirements for individual U.S. banking organizations and U.S. banking organizations as a whole. This may affect the Agencies' further proposals through recalibrating the A-IRB risk weight formulas and making other modifications to the proposed approaches if the capital requirements do not seem consistent with the overall risk profiles of banking organizations or safe and sound banking practices.

If competitive effects of the New Accord are determined to be significant, the Agencies would need to consider potential ways to address those effects while continuing to seek to achieve the objectives of the current proposal. Alternatives could potentially include modifications to the proposed approaches, as well as fundamentally different approaches. The Agencies recognize that an optimal capital system must strike a balance between the objectives of simplicity and regulatory consistency across banking organizations on the one hand, and the degree of risk sensitivity of the regulation on the other. There are many criteria that must be evaluated in achieving this balance, including the resulting incentives for improving risk measurement and management practices, the ease of supervisory and regulatory enforcement, the degree to which the overall level of regulatory capital in the banking system is broadly preserved, and the effects on domestic and international competition. The Agencies are interested in commenters' views on alternatives to the advanced approaches that could achieve this balance, and in particular on alternatives that could do so without a bifurcated approach. ${ }^{9}$

The Agencies are committed to investigate the full scope of possible competitive impact and welcome all comments in this regard. Some questions are suggested below that may serve to focus commenters' general reactions. More specific questions also are suggested throughout this ANPR. These questions should not be viewed as limiting the Agencies' areas of interest or commenters' submissions on the proposals. The Agencies encourage commenters to provide supporting data and analysis, if available.

What are commenters' views on the relative pros and cons of a bifurcated regulatory capital framework versus a single regulatory capital framework? Would a

\footnotetext{
${ }^{9}$ In this regard, alternative approaches would take time to develop, but might present fewer implementation challenges. Additional work would be necessary to advance the goal of competitive equity among internationally active banking organizations. If consensus on alternative approaches could not be reached at the BSC, a departure from the Basel framework also could raise significant international and domestic issues.
} 
bifurcated approach lead to an increase in industry consolidation? Why or why not? What are the competitive implications for community and mid-size regional banks? Would institutions outside of the core group be compelled for competitive reasons to optin to the advanced approaches? Under what circumstances might this occur and what are the implications? What are the competitive implications of continuing to operate under a regulatory capital framework that is not risk sensitive?

If regulatory minimum capital requirements declined under the advanced approaches, would the dollar amount of capital held by advanced approach banking organizations also be expected to decline? To the extent that advanced approach institutions have lower capital charges on certain assets, how probable and significant are concerns that those institutions would realize competitive benefits in terms of pricing credit, enhanced returns on equity, and potentially higher risk-based capital ratios? To what extent do similar effects already exist under the current general risk-based capital rules (for example, through securitization or other techniques that lower relative capital charges on particular assets for only some institutions)? If they do exist now, what is the evidence of competitive harm?

Apart from the approaches described in this ANPR, are there other regulatory capital approaches that are capable of ameliorating competitive concerns while at the same time achieving the goal of better matching regulatory capital to economic risks? Are there specific modifications to the proposed approaches or to the general risk-based capital rules that the Agencies should consider?

\section{Application of the Advanced Approaches in the United States}

By its terms, the 1988 Accord applied only to internationally active banks. Under the New Accord, the scope of application has been broadened also to encompass bank holding companies that are parents of internationally active "banking groups."

\section{A. Threshold Criteria for Mandatory Advanced Approach Organizations}

The Agencies believe that for large, internationally active U.S. institutions only the advanced approaches are appropriate. Accordingly, the Agencies intend to identify three groups of banking organizations: (1) large, internationally active banking organizations that would be subject to the A-IRB approach and AMA on a mandatory basis (core banks); (2) organizations not subject to the advanced approaches on a mandatory basis, but that voluntarily choose to adopt those approaches (opt-in banks); and all remaining organizations that are not mandatorily subject to and do not apply the advanced approaches (general banks).

For purposes of identifying core banks, the Agencies are proposing a set of objective criteria for industry consideration. Specifically, the Agencies are proposing to treat as a core bank any banking organization that has (1) total commercial bank (and thrift) assets of $\$ 250$ billion or more, as reported on year-end regulatory reports (with banking assets of consolidated 
groups aggregated at the U.S. bank holding company level); ${ }^{10}$ or (2) total on-balance-sheet foreign exposure of $\$ 10$ billion or more, as reported on the year-end Country Exposure Report (FFIEC 009) (with foreign exposure of consolidated groups aggregated at the U.S. bank holding company level). These threshold criteria are independent; meeting either condition would mean an institution is a core bank.

Once an institution becomes a core bank it would remain subject to the advanced approaches on a going forward basis. If, in subsequent years, such an institution were to drop below both threshold levels it would continue to be a core bank unless it could demonstrate to its primary Federal supervisor that it has substantially and permanently downsized and should no longer be a core bank. The Agencies are proposing an annual test for assessing banking organizations in reference to the threshold levels. However, as a banking organization approaches either of the threshold levels the Agencies would expect to have ongoing dialogue with that organization to ensure that appropriate practices are in place or are actively being developed to prepare the organization for implementation of the advanced approaches.

Institutions that by expansion or merger meet the threshold levels must qualify for use of the advanced approaches and would be subject to the same implementation plan requirements and minimum risk-based capital floors applicable to core and opt-in banks as described below. Institutions that seek to become opt-in banks would be expected to notify their primary Federal supervisors well in advance of the date by which they expect to qualify for the advanced approaches. Based on the aforementioned threshold levels, the Agencies anticipate at this time that approximately ten U.S. institutions would be core banks.

\section{Application of Advanced Approaches at Individual Bank/Thrift Levels}

The Agencies are aware that some institutions might, on a consolidated basis, exceed one of the threshold levels for mandatory application of the A-IRB approach and AMA and, yet, might be comprised of distinct bank and thrift charters whose respective sizes fall well below the thresholds. In those cases, the Agencies believe that all bank and thrift institutions that are members of a consolidated group that is itself a core bank or an opt-in bank should calculate and report their risk-based capital requirements under the advanced approaches. However, recognizing that separate bank and thrift charters may, to a large extent, be independently managed and have different systems and portfolios, the Agencies are interested in comment on the efficacy and burden of a framework that requires the advanced approaches to be implemented by (or pushed down to) each of the separate subsidiary banks and thrifts that make up the consolidated group.

\section{U.S. Banking Subsidiaries of Foreign Banking Organizations}

Any U.S. bank or thrift that is a subsidiary of a foreign bank would have to comply with the prevailing U.S. regulatory capital requirements applied to U.S. banks. Thus, if a U.S. bank or thrift that is owned by a foreign bank meets the threshold levels for mandatory application of the advanced approaches, the U.S. bank or thrift would be a core bank. If it does not meet those

\footnotetext{
${ }^{10}$ For banks this means the December Consolidated Report of Condition and Income (Call Report). For thrifts this means the December Thrift Financial Report.
} 
thresholds, it would have the choice to opt-in to the advanced approaches (and be subject to the same supervisory framework as other U.S. banking organizations) or to remain a general bank. A top-tier U.S. bank holding company that is owned by a foreign bank also would be subject to the same threshold levels for core bank determination and would be subject to the applicable U.S. bank holding company capital rules. However, Federal Reserve SR Letter 01-1 (January 5, 2001) would remain in effect. Thus, subject to the conditions in SR Letter 01-1, a top-tier U.S. bank holding company that is owned or controlled by a foreign bank that is a qualifying financial holding company generally would not be required to comply with the Board's capital adequacy guidelines.

The Agencies are interested in comment on the extent to which alternative approaches to regulatory capital that are implemented across national boundaries might create burdensome implementation costs for the U.S. subsidiaries of foreign banks.

\section{B. Implementation for Advanced Approach Organizations}

As noted earlier, U.S. banking organizations that apply the advanced approaches would be required to comply with supervisory standards prior to use.

The BSC has targeted December 31, 2006 as the effective date for the international capital rules based on the New Accord. The Agencies are proposing an implementation date of January 1, 2007. The establishment of a final effective date in the United States, however, would be contingent on the issuance for public comment of a Notice of Proposed Rulemaking, and subsequent finalization of any changes in capital regulations that the Agencies ultimately decide to adopt.

Because of the need to pre-qualify for the advanced approaches, banking organizations would need to take a number of steps upon the finalization of any changes to the capital regulations. These steps would include developing detailed written implementation plans for the A-IRB approach and the AMA and keeping their primary supervisors advised of these implementation plans and schedules. Implementation plans would need to address all supervisory standards for the A-IRB approach and the AMA, include objectively measurable milestones, and demonstrate that adequate resources would be realistically budgeted and made available. An institution's board of directors would need to approve its implementation plans.

The Agencies expect core banks to make every effort to meet the supervisory standards as soon as practicable. In this regard, it is possible that some core banks would not qualify to use the advanced approaches in time to meet the effective date that is ultimately established. For those banking organizations, the implementation plan would need to identify when the supervisory standards would be met and when the institution would be ready for implementation. The Agencies note that developing an appropriate infrastructure to support the advanced approaches for regulatory capital that fully complies with supervisory conditions and expectations and the associated supervisory guidance will be challenging. The Agencies believe, however, that institutions would need to be fully prepared before moving to the advanced approaches. 
Use of the advanced approaches would require the primary Federal supervisor's approval. Core banks unable to qualify for the advanced approaches in time to meet the effective date would remain subject to the general risk-based capital rules existing at that time. The Agencies would consider the effort and progress made to meet the qualifying standards and would consider whether, under the circumstances, supervisory action should be taken against or penalties imposed on individual core banks that have not adhered to the schedule outlined in the implementation plan they submitted to their primary Federal supervisor.

Opt-in banks meeting the supervisory standards could seek to qualify for the advanced approaches in time to meet the ultimate final effective date or any time thereafter. Institutions contemplating opting-in to the advanced approaches would need to provide notice to, and submit an implementation plan and schedule to be approved by, their primary Federal supervisor. As is true of core banks, opt-in banks would need to allow ample time for developing and executing implementation plans.

An institution's primary Federal supervisor would have responsibility for determining the institution's readiness for an advanced approach and would be ultimately responsible, after consultation with other relevant supervisors, for determining whether the institution satisfies the supervisory expectations for the advanced approaches. The Agencies recognize that a consistent and transparent process to oversee implementation of the advanced approaches would be crucial. The Agencies intend to develop interagency validation standards and procedures to help ensure consistency. The Agencies would consult with each other on significant issues raised during the validation process and ongoing implementation.

\section{Other Considerations}

\section{General Banks}

The Agencies expect that the vast majority of U.S. institutions would be neither core banks nor opt-in banks. Most institutions would remain subject to the general risk-based capital rules. However, as has been the case since the 1988 Accord was initially implemented in the United States, the Agencies will continue to make necessary modifications to the general riskbased capital rules as appropriate. In the event changes are warranted, the Agencies could implement revisions through notice and comment procedures prior to the proposed effective date of the advanced approaches in 2007.

The Agencies seek comment on whether changes should be made to the existing general risk-based capital rules to enhance their risk-sensitivity or to reflect changes in the business lines or activities of banking organizations without imposing undue regulatory burden or complication. In particular, the Agencies seek comment on whether any changes to the general risk-based capital rules are necessary or warranted to address any competitive equity concerns associated with the bifurcated framework. 


\section{Majority-Owned or Controlled Subsidiaries}

The New Accord generally applies to internationally active banking organizations on a fully consolidated basis. Thus, consistent with the Agencies' general risk-based capital rules, subsidiaries that are consolidated under U.S. generally accepted accounting principles (GAAP) typically should be consolidated for regulatory capital calculation purposes under the advanced approaches as well. ${ }^{11}$ With regard to investments in consolidated insurance underwriting subsidiaries, the New Accord notes that deconsolidation of assets and deduction of capital is an appropriate approach. The Federal Reserve is actively considering several approaches to the capital treatment for investments by bank holding companies in insurance underwriting subsidiaries. For example, the Federal Reserve is currently assessing the merits and weaknesses of an approach that would consolidate an insurance underwriting subsidiary's assets at the holding company level and permit excess capital of the subsidiary to be included in the consolidated regulatory capital of the holding company. A deduction would be required for capital that is not readily available at the holding company level for general use throughout the organization.

The Federal Reserve specifically seeks comment on the appropriate regulatory capital treatment for investments by bank holding companies in insurance underwriting subsidiaries as well as other nonbank subsidiaries that are subject to minimum regulatory capital requirements.

\section{Transitional Arrangements}

Core and opt-in banks would be required to calculate their capital ratios using the A-IRB and AMA methodologies, as well as the general risk-based capital rules, for one year prior to using the advanced approaches on a stand-alone basis. In order to begin this parallel-run year, however, the institution would have to demonstrate to its supervisor that it meets the supervisory standards. Therefore, banking organizations planning to meet the January 1, 2007 target effective date for implementation of the advanced approaches would have to receive approval from their primary Federal supervisor before year-end 2005. Banking organizations that later adopt the advanced approaches also would have a one-year dual calculation period prior to moving to stand-alone usage of the advanced approaches.

An institution would be subject to a minimum risk-based capital floor for two years following moving to the advanced approaches on a stand-alone basis. Specifically, in the first year of stand-alone usage of the advanced approaches, an institution's calculated risk-weighted assets could not be less than 90 percent of risk-weighted assets calculated under the general riskbased capital rules. In the following year, an institution's minimum calculated risk-weighted assets could not be less than 80 percent of risk-weighted assets calculated under the general riskbased capital rules. $^{12}$

\footnotetext{
${ }^{11}$ One notable exception exists at the bank level where there is an investment in a financial subsidiary as defined in the Gramm-Leach-Bliley Act of 1999. For such a subsidiary, assets would continue to be deconsolidated from the bank's on-balance-sheet assets, and capital at the subsidiary level would be deducted from the bank's capital.

12 The Agencies note that the text above differs from the floor text in the New Accord, which is based on 90 and 80 percent of the minimum capital requirement under the 1988 Accord, rather than on risk-weighted assets. The Agencies expect that the final language of the New Accord would need to be consistent with this approach. The
} 
As a consequence, advanced approach banking organizations would need to conduct two sets of capital calculations for at least three years. The pre-implementation calculation of A-IRB and AMA capital would not need to be made public, but the banking organization would be required to disclose risk-based capital ratios calculated under both advanced and general riskbased approaches during the two-year post-implementation period. The Agencies would not propose to eliminate the floors after the two-year transition period for any institution applying the advanced approaches until the Agencies are fully satisfied that the institution's systems are sound and accurately assess risk and that resulting capital levels are prudent.

These transitional arrangements and the floors established above relate only to risk-based capital ratios and do not affect the continued applicability to all advanced banking organizations of the leverage ratio and associated PCA regulations for banks and thrifts. Importantly, the minimum capital requirements and the PCA thresholds would not be changed. Furthermore, during the implementation period and before removal of the floors the Agencies intend to closely monitor the effect that the advanced approaches would have on capital levels at individual institutions and industry-wide capital levels. Once the results of this monitoring process are assessed, the Agencies may consider modifications to the advanced approaches to ensure that capital levels remain prudent.

Given the general principle that the advanced approaches are expected to be implemented at the same time across all material portfolios, business lines, and geographic regions, to what degree should the Agencies be concerned that, for example, data may not be available for key portfolios, business lines, or regions? Is there a need for further transitional arrangements? Please be specific, including suggested durations for such transitions.

Do the projected dates provide an adequate timeframe for core banks to be ready to implement the advanced approaches? What other options should the Agencies consider?

The Agencies seek comment on appropriate thresholds for determining whether a portfolio, business line, or geographic exposure would be material. Considerations should include relative asset size, percentages of capital, and associated levels of risk for a given portfolio, business line, or geographic region.

following example reflects how the floor in the first year would by applied by a U.S. banking organization. If the banking organization's general risk-based capital calculation produced risk-weighted assets of $\$ 100$ billion in its first year of implementation of the advanced approaches, then its risk weighted assets in that year could not be less than $\$ 90$ billion. If the advanced approach calculation produced risk-weighted assets of $\$ 75$ billion (a decrease of one quarter compared to the general risk-based capital rules), the organization would not calculate risk-based capital ratios on the basis of that $\$ 75$ billion; rather, its risk-weighted assets would be $\$ 90$ billion. Consequently, its minimum total risk-based capital charge would be $\$ 7.2$ billion, and it would need $\$ 9$ billion to satisfy PCA well-capitalized criteria. 


\section{Advanced Internal Ratings-Based (A-IRB) Approach}

This section describes the proposed A-IRB framework for the measurement of capital requirements for credit risk. Under this framework, banking organizations that meet the A-IRB infrastructure requirements and supervisory standards would incorporate internal estimates of risk inputs into supervisor-provided capital formulas for the various debt and equity portfolios to calculate the capital requirements for each portfolio. The discussion below provides background on the conceptual basis of the A-IRB approach and then describes the specific details of the capital formulas for two of the main exposure categories, wholesale and retail. Separate sections follow that describe the A-IRB treatments of loan loss reserves and partial charge-offs, the AIRB treatment of purchased receivables, the A-IRB treatment of equity exposures, and the AIRB treatment of securitization exposures. The A-IRB supervisory requirements and the A-IRB approach to credit risk mitigation techniques also are discussed in separate sections.

\section{A. Conceptual Overview}

The A-IRB framework has as its conceptual foundation the belief that any range of possible losses on a portfolio of credit exposures can be represented by a probability density function (PDF) of possible losses over a one-year time horizon. If known, the parameters of a PDF can be used to specify a particular level of capital that will lower the probability of the institution's insolvency due to adverse credit risk outcomes to a stated confidence level. With a known or estimated PDF, the probability of insolvency can be measured or estimated directly, based on the level of reserves and capital available to an institution.

The A-IRB framework builds off this concept and reflects an effort to develop a common set of risk-sensitive formulas for the calculation of required capital for credit risk. To a large extent, this framework resembles more systematic quantitative approaches to the measurement of credit risk that many banking organizations have been developing. These approaches being developed by banking organizations generally rely on a statistical or probability-based assessment of credit risk and use inputs broadly similar to those required under the A-IRB approach. Like the value-at-risk (VaR) model that forms the basis for the market risk capital rules, the output of these statistical approaches to credit risk is typically an estimate of loss threshold on a credit exposure or pool of credit exposures that is highly unlikely to be exceeded by actual credit-related losses on the exposure or pool.

Many banking organizations now use such a credit VaR amount as the basis for an internal assessment of the economic capital necessary to cover credit risk. In this context, it is common for banking organizations' internal credit risk models to consider a one-year loss horizon, and to focus on a high loss threshold confidence level (that is, a loss threshold that has a small probability of being exceeded), such as the $99.95^{\text {th }}$ percentile. This is because banking organizations typically seek to hold an amount of economic capital for credit risk whose probability of being exceeded is broadly consistent with the institution's external credit rating and its associated default probability. For example, the one-year historical probability of default for AA-rated firms is less than 5 basis points ( 0.05 percent). 
There is a great deal of variation across banking organizations in the specifics of their credit risk measurement approaches. It is important to recognize that the A-IRB approach is not intended to allow banking organizations to use all aspects of their own models to estimate regulatory capital for credit risk. The A-IRB approach has been developed as a single, common methodology that all advanced approach banking organizations would use, and consists of a set of formulas (or functions) and a single set of assumptions regarding critical parameters for the formulas. The A-IRB approach draws on the same conceptual underpinnings as the credit VaR approaches that banking organizations have developed individually, but likely differs in many specifics from the approach used by any individual institution.

The specific A-IRB formulas require the banking organization first to estimate certain risk inputs, which the organization may do using a variety of techniques. The formulas themselves, into which the estimated risk inputs are inserted, are broadly consistent with the most common statistical approaches for measuring credit risk, but also are more straightforward to calculate than those typically employed by banking organizations (which often require computer simulations). In particular, an important property of the A-IRB formulas is portfolio invariance. That is, the A-IRB capital requirement for a particular exposure generally does not depend on the other exposures held by the banking organization; as with the general risk-based capital rules, the total credit risk capital requirement for a banking organization is simply the sum of the credit risk capital requirements on individual exposures or pools of exposures. ${ }^{13}$

As with the existing credit VaR models, the output of the A-IRB formulas is an estimate of the amount of credit losses over a one-year period that would only be exceeded a small percentage of the time. In the case of the A-IRB formulas, this nominal confidence level is set to 99.9 percent. This means that within the context of the A-IRB modeling assumptions a banking organization's overall credit portfolio capital requirement can be thought of as an estimate of the $99.9^{\text {th }}$ percentile of potential losses on that portfolio over a one-year period. In practice, however, this 99.9 percent nominal target likely overstates the actual level of confidence because the A-IRB framework does not explicitly address portfolio concentration issues or the possibility of errors in estimating PDs, LGDs, or EADs. The choice of the $99.9^{\text {th }}$ percentile reflects a desire on the part of the Agencies to align the regulatory capital standard with the default probabilities typically associated with maintaining low investment grade ratings (that is, BBB) even in periods of economic adversity and to ensure neither a substantial increase or decrease in overall required capital levels among A-IRB banking organizations compared with the capital levels that would be required under the general risk-based capital rules. It also recognizes that the risk-based capital rules count a broader range of instruments as eligible capital (for example, certain subordinated debt) than do internal economic capital methodologies.

\footnotetext{
${ }^{13}$ The theoretical underpinnings for obtaining portfolio-invariant capital charges within credit VaR models are provided in the paper "A Risk-Factor Model Foundation for Ratings-Based Bank Capital Rules," by Michael Gordy, forthcoming in the Journal of Financial Intermediation. The A-IRB formulas are derived as an application of these results to a single-factor CreditMetrics-style model. For mathematical details on this model, see M. Gordy, “A Comparative Anatomy of Credit Risk Models.” Journal of Banking and Finance, January 2000, or H.U. Koyluogu and A. Hickman, “Reconcilable Differences.” Risk, October 1998.
} 


\section{Expected Losses versus Unexpected Losses}

The diagram below shows a hypothetical loss distribution for a portfolio of credit exposures over a one-year horizon. The loss distribution is represented by the curve, and is drawn in such a way that it depicts a higher proportion of losses falling below the mean value than falling above the mean. The average value of credit losses is referred to as expected loss (EL). The losses that exceed the expected level are labeled unexpected loss (UL). An overarching policy question concerns whether the proposed design of the A-IRB capital requirements should reflect an expectation that institutions would allocate capital to cover both EL and a substantial portion of the range of possible UL outcomes, or only the UL portion of the range of possible losses (that is, from the EL point out to the $99.9^{\text {th }}$ percentile).

The Agencies recognize that some institutions, in their comment letters on earlier BSC proposals and in discussion with supervisory staffs, have highlighted the view that regulatory capital should not be allocated for EL. They emphasize that EL is normally incorporated into the interest rate and spreads charged on specific products, such that EL is covered by net interest margin and provisioning. The implication is that supervisors would review provisioning policies and the adequacy of reserves as part of a supervisory review, much as they do today, and would require additional reserves and/or regulatory capital for EL in cases where reserves were deemed insufficient. However, the Agencies are concerned that the accounting definition of general reserves differs significantly across countries, and that banking practices with respect to the recognition of impairment also are very different. Thus, the Agencies are proposing to include EL in the calibration of the risk weight functions.

The Agencies also note that the current regulatory definition of capital includes a portion of general reserves. That is, general reserves up to 1.25 percent of risk-weighted assets are included in the Tier 2 portion of total capital. If the risk weight functions were calibrated solely to UL, it could be argued that the definition of capital would also need to be revisited. In the United States, such a discussion would require a review of the provisioning practices of institutions under GAAP and of the distinctions drawn between specific and general provisions.

Probability Density Function of Credit Losses

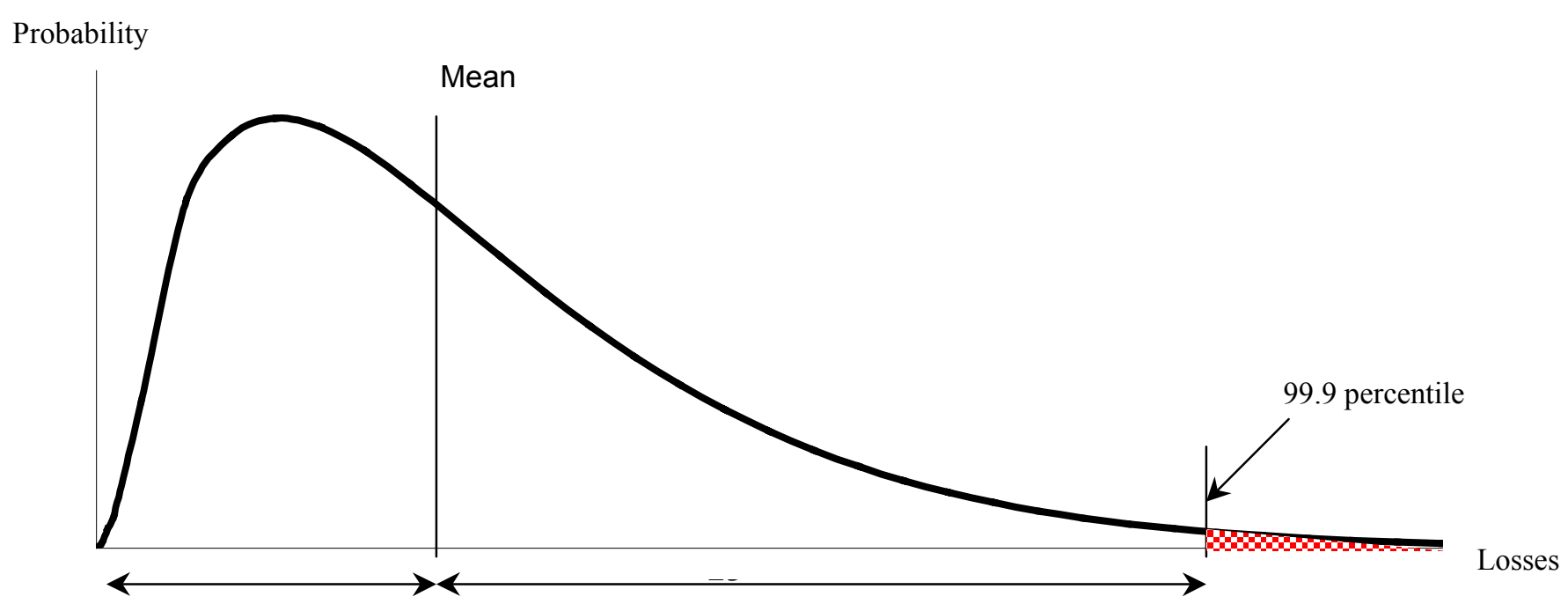

Expected Losses

Unexpected Losses 
The framework described in this ANPR calibrates the risk-based capital requirements to the sum of EL plus UL, which raises significant calibration issues. Those calibration issues would be treated differently if the calibration were based only on the estimate of UL. That is, decisions with respect to significant policy variables that are described below hinge crucially on the initial decision to base the calibration on EL plus UL, rather than UL only. These issues include, for example, the appropriate mechanism for incorporating any future margin income (FMI) that is associated with particular business lines, as well as the appropriate method for incorporating general and specific reserves into the risk-based capital ratios.

A final overarching assumption of the A-IRB framework is the role of asset correlations. Within the A-IRB capital formulas (as in the credit VaR models of many banking organizations), asset correlation parameters provide a measure of the extent to which changes in the economic value of separate exposures are presumed to move together. A higher asset correlation between a particular asset and other assets in the same portfolio implies a greater likelihood that the asset will decline in value at the same time as the portfolio as a whole declines in value. Because this means a greater chance that the asset will be a contributor to high loss scenarios, its capital requirement under the $\mathrm{A}-\mathrm{IRB}$ framework also is higher.

Specifically, the A-IRB capital formulas described in detail below are based on the assumption that correlation in defaults across borrowers is attributable to their common dependence on one or more systematic risk factors. The basis for this assumption is the observation that a banking organization's borrowers are generally susceptible to adverse changes in the global economy. These systematic factors are distinct from the borrower-specific, or idiosyncratic, risk factors that determine the probability that a specific loan will be repaid. Like other risk-factor models, the A-IRB framework assumes that these borrower-specific factors represent idiosyncratic sources of risk, and thus (unlike the systematic risk-factors) are diversified in a large lending portfolio.

The A-IRB approach allows for much improved sensitivity to many of the loan-level determinants of economic capital (such as PD and LGD), but does not explicitly address how an exposure's economic capital might vary with the degree of concentration in the overall portfolio to specific industries or regions, or even to specific borrowers. That is, it neither rewards nor penalizes differences across banking organizations in diversification or concentration across industry, geography, and names. To introduce such rewards and penalties in an appropriate manner would necessarily entail far greater operational complexity for both regulatory and financial institutions.

In contrast, the portfolio models of credit risk employed by many banking organizations are quite sensitive to all forms of diversification. That is, the economic capital charge assigned to a loan within such a model will depend on the portfolio as a whole. In order to apply a portfolio model to the calibration of A-IRB capital charges, it would be necessary to identify the assumptions needed so that a portfolio model would yield economic capital charges that do not depend on portfolio characteristics. Recent advances in the finance literature demonstrate that economic capital charges are portfolio-invariant if (and only if) two assumptions are imposed. ${ }^{14}$

\footnotetext{
${ }^{14}$ See forthcoming paper by M. Gordy referenced in footnote number 12 above.
} 
First, the portfolio must be infinitely fine-grained. Second, there must be only a single systematic risk factor.

Infinite granularity, while never literally attained, is satisfied in an approximate sense by the portfolios of large, internationally active banks. Analysis of data provided by such institutions shows that taking account of single-name concentrations in such portfolios would lead to only trivial changes in the total capital requirement. The single risk-factor assumption would appear, at first glance, more troublesome. As an empirical matter, there undoubtedly are distinct cyclical factors for different industries and different geographic regions. From a substantive perspective, however, the relevant question is whether portfolios at large financial institutions are diversified across the various sub-sectors of the economy in a reasonably similar manner. If so, then the portfolio can be modeled as if there were only a single factor, namely, the credit cycle as a whole.

The Agencies seek comment on the conceptual basis of the A-IRB approach, including all of the aspects just described. What are the advantages and disadvantages of the A-IRB approach relative to alternatives, including those that would allow greater flexibility to use internal models and those that would be more cautious in incorporating statistical techniques (such as greater use of credit ratings by external rating agencies)? The Agencies also encourage comment on the extent to which the necessary conditions of the conceptual justification for the A-IRB approach are reasonably met, and if not, what adjustments or alternative approach would be warranted.

Should the A-IRB capital regime be based on a framework that allocates capital to EL plus UL, or to UL only? Which approach would more closely align the regulatory framework to the internal capital allocation techniques currently used by large institutions? If the framework were recalibrated solely to UL, modifications to the rest of the A-IRB framework would be required. The Agencies seek commenters' views on issues that would arise as a result of such recalibration.

\section{B. A-IRB Capital Calculations}

A common characteristic of the A-IRB capital formulas is that they calculate the actual dollar value of the minimum capital requirement associated with an exposure (or, in the case of retail exposures, a pool of exposures). This capital requirement must be converted to an equivalent amount of risk-weighted assets in order to be inserted into the denominator of a banking organization's risk-based capital ratios. Because the minimum risk-based capital ratio in the United States is 8 percent, the minimum capital requirement on any asset would be equal to 8 percent of the risk-weighted asset amount associated with that asset. Therefore, in order to determine the amount of risk-weighted assets to associate with a given minimum capital requirement, it would be necessary to multiply the dollar capital requirement generated by the AIRB formulas by the reciprocal of 8 percent, or 12.5 .

The following subsections of the ANPR detail the specific features of the A-IRB capital formulas for two principal categories of credit exposure: wholesale and retail. Both of these subsections include a proposed definition of the exposure category, a description of the banking 
organization-estimated inputs required to complete the capital calculations, a description of the specific calculations required to determine the A-IRB capital requirement, and tables depicting a range of representative results.

\section{Wholesale Exposures: Definitions and Inputs}

The Agencies propose that a single credit exposure category - wholesale exposures would encompass most non-retail credit exposures in the A-IRB framework. The wholesale category would include the sub-categories of corporate, sovereign, and interbank exposures as well as all types of specialized lending exposures. Wholesale exposures would include debt obligations of corporations, partnerships, limited liability companies, proprietorships, and special-purpose entities (including those created specifically to finance and/or operate physical assets). Wholesale exposures also would include debt obligations of banks and securities firms (interbank exposures), and debt obligations of central governments, central banks, and certain public-sector entities (sovereign exposures). The wholesale exposure category would not include securitization exposures, or certain small-business exposures that are eligible to be treated as retail exposures.

The Agencies propose that advanced approach banking organizations would use the same A-IRB capital formula to compute capital requirements on all wholesale exposures with two exceptions. First, wholesale exposures to small- and medium-sized enterprises (SMEs) would use a downward adjustment to the wholesale A-IRB capital formula typically based on borrower size. Second, the A-IRB capital formula for HVCRE loans (generally encompassing certain speculative ADC loans) would use a higher asset correlation assumption than other wholesale exposures.

The proposed A-IRB capital framework for wholesale exposures would require banking organizations to assign four key risk inputs for each individual wholesale exposure: (1) probability of default (PD); (2) loss given default (LGD); (3) exposure at default (EAD); and (4) effective remaining maturity $(\mathrm{M})$. In addition, to use the proposed downward adjustment for wholesale SMEs described in more detail below, banking organizations would be required to provide an additional input for borrower size $(\mathrm{S})$.

\section{Probability of Default}

The first principal input to the wholesale A-IRB calculation is the measure of PD. Under the A-IRB approach, a banking organization would assign an internal rating to each of its wholesale obligors (or in other words, assign each wholesale exposure to an internal rating grade applicable to the obligor). The internal rating would have to be produced by a rating system that meets the A-IRB infrastructure requirements and supervisory standards for wholesale exposures, which are intended to ensure (among other things) that the rating system results in a meaningful differentiation of risk among exposures. For each internal rating, the banking organization must associate a specific one-year PD value. Various approaches may be used to develop estimates of PDs; however, regardless of the specific approach, banking organizations would be expected to satisfy the supervisory standards. The minimum PD that may be assigned to most wholesale exposures is 3 basis points ( 0.03 percent). Certain wholesale exposures are exempt from this 
floor, including exposures to sovereign governments, their central banks, the BIS, IMF, European Central Bank, and high quality multilateral development banks (MDBs) with strong shareholder support.

The Agencies intend to apply standards to the PD quantification process that are consistent with the broad guidance outlined in the New Accord. More detailed discussion of those points is provided in the draft supervisory guidance on IRB approaches for corporate exposures published elsewhere in today's Federal Register.

\section{$\underline{\text { Loss Given Default }}$}

The second principal input to the A-IRB capital formula for wholesale exposures is LGD. Under the A-IRB approach, banking organizations would estimate an LGD for each wholesale exposure. An LGD estimate for a wholesale exposure should provide an assessment of the expected loss in the event of default of the obligor, expressed as a percentage of the institution's estimated total exposure at default. The LGD for a defaulted exposure would be estimated as the expected economic loss rate on that exposure taking into account, where appropriate, recoveries, workout costs, and the time value of money. Banking organizations would estimate LGDs as the loss severities expected to prevail when default rates are high, unless they have information indicating that recoveries on a particular class of exposure are unlikely to be affected to an appreciable extent by cyclical factors. As with estimates of other A-IRB inputs, banking organizations would be expected to be conservative in assigning LGDs.

Although estimated LGDs should be grounded in historical recovery rates, the A-IRB approach is structured to allow banking organizations to assess the differential impact of various factors, including, for example, the presence of collateral or differences in loan terms and covenants. The Agencies expect to impose limitations on the use of guarantees and credit derivatives in a banking organization's LGD estimates. These limitations are discussed in the separate section of this ANPR on the A-IRB treatment of credit risk mitigation techniques.

\section{$\underline{\text { Exposure at Default }}$}

The third principal input to the wholesale A-IRB capital formula is EAD. The Agencies are proposing that banking organizations would provide their own estimate of EAD for each exposure. The EAD for an exposure would be defined as the amount legally owed to the banking organization (net of any charge-offs) in the event that the borrower defaults on the exposure. For on-balance-sheet items, banking organizations would estimate EAD as no less than the current drawn amount. For off-balance-sheet items, except over-the-counter (OTC) derivative transactions, banking organizations would assign an EAD equal to an estimate of the long-run default-weighted average EAD for similar facilities and borrowers or, if EADs are highly cyclical, the EAD expected to prevail when default rates are high. The EAD associated with OTC derivative transactions would continue to be estimated using the "add-on" approach contained in the general risk-based capital rules. ${ }^{15}$ In addition, there would be a specific EAD

\footnotetext{
${ }^{15}$ Under the add-on approach, an institution would determine its EAD for an OTC derivative contract by adding the current value of the contract (zero if the current value is negative) and an estimate of potential future exposure
} 
calculation for the recognition of collateral in the context of repo-style transactions subject to a master netting agreement, the features of which are outlined below in the section on the A-IRB treatment of credit risk mitigation techniques. ${ }^{16}$

\section{Definition of Default and Loss}

A banking organization would estimate inputs relative to the following definition of default and loss. A default is considered to have occurred with respect to a particular borrower when either or both of the following two events has taken place: (1) the banking organization determines that the borrower is unlikely to pay its obligations to the organization in full, without recourse to actions by the organization such as the realization of collateral; or (2) the borrower is more than 90 days past due on principal or interest on any material obligation to the organization. The Agencies believe that the use of the concept of "unlikely to pay" is largely consistent with the practice of U.S. banking organizations in assessing whether a loan is on nonaccrual status.

\section{Maturity}

The fourth principal input to the A-IRB capital formula is effective remaining maturity (M), measured in years. If a wholesale exposure is subject to a determinable cash flow schedule, the banking organization would calculate $\mathrm{M}$ as the weighted-average remaining maturity of the expected cash flows, using the amounts of the cash flows as the relevant weights. The banking organization also would be able to use the nominal remaining maturity of the exposure if the weighted-average remaining maturity of the exposure cannot be calculated. For OTC derivatives and repo-style transactions subject to master netting agreements, the institution would set $\mathrm{M}$ equal to the weighted-average remaining maturity of the individual transactions, using the notional amounts of the individual transactions as the relevant weights.

In all cases, $M$ would be set no greater than five years and, with few exceptions, $M$ would be set no lower than one year. The exceptions apply to certain transactions that are not part of a banking organization's ongoing financing of a borrower. For wholesale exposures that have an original maturity of less than three months -- including repo-style transactions, money market transactions, trade finance-related transactions, and exposures arising from payment and settlement processes -- M may be set as low as one day. For OTC derivatives and repo-style transactions subject to a master netting agreement, $M$ would be set at no less than five days.

As with the assignment of PD estimates, the Agencies propose to apply supervisory standards for the estimation of LGD, EAD, and M that are consistent with the broad guidance contained in the New Accord. More detailed discussion of these issues is provided in the draft supervisory guidance on IRB approaches for corporate exposures published elsewhere in today's Federal Register.

(PFE) on the contract. The estimated PFE would be equal to the notional amount of the derivative multiplied by a supervisor-provided add-on factor that takes into account the type of instrument and its maturity.

${ }^{16}$ Repo-style transactions include reverse repurchase agreements and repurchase agreements and securities lending and borrowing. 
The Agencies seek comment on the proposed definition of wholesale exposures and on the proposed inputs to the wholesale A-IRB capital formulas. What are views on the proposed definitions of default, PD, LGD, EAD, and M? Are there specific issues with the standards for the quantification of PD, LGD, EAD, or M on which the Agencies should focus?

\section{Wholesale Exposures: Formulas}

The calculation of the A-IRB capital requirement for a particular wholesale exposure would be accomplished in three steps:

(1) Calculation of the relevant asset correlation parameter, which would be a function of PD (as well as borrower size (S) for SMEs);

(2) Calculation of a preliminary capital requirement assuming a maturity of one year, which would be a function of PD, LGD, EAD, and the asset correlation parameter calculated in the first step; and

(3) Application of a maturity adjustment for differences between the actual effective remaining maturity of the exposure and the one-year maturity assumption in the second step, where the adjustment would be a function of both PD and M.

These calculations result in the A-IRB capital requirement, expressed in dollars, for a particular wholesale exposure. As noted earlier, this amount would be converted to a riskweighted assets equivalent by multiplying the amount by 12.5 , and the risk-weighted assets equivalent would be included in the denominator of the risk-based capital ratios.

\section{$\underline{\text { Asset Correlation }}$}

The first step in the calculation of the A-IRB capital requirement for a wholesale exposure is the calculation of the asset correlation parameter, which is denoted by the letter " $R$ " in the formulas below. This asset correlation parameter is not a fixed amount; rather, the parameter varies as an inverse function of PD. For all wholesale exposures except HVCRE exposures, the asset correlation parameter approaches an upper bound value of 24 percent for very low PD values and approaches a lower bound value of 12 percent for very high PD values. This reflects the Agencies' view that borrowers with lower credit quality (that is, higher PDs) are likely to be more idiosyncratic in the factors affecting their likelihood of default than borrowers with higher credit quality (lower PDs). Therefore, the higher PD borrowers are proportionately less influenced by systematic (sector-wide or economy-wide) factors common to all borrowers. ${ }^{17}$

An important practical impact of having asset correlation decline with increases in PD is to reduce the speed with which capital requirements increase as PDs increase, and to increase the speed with which EL dominates the total capital charge, thereby tending to reduce procyclicality in the application of the wholesale A-IRB capital formulas. The specific formula for determining the asset correlation parameter for all wholesale exposures except HVCRE exposures is as follows:

\footnotetext{
${ }^{17}$ See Jose Lopez, "The Empirical Relationship between Average Asset Correlation, Firm Probability of Default, and Asset Size." Federal Reserve Bank of San Francisco Working Paper 02-05 (June 2002).
} 
Where:

$$
\mathrm{R}=0.12 *(1-\operatorname{EXP}(-50 * \mathrm{PD}))+0.24 *[1-(1-\operatorname{EXP}(-50 * \mathrm{PD}))]
$$

R denotes asset correlation;

$\operatorname{EXP}(\mathrm{x})$ denotes the natural exponential function; and

PD denotes probability of default.

\section{Capital Requirement with Assumed One-Year Maturity Adjustment}

The second step in the calculation of the A-IRB capital requirement for a particular wholesale exposure is the calculation of the capital requirement that would apply to the exposure assuming a one-year effective remaining maturity. The specific formula to calculate this oneyear-maturity capital requirement is as follows:

Where:

$$
\mathrm{K}_{1}=\mathrm{EAD} * \mathrm{LGD} * \mathrm{~N}\left[(1-\mathrm{R})^{\wedge}-0.5 * \mathrm{G}(\mathrm{PD})+(\mathrm{R} /(1-\mathrm{R}))^{\wedge} 0.5 * \mathrm{G}(0.999)\right]
$$

$\mathrm{K}_{1}$ denotes the one-year-maturity capital requirement;

EAD denotes exposure at default;

LGD denotes loss given default;

$\mathrm{N}(\mathrm{x})$ denotes the standard normal cumulative distribution function;

$\mathrm{R}$ denotes asset correlation;

$\mathrm{G}(\mathrm{x})$ denotes the inverse of the standard normal cumulative distribution function; and ${ }^{18}$

PD denotes probability of default.

There are several important aspects of this formula. First, it rises in a straight-line fashion with increases in EAD, meaning that a doubling of the exposure amount would result in a doubling of the capital requirement. It also rises in a straight-line fashion with increases in LGD, which similarly implies that a loan with an LGD estimate twice that of an otherwise identical loan would have twice the capital requirement of the other loan. This also implies that as LGD or EAD estimates approach zero, the capital requirement would likewise approach zero. The remainder of the formula is a function of $\mathrm{PD}$, asset correlation (R), which is itself a function of $\mathrm{PD}$, and the target loss percentile amount of 99.9 percent discussed earlier.

\section{Maturity Adjustment}

The third stage in the calculation of the A-IRB capital requirement for a particular wholesale exposure is the application of a maturity adjustment to reflect the exposure's actual effective remaining maturity $(\mathrm{M})$. The A-IRB maturity adjustment multiplies the one-yearmaturity capital requirement $\left(\mathrm{K}_{1}\right)$ by a factor that depends on both $\mathrm{M}$ and $\mathrm{PD}$. The fact that the A-IRB maturity adjustment depends on PD reflects the Agencies' view that there is a greater proportional need for maturity adjustments for high-quality exposures (those with low PDs) because there is a greater potential for such exposures to deteriorate in credit quality than for

\footnotetext{
${ }^{18}$ The $\mathrm{N}(\mathrm{x})$ and $\mathrm{G}(\mathrm{x})$ functions are widely used in statistics and are commonly available in computer spreadsheet programs. A description of these functions may be found in the Help function of most spreadsheet programs or in basic statistical textbooks.
} 
exposures whose credit quality is lower. The specific formula for applying the maturity adjustment and generating the A-IRB capital requirement is as follows:

$$
\begin{gathered}
\mathrm{K}=\mathrm{K}_{1} *[1+(\mathrm{M}-2.5) * \mathrm{~b}] /[(1-1.5 * \mathrm{~b})], \text { where } \\
\mathrm{b}=(0.08451-0.05898 * \mathrm{LN}(\mathrm{PD}))^{\wedge} 2
\end{gathered}
$$

and:

$\mathrm{K}$ denotes the A-IRB capital requirement;

$\mathrm{K}_{1}$ denotes the one-year-maturity capital requirement;

$\mathrm{M}$ denotes effective remaining maturity;

$\mathrm{LN}(\mathrm{x})$ denotes the natural logarithm; and

PD denotes probability of default.

In this formula, the value " $b$ " effectively determines the slope of the maturity adjustment and is itself a function of PD. Note that if $\mathrm{M}$ is set equal to one, the maturity adjustment also equals one and $\mathrm{K}$ will therefore equal $\mathrm{K}_{1}$.

To provide a more concrete sense of the range of capital requirements under the wholesale A-IRB framework, the following table presents the A-IRB capital requirements (K) for a range of values of both PD and M. In this table LGD is assumed to equal 45 percent. For comparison purposes, the general risk-based capital rules assign a capital requirement of 8 percent for most commercial loans.

Capital Requirements (in percentage points)

\begin{tabular}{|c|c|c|c|c|}
\hline & \multicolumn{4}{|c|}{ Effective Remaining Maturity (M) } \\
\hline PD & 1 month & 1 year & 3 years & 5 years \\
\hline 0.05 percent & 0.50 & 0.92 & 1.83 & 2.74 \\
\hline 0.10 percent & 1.00 & 1.54 & 2.71 & 3.88 \\
\hline 0.25 percent & 2.17 & 2.89 & 4.44 & 5.99 \\
\hline 0.50 percent & 3.57 & 4.40 & 6.21 & 8.03 \\
\hline 1.00 percent & 5.41 & 6.31 & 8.29 & 10.27 \\
\hline 2.00 percent & 7.65 & 8.56 & 10.56 & 12.56 \\
\hline 5.00 percent & 11.91 & 12.80 & 14.75 & 16.69 \\
\hline 10.00 percent & 17.67 & 18.56 & 20.50 & 22.45 \\
\hline 20.00 percent & 26.01 & 26.84 & 28.65 & 30.47 \\
\hline
\end{tabular}

The impact of the A-IRB capital formulas on minimum risk-based capital requirements for wholesale exposures would, of course, depend on the actual values of PD, LGD, EAD, and M that banking organizations would use as inputs to the wholesale formulas. Subject to the caveats noted earlier, evidence from QIS3 suggested an average reduction in credit risk capital requirements for corporate exposures of about 26 percent for twenty large U.S. banking organizations.

\section{$\underline{\text { SME Adjustment }}$}

For loans to SMEs not eligible for retail A-IRB treatment, the proposed calculation of the A-IRB capital requirement has one additional element - a downward adjustment based on 
borrower size (S). This adjustment would effectively lower the A-IRB capital requirement on wholesale exposures to SMEs with annual sales (or total assets) of less than $\$ 50$ million. The Agencies believe the measure of borrower size should be based on annual sales (rather than total assets), unless the banking organization can demonstrate that it would be more appropriate for the banking organization to use the total assets of the borrower as its measure of borrower size. The borrower size adjustment would be made to the asset correlation parameter (R), as shown in the following formula:

Where

$$
\mathrm{R}_{\mathrm{SME}}=\mathrm{R}-0.04 *[1-(\mathrm{S}-5) / 45]
$$

$\mathrm{R}_{\mathrm{SME}}$ denotes the size-adjusted asset correlation;

$\mathrm{R}$ denotes asset correlation; and

$\mathrm{S}$ denotes borrower size (expressed in millions of dollars).

The maximum reduction in the asset correlation parameter based on this formula is 4 percent, and is achieved when borrower size is $\$ 5$ million. For all borrower sizes below $\$ 5$ million, borrower size would be set equal to $\$ 5$ million. The adjustment shrinks to zero as borrower size approaches $\$ 50$ million. The broad rationale for this adjustment is the view that the credit condition of SMEs will be influenced relatively more by idiosyncratic factors than is the case for larger firms, and, thus, SMEs would be less likely to deteriorate simultaneously with other exposures. This greater susceptibility to idiosyncratic factors would imply lower asset correlation. The evidence in favor of this view is mixed, particularly after considering that the A-IRB framework already incorporates a negative relationship between asset correlation and PD. The following table illustrates the practical effect of the SME adjustment by depicting the capital requirements $(\mathrm{K})$ across a range of PDs and borrower sizes. As in the previous table, LGD is assumed to equal 45 percent. For this table, $M$ is assumed to be equal to three years. Note that the last column is identical to the three-year maturity column in the preceding table because the SME adjustment is phased out for borrowers of $\$ 50$ million or more in size.

Capital Requirements (in percentage points)

\begin{tabular}{|c|c|c|c|c|}
\hline & \multicolumn{4}{|c|}{ Borrower Size (S) } \\
\hline PD & \$5 million & \$20 million & \$35 million & $\geq \$ 50$ million \\
\hline 0.05 percent & 1.44 & 1.57 & 1.70 & 1.83 \\
\hline 0.10 percent & 2.14 & 2.33 & 2.51 & 2.71 \\
\hline 0.25 percent & 3.54 & 3.83 & 4.13 & 4.44 \\
\hline 0.50 percent & 4.97 & 5.37 & 5.79 & 6.21 \\
\hline 1.00 percent & 6.63 & 7.17 & 7.72 & 8.29 \\
\hline 2.00 percent & 8.40 & 9.11 & 9.83 & 10.56 \\
\hline 5.00 percent & 11.70 & 12.73 & 13.74 & 14.75 \\
\hline 10.00 percent & 16.76 & 18.05 & 19.30 & 20.50 \\
\hline 20.00 percent & 24.67 & 26.08 & 27.40 & 28.65 \\
\hline
\end{tabular}

Subject to the caveats mentioned above, evidence from QIS3 suggested an average reduction in credit risk-based capital requirements for corporate SME exposures of about 39 percent for twenty large U.S. banking organizations. 
If the Agencies include a SME adjustment, are the $\$ 50$ million threshold and the proposed approach to measurement of borrower size appropriate? What standards should be applied to the borrower size measurement (for example, frequency of measurement, use of size buckets rather than precise measurements)?

Does the proposed borrower size adjustment add a meaningful element of risk sensitivity sufficient to balance the costs associated with its computation? The Agencies are interested in comments on whether it is necessary to include an SME adjustment in the A-IRB approach. Data supporting views is encouraged.

\section{Wholesale Exposures: Other Considerations}

\section{Specialized Lending}

The specialized lending (SL) asset class encompasses exposures for which the primary source of repayment is the income generated by the specific asset(s) being financed, rather than the financial capacity of a broader commercial enterprise. The SL category encompasses four broad exposure types:

- Project finance (PF) exposures finance large, complex, expensive installations that produce goods or services for sale, such as power plants, chemical processing plants, mines, or transportation infrastructure, where the source of repayment is primarily the revenues generated by sale of the goods or services by the installations.

- Object finance (OF) exposures finance the acquisition of (typically moveable) physical assets, such as ships or aircraft, where the source of repayment is primarily the revenues generated by the assets being financed, often through rental or lease contracts with third parties.

- Commodities finance (CF) exposures are structured short-term financings of reserves, inventories, or receivables of exchange-traded commodities, such as crude oil, metals, or agricultural commodities, where the source of repayment is the proceeds of the sale of the commodity.

- Commercial real estate (CRE) exposures finance the construction or acquisition of real estate (including land as well as improvements) where the prospects for repayment and recovery depend primarily on the cash flows generated by the lease, rental, or sale of the real estate. ${ }^{19}$ The broad CRE category is further divided into two groups: low-asset-correlation CRE and HVCRE. $^{20}$

${ }^{19} \mathrm{CRE}$ exposures are typically non-recourse exposures, often to special purpose vehicles, and are distinguishable from corporate exposures that are collateralized by real estate for which the prospects for repayment and recovery depend primarily on the financial performance of the broader commercial enterprise that is the obligor.

${ }^{20}$ To describe a loan portfolio as having a relatively high asset correlation means that any defaults that occur in that portfolio are relatively likely to occur at the same time, and for this reason the portfolio is likely to exhibit greater variability in aggregate default rates. For two portfolios with the same EL, the portfolio with more highly variable aggregate default rates warrants higher capital to cover UL ("bad-tail events") with the same level of confidence. Describing a portfolio as having a relatively high asset correlation does not imply that loans in that portfolio have relatively high PD, LGD, or EL. In particular, loans in high asset correlation portfolios may well have very low PDs and LGDs (and therefore ELs); conversely, loans in low asset correlation portfolios may have very high PDs and LGDs (and ELs). For any two loans from a portfolio with a given asset correlation (or from two different portfolios with the same asset correlation), the loan with the lower EL should be assigned 
Most of the issues raised below for comment are described in substantially greater detail, in the context of CRE exposures, in a white paper entitled "Loss Characteristics of CRE Loan Portfolios," released by the Federal Reserve Board on June 10, 2003. Commenters are encouraged to read the white paper in conjunction with this section.

A defining characteristic of SL exposures (including CRE) is that the risk factors influencing actual default rates are likely to influence LGDs as well. This is because both the borrower's ability to repay an exposure and the banking organization's recovery on an exposure in the event of default are likely to depend on the same underlying factors, such as the net cash flows of the property being financed. This suggests a positive correlation between observed default frequencies and observed loss rates on defaulted loans, with both declining during periods of favorable economic conditions and both increasing during unfavorable economic periods. While cyclicality in LGDs may be significant for a number of lending activities, the Agencies believe that cyclicality is likely to be the norm for SL portfolios, and that a banking organization's procedures for estimating LGD inputs for SL exposures should assess and quantify this cyclicality in a comprehensive and systematic fashion.

The Agencies invite comment on ways to deal with cyclicality in LGDs. How can risk sensitivity be achieved without creating undue burden?

For core and opt-in banks that may not be able to provide sufficiently reliable estimates of PD, LGD, and M for each SL exposure, the New Accord offers a Supervisory Slotting Criteria (SSC) approach. Under this approach, rather than estimating the loan-level risk parameters, banking organizations would use slotting criteria to map their internal risk rating grades to one of five supervisory rating grades: Strong, Good, Satisfactory, Weak, and Default. In addition, supervisory risk weights would be assigned to each of these supervisory rating grades. To assist banking organizations in implementing these supervisory rating grades, for reference purposes the New Accord associates each with an explicit range of external rating grades. If the SSC approach were allowed in the United States, the Agencies would have to develop slotting criteria that would take into account factors such as market conditions; financial ratios such as debt service coverage or loan-to-value ratios; cash flow predictability; strength of sponsor or developer; and other factors likely to affect the PD and/or LGD of each loan.

The Agencies invite comment on the merits of the SSC approach in the United States. The Agencies also invite comment on the specific slotting criteria and associated risk weights that should be used by organizations to map their internal rating grades to supervisory rating grades if the SSC approach were to be adopted in the United States.

Under the A-IRB approach, a banking organization would estimate the risk inputs for each SL exposure and then calculate the A-IRB capital charge for the exposure by substituting the estimated PD, LGD, EAD, and $\mathrm{M}$ into one of two risk weight functions. The first risk weight function is the wholesale risk weight function and applies to all $\mathrm{PF}, \mathrm{OF}$, and $\mathrm{CF}$ exposures, as well as to all low-asset-correlation CRE exposures (including in-place commercial properties).

a lower risk weight. For any two loans with the same EL, the loan from the portfolio with the lower asset correlation should incur a lower capital charge, because bad-tail events are less likely to occur in that portfolio. 
The second risk weight function applies to all HVCRE exposures. It also is the same as the wholesale risk weight function, except that it incorporates a higher asset correlation parameter. The asset correlation equation for HVCRE is as follows:

Where

$$
\mathrm{R}=0.12 \times(1-\mathrm{EXP}(-50 \times \mathrm{PD}))+0.30 \times[\mathrm{EXP}(-50 \times \mathrm{PD})]
$$

$\mathrm{R}$ denotes asset correlation;

EXP denotes the natural exponential function; and

PD denotes probability of default.

The following table presents the A-IRB capital requirement $(\mathrm{K})$ for a range of values of both PD and M. In this table, LGD is assumed to equal 45 percent. This LGD is used for consistency with the similar table above for wholesale exposures and should not be construed as an indication that 45 percent is a typical LGD for HVCRE exposures.

HVCRE Capital Requirements (in percentage points)

Effective Remaining Maturity

\begin{tabular}{|c|c|c|c|}
\hline PD & 1 year & 3 years & 5 years \\
\hline 0.05 percent & 1.24 & 2.46 & 3.68 \\
\hline 0.10 percent & 2.05 & 3.61 & 5.16 \\
\hline 0.25 percent & 3.74 & 5.76 & 7.77 \\
\hline 0.50 percent & 5.52 & 7.79 & 10.07 \\
\hline 1.00 percent & 7.53 & 9.89 & 12.25 \\
\hline 2.00 percent & 9.55 & 11.79 & 14.02 \\
\hline 5.00 percent & 13.12 & 15.12 & 17.11 \\
\hline 10.00 percent & 18.59 & 20.54 & 22.49 \\
\hline 20.00 percent & 26.84 & 28.65 & 30.47 \\
\hline
\end{tabular}

All ADC loans would be treated as HVCRE exposures, unless the borrower has "substantial equity" at risk or the property is pre-sold or sufficiently pre-leased. In part, this reflects some empirical evidence suggesting that most ADC loans have relatively high asset correlations. It also, however, reflects a longstanding supervisory concern that CRE lending to finance speculative construction and development is vulnerable to, and may worsen, speculative swings in CRE markets, especially when there is little borrower equity at risk. Such lending was a major factor causing the stress experienced by many banks in the early 1990s, not only in the United States but in other countries as well.

Under the New Accord, SL loans financing the construction of one- to four-family residential properties (single or in subdivisions) are included with other ADC loans in the high asset correlation category. However, loans financing the construction of pre-sold one- to fourfamily residential properties would be eligible to be treated as low-asset-correlation CRE exposures. In some cases the loans may finance the construction of subdivisions or other groups of houses, some of which are pre-sold while others are not.

Under the New Accord, each national supervisory authority is directed to recognize and incorporate into its implementation of the New Accord the high asset correlation determinations 
of other national supervisory authorities for loans made in their respective jurisdictions. Thus, when the Agencies designate certain CRE properties as HVCRE, foreign banking organizations making extensions of credit to those properties also would be expected to treat them as HVCRE. Similarly, when non-U.S. supervisory authorities designate certain CRE as HVCRE, U.S. banking organizations that extend credit to those properties would be expected to treat them as HVCRE.

The Agencies invite the submission of empirical evidence regarding the (relative or absolute) asset correlations characterizing portfolios of ADC loans, as well as comments regarding the circumstances under which such loans would appropriately be categorized as HVCRE.

The Agencies also invite comment on the appropriateness of exempting from the high-asset-correlation category ADC loans with substantial equity or that are pre-sold or sufficiently pre-leased. The Agencies invite comment on what standard should be used in determining whether a property is sufficiently pre-leased when prevailing occupancy rates are unusually low.

The Agencies invite comment on whether high-asset-correlation treatment for one- to four-family residential construction loans is appropriate, or whether they should be included in the low-asset-correlation category. In cases where loans finance the construction of a subdivision or other group of houses, some of which are pre-sold while others are not, the Agencies invite comment regarding how the "pre-sold" exception should be interpreted.

The Agencies invite comment on the competitive impact of treating defined classes of CRE differently. What are commenters' views on an alternative approach where there is only one risk weight function for all CRE? If a single risk weight function for all CRE is considered, what would be the appropriate asset correlation to employ?

\section{$\underline{\text { Lease Financings }}$}

Under the wholesale A-IRB framework, some lease financings require special consideration. A distinction is made for leases that expose the lessor to residual value risk, namely the risk of the fair value of the assets declining below the banking organization's estimate of residual risk at lease inception. If a banking organization has exposure to residual value risk, it would assign a 100 percent risk weight to the residual value amount and determine a risk-weighted asset equivalent for the lease's remaining net investment (net of residual value amount) using the same methodology as for any other wholesale exposure. The sum of these components would be the risk-weighted asset amount for a particular lease. Where a banking organization does not have exposure to residual value risk, the lease's net investment would be subject to a capital charge using the same methodology applied to any other wholesale exposure.

This approach would be used regardless of accounting classification as a direct finance, operating or leveraged lease. For leveraged leases, when the banking organization is the equity participant it would net the balance of the non-recourse debt against the discounted lease 
payment stream prior to applying the risk weight. If the banking organization is the debt participant, the exposure would be treated as any other wholesale exposure.

The Agencies are seeking comment on the wholesale A-IRB capital formulas and the resulting capital requirements. Would this approach provide a meaningful and appropriate increase in risk sensitivity in the sense that the results are consistent with alternative assessments of the credit risks associated with such exposures or the capital needed to support them? If not, where are there material inconsistencies?

Does the proposed A-IRB maturity adjustment appropriately address the risk differences between loans with differing maturities?

\section{$\underline{\text { Retail Exposures: Definitions and Inputs }}$}

The second major exposure category in the A-IRB framework is the retail exposure category. This category encompasses the vast majority of credit exposures to individual consumers. The Agencies also are considering whether certain SME exposures should be eligible for retail A-IRB treatment. The retail exposure category has three distinct subcategories: (1) residential mortgages (and related exposures); (2) qualifying revolving exposures (QREs); and (3) other retail exposures. There are separate A-IRB capital formulas for each of these three sub-categories to reflect different levels of associated risk.

The Agencies propose that the residential mortgage exposure sub-category be defined to include loans secured by first or subsequent liens on one- to four-family residential properties, including term loans and revolving lines of credit secured by home equity. There would be no upper limit on the size of the exposure that could be included in the residential mortgage exposure sub-category, but the borrower would have to be an individual and the banking organization should generally manage the exposure as part of a pool of similar exposures. Residential mortgage exposures that are individually internally rated and managed similarly to commercial exposures, rather than managed and internally rated as pools, would be treated under the wholesale A-IRB framework.

The second sub-category of retail exposures is qualifying revolving exposures (QREs). The Agencies propose to define QREs as exposures to individuals that are revolving, unsecured, uncommitted, less than $\$ 100,000$, and managed as part of a pool of similar exposures. In practice, QREs will include primarily exposures where customers' outstanding borrowings are permitted to fluctuate based on their own decisions to borrow and repay, up to a limit established by the banking organization. Most credit card exposures to individuals and overdraft lines on individual checking accounts would be QREs.

The third sub-category of retail exposures, other retail exposures, includes two types of exposures. First, it encompasses all exposures to individuals for non-business purposes that are generally managed as part of a pool of similar exposures and that do not meet the conditions for inclusion in the first two sub-categories of retail exposures. The Agencies are not proposing to establish a fixed upper limit on the size of exposures to individuals that are eligible for the other retail treatment. In addition, the Agencies are proposing that the other retail sub-category 
include certain SME exposures that are managed on a pool basis similar to retail exposures. These exposures could be to a company or to an individual. The Agencies are considering an individual borrower exposure threshold of $\$ 1$ million for such exposures. For the purpose of assessing compliance with the individual borrower exposure threshold, the banking organization would aggregate all exposures to a particular borrower on a fully consolidated basis. Credit card accounts with balances between $\$ 100,000$ and $\$ 1$ million would be considered other retail exposures rather than QRE, even if the accounts are extended to or guaranteed by an individual and used exclusively for small business purposes.

The Agencies are interested in comment on whether the proposed \$1 million threshold provides the appropriate dividing line between those SME exposures that banking organizations should be allowed to treat on a pooled basis under the retail A-IRB framework and those SME exposures that should be rated individually and treated under the wholesale A-IRB framework.

One of the most significant differences between the wholesale and retail A-IRB categories is that the risk inputs for retail exposures do not have to be assigned at the level of an individual exposure. The Agencies recognize that banking organizations typically manage retail exposures on a portfolio or pool basis, where each portfolio or pool contains exposures with similar risk characteristics. Therefore, a key characteristic of the retail A-IRB framework is that the risk inputs for retail exposures would be assigned to portfolios or pools of exposures rather than to individual exposures.

It is important to highlight that within each of the three sub-categories of retail exposures, the retail A-IRB framework is intended to provide banking organizations with substantial flexibility to use the retail portfolio segmentation that they believe is most appropriate for their activities. In determining how to group their retail exposures within each sub-category into portfolio segments for the purpose of assigning A-IRB risk inputs, the Agencies believe that banking organizations should use a segmentation approach that is consistent with their approach for internal risk assessment purposes and that classifies exposures according to predominant risk characteristics.

As general principles for segmentation, banking organizations should group exposures in each of the three retail sub-categories into portfolios or pools according to the sub-category's principal risk drivers, and would have to be able to demonstrate that the resultant segmentation effectively differentiates and rank orders risk and provides reasonably accurate and consistent quantitative estimates of PD, LGD, and EAD. With the exceptions noted below, the Agencies are not proposing that institutions must consider any particular risk drivers or employ any minimum number of portfolios or pools in any of the three retail sub-categories. The only specific limitations that the Agencies would propose in regard to the portfolio segmentation of retail exposures are (1) banking organizations generally would not be permitted to combine retail exposures from multiple countries into the same portfolio segment (because of differences in national legal systems and bankruptcy regimes), and (2) banking organizations would need to separately segment delinquent retail exposures. 
The inputs to the retail A-IRB capital formulas differ slightly from the inputs to the wholesale A-IRB capital formulas. Measures of PD, LGD, and EAD remain important elements, but there is no $\mathrm{M}$ input to the retail A-IRB capital formulas. Rather, the retail A-IRB capital formulas implicitly incorporate average maturity effects in general, such as in the residential mortgage sub-category.

Aside from the applicable definition of default, discussed below, the definitions of PD, LGD, and EAD for retail exposures are generally equivalent to those for wholesale exposures. One additional element of potential flexibility for banking organizations in the retail context needs to be highlighted. The Agencies recognize that certain banking organizations that may qualify for the advanced approaches segment their retail portfolios for management purposes by EL, rather than by separately measuring PD and LGD, as required under the A-IRB framework. Therefore, the Agencies propose that banking organizations be permitted substantial flexibility in translating measures of EL into the requisite PD and LGD inputs. For non-revolving portfolio segments, EL generally would equal the product of PD and LGD, so that if a banking organization has an estimate of EL and either PD or LGD, it would be able to infer an estimate of the other required input.

In addition, the Agencies are proposing that if one or the other of PD and LGD did not tend to vary significantly across portfolio segments, the banking organization would be permitted to apply a general estimate of that input to multiple segments and to use that general estimate, together with segment-specific estimates of EL, to infer segment-specific estimates of the other required input. The Agencies note, however, that this proposal offers substantial flexibility to institutions and may, in fact, be overly flexible (for example, because LGDs on residential mortgages tend to be quite cyclical). For these loans, the above method of inferring PDs or LGDs from a long-run average EL would not necessarily result in PD being estimated as a longrun average, and LGD would not necessarily reflect the loss rate expected to prevail when default rates are high. Banking organizations using an EL approach to retail portfolio segmentation would have to ensure that the A-IRB capital requirement under this method is at least as conservative as a PD/LGD method in order to minimize any potential divergences between capital requirements computed under the PD/LGD approach versus an EL approach.

As in the wholesale A-IRB framework, a floor of 3 basis points ( 0.03 percent) applies to the PD estimates for all retail exposures (that is, the minimum PD is 3 basis points). In addition, for residential mortgage exposures other than those guaranteed by a sovereign government, a floor of 10 percent on the LGD estimate would apply, based on the view that LGDs during periods of high default rates are unlikely to fall below this level if measured appropriately. Along with the overall monitoring of the implementation of the advanced approaches and the determination whether to generally relax the floors established during the initial implementation phases (that is, the 90 and 80 percent floors discussed above), the Agencies intend to review the need to retain PD and LGD floors for retail exposures following the first two years of implementation of the A-IRB framework.

The Agencies are proposing the following data requirements for retail A-IRB. Banking organizations would have to have a minimum of five years of data history for PD, LGD, and $\mathrm{EAD}$, and preferably longer periods so as to include a complete economic cycle. Banking 
organizations would not have to give equal weight to all historical factors if they can demonstrate that the more recent data are better predictors of the risk inputs. Also, banking organizations would have to have a minimum of three years of experience with their portfolio segmentation and risk management systems.

\section{$\underline{\text { Definition of Default and Loss }}$}

The retail definition of default and loss being proposed by the Agencies differs significantly from that proposed for the wholesale portfolio. Specifically, the Agencies propose to use the definitions of loss recognition embodied in the Federal Financial Institutions Examination Council (FFIEC) Uniform Retail Credit Classification and Account Management Policy. $^{21}$ All residential mortgages and all revolving credits would be charged off, or charged down to the value of the property, after a maximum of 180 days past due; other credits would be charged off after a maximum of 120 days past due.

In addition, the Agencies are proposing to define a retail default to include the occurrence of any one of the three following events if it occurs prior to the respective 120- or 180-day FFIEC policy trigger: (1) a full or partial charge-off resulting from a significant decline in credit quality of the exposure; (2) a distressed restructuring or workout involving forbearance and loan modification; or (3) a notification that the obligor has sought or been placed in bankruptcy. Finally, for retail exposures (as opposed to wholesale exposures) the definition of default may be applied to a particular facility, rather than to the obligor. That is, default on one obligation would not require a banking organization to treat all other obligations of the same obligor as defaulted.

\section{Undrawn Lines}

The treatment of undrawn lines of credit, in particular those associated with credit cards, merits specific discussion. Banking organizations would be permitted to incorporate undrawn retail lines in one of two ways. First, banking organizations could incorporate them into their EAD estimates directly, by assessing the likelihood that undrawn balances would be drawn at the time of an event of default. Second, banking organizations could incorporate them into LGD estimates by assessing the size of potential losses in default (including those arising from both currently drawn and undrawn balances) as a proportion of the current drawn balance. In the latter case, it is possible that the relevant LGD estimates would exceed 100 percent. While the proposed EAD approach for undrawn wholesale and retail lines is the same, the Agencies are aware that the sheer volume of credit card undrawn lines and the ratio of undrawn lines to outstanding balances create issues for undrawn retail lines that differ from undrawn wholesale lines not only in degree but also in kind.

An additional issue arises in connection with the undrawn lines associated with credit card accounts whose drawn balances (but not undrawn balances) have been securitized. To the extent that banking organizations remain exposed to the risk that such undrawn lines will be drawn, but such undrawn lines are not themselves securitized, then there is a need for institutions

\footnotetext{
${ }^{21}$ The FFIEC Uniform Retail Credit Classification and Account Management Policy was issued on June 12, 2000.
} It is available on the FFIEC website at www.FFIEC.gov. 
to hold regulatory capital against such undrawn lines. The Agencies propose that a banking organization would be required to hold capital against the full amount of any undrawn lines regardless of whether drawn amounts are securitized. This presumes that the institution itself is exposed to the credit risk associated with future draws.

The Agencies are interested in comments and specific proposals concerning methods for incorporating undrawn credit card lines that are consistent with the risk characteristics and loss and default histories of this line of business.

The Agencies are interested in further information on market practices in this regard, in particular the extent to which banking organizations remain exposed to risks associated with such accounts. More broadly, the Agencies recognize that undrawn credit card lines are significant in both of the contexts discussed above, and are particularly interested in views on the appropriate retail A-IRB treatment of such exposures.

$\underline{\text { Future Margin Income }}$

In the New Accord, the retail A-IRB treatment of QREs includes a unique additional input that arises because of the large amount of expected losses typically associated with QREs. As noted above, the A-IRB approach would require banking organizations to hold regulatory capital against both EL and UL. Banking organizations typically seek to cover expected losses through interest income and fees for all of their business activities, and the Agencies recognize that this practice is a particularly important aspect of the business model for QREs.

The Agencies are including in this proposal, for the QRE sub-category only, that future margin income (FMI) be permitted to offset a portion of the A-IRB retail capital charge relating to EL. For this purpose, the Agencies propose to define the amount of eligible FMI for the QRE sub-category as the amount of income anticipated to be generated by the relevant exposures over the next twelve months that can reasonably be assumed to be available to cover potential credit losses on the exposures after covering expected business expenses, and after subtracting a cushion to account for potential volatility in credit losses (UL). FMI would not be permitted to include anticipated income from new accounts and would have to incorporate assumptions about income from existing accounts that are in line with the banking organization's historical experience. The amount of the cushion to account for potential volatility in credit losses would be set equal to two standard deviations of the banking organization's annualized loss rate on the exposures. The Agencies would expect banking organizations to be able to support their estimates of eligible FMI on the basis of historical data and would disallow the use of FMI in the QRE capital formula if this is not the case. The step needed to recognize eligible FMI is discussed below.

Permitting a FMI offset to the A-IRB capital requirement for QREs could have a significant impact on the level of minimum regulatory capital at institutions adopting the advanced approaches. The Agencies would need to fully assess and analyze the impact of such an FMI offset on institutions' risk-based capital ratios prior to final implementation of the A-IRB 
approach. Furthermore, the Agencies anticipate the need to issue additional guidance setting out more specific expectations in this regard.

For the QRE sub-category of retail exposures only, the Agencies are seeking comment on whether or not to allow banking organizations to offset a portion of the AIRB capital requirement relating to EL by demonstrating that their anticipated FMI for this sub-category is likely to more than sufficiently cover EL over the next year.

The Agencies are seeking comment on the proposed definitions of the retail AIRB exposure category and sub-categories. Do the proposed categories provide a reasonable balance between the need for differential treatment to achieve risk-sensitivity and the desire to avoid excessive complexity in the retail A-IRB framework? What are views on the proposed approach to inclusion of SMEs in the other retail category?

The Agencies are also seeking views on the proposed approach to defining the risk inputs for the retail A-IRB framework. Is the proposed degree of flexibility in their calculation, including the application of specific floors, appropriate? What are views on the issues associated with undrawn retail lines of credit described here and on the proposed incorporation of FMI in the QRE capital determination process?

The Agencies are seeking comment on the minimum time requirements for data history and experience with portfolio segmentation and risk management systems: Are these time requirements appropriate during the transition period? Describe any reasons for not being able to meet the time requirements.

\section{$\underline{\text { Retail Exposures: Formulas }}$}

The retail A-IRB capital formulas are very similar to the wholesale A-IRB formulas, and are based on the same underlying concepts. However, because there is no M adjustment associated with the retail A-IRB framework, the retail A-IRB capital calculations generally involve fewer steps than the wholesale A-IRB capital calculations. As with the wholesale A-IRB framework, the output of the retail A-IRB formulas is a minimum capital requirement, expressed in dollars, for the relevant pool of exposures. The capital requirement would be converted into an equivalent amount of risk-weighted assets by multiplying the capital requirement by 12.5 . The two key steps in implementing the retail A-IRB capital formulas are (1) assessing the relevant asset correlation parameter, and (2) calculating the minimum capital requirement for the relevant pool of exposures.

\section{$\underline{\text { Residential Mortgages and Related Exposures }}$}

For residential mortgage and related exposures, the retail A-IRB capital formula requires only one step. This is because the asset correlation parameter for such exposures is fixed at 15 percent, regardless of the PD of any particular pool of exposures. The fixed asset correlation parameter reflects the Agencies' view that the arguments for linking the asset correlation to PD, as occurs in the wholesale A-IRB framework and in the other two sub-categories of retail exposures, are not as relevant for residential mortgage-related exposures, whose performance is 
significantly influenced by broader trends in the housing market for borrowers of all credit qualities. The assumed asset correlation of 15 percent also seeks implicitly to reflect the higher average maturity associated with residential mortgage exposures and is therefore higher than would likely be the case if a specific maturity adjustment were also included in the retail A-IRB framework. The proposed retail A-IRB capital formula for residential mortgage and related exposures is as follows:

Where

$$
\mathrm{K}=\mathrm{EAD} * \mathrm{LGD} * \mathrm{~N}[1.08465 * \mathrm{G}(\mathrm{PD})+0.4201 * \mathrm{G}(0.999)]
$$

$\mathrm{K}$ denotes the capital requirement;

EAD denotes exposure at default;

LGD denotes loss given default;

$\mathrm{N}(\mathrm{x})$ denotes the standard normal cumulative distribution function;

$\mathrm{G}(\mathrm{x})$ denotes the inverse of the standard normal cumulative distribution function; and

PD denotes probability of default.

The following table depicts a range of representative capital requirements $(\mathrm{K})$ for residential mortgage and related exposures based on this formula. Three different illustrative LGD assumptions are shown: 15 percent, 35 percent, and 55 percent. For comparison purposes, the current capital requirement on most first mortgage loans is 4 percent and on most home equity loans is 8 percent.

Capital Requirements (in percentage points)

\begin{tabular}{|c|c|c|c|}
\hline & \multicolumn{3}{|c|}{ LGD } \\
\hline PD & 15 percent & 35 percent & 55 percent \\
\hline 0.05 percent & 0.17 & 0.41 & 0.64 \\
\hline 0.10 percent & 0.30 & 0.70 & 1.10 \\
\hline 0.25 percent & 0.61 & 1.41 & 2.22 \\
\hline 0.50 percent & 1.01 & 2.36 & 3.70 \\
\hline 1.00 percent & 1.65 & 3.86 & 6.06 \\
\hline 2.00 percent & 2.64 & 6.17 & 9.70 \\
\hline 5.00 percent & 4.70 & 10.97 & 17.24 \\
\hline 10.00 percent & 6.95 & 16.22 & 25.49 \\
\hline 20.00 percent & 9.75 & 22.75 & 35.75 \\
\hline
\end{tabular}

Subject to the caveats noted earlier, evidence from QIS3 suggested that advanced approach banking organizations would experience a reduction in credit risk capital requirements for residential mortgage exposures of about 56 percent.

\section{$\underline{\text { Private Mortgage Insurance }}$}

The Agencies wish to highlight one issue associated with the A-IRB capital requirements for the residential mortgage sub-category relating to the treatment of private mortgage insurance (PMI). Most PMI arrangements effectively provide partial compensation to the banking organization in the event of a mortgage default. Accordingly, the Agencies consider that it may be appropriate for banking organizations to recognize such effects in the LGD estimates for 
individual mortgage portfolio segments, consistent with the historical loss experience on those segments during periods of high default rates. Such an approach would avoid requiring banking organizations to quantify specifically the effect of PMI on a loan-by-loan basis; rather, they could estimate the effect of PMI on an average basis for each segment. This approach effectively ignores the risk that the mortgage insurers themselves could default.

The Agencies seek comment on the competitive implications of allowing PMI recognition for banking organizations using the A-IRB approach but not allowing such recognition for general banks. In addition, the Agencies are interested in data on the relationship between PMI and LGD to help assess whether it may be appropriate to exclude residential mortgages covered by PMI from the proposed 10 percent LGD floor. The Agencies request comment on whether or the extent to which it might be appropriate to recognize PMI in LGD estimates.

More broadly, the Agencies are interested in information regarding the risks of each major type of residential mortgage exposure, including prime first mortgages, subprime mortgages, home equity term loans, and home equity lines of credit. The Agencies are aware of various views on the resulting capital requirements for several of these product areas, and wish to ensure that all appropriate evidence and views are considered in evaluating the A-IRB treatment of these important exposures.

The risk-based capital requirements for credit risk of prime mortgages could well be less than one percent of their face value under this proposal. The Agencies are interested in evidence on the capital required by private market participants to hold mortgages outside of the federally insured institution and GSE environment. The Agencies also are interested in views on whether the reductions in mortgage capital requirements on mortgage loans contemplated here would unduly extend the federal safety net and risk contributing to a credit-induced bubble in housing prices. In addition, the Agencies are also interested in views on whether there has been any shortage of mortgage credit under the general risk-based capital rules that would be alleviated by the proposed changes.

\section{Qualifying Revolving Exposures}

The second sub-category of retail exposures is QREs. The calculation of A-IRB capital requirements for QREs would require three steps: (1) calculation of the relevant asset correlation parameter, (2) calculation of the minimum capital requirement assuming no offset for eligible FMI, and (3) application of the offset for eligible FMI. These steps would be performed for each QRE portfolio segment individually.

As in the case of wholesale exposures, it is assumed that the asset correlation for QREs declines as PD rises. This reflects the view that pools of borrowers with lower credit quality (higher PD) are less likely to experience simultaneous defaults than pools of higher credit quality (lower PD) borrowers, because with higher PD borrowers defaults are more likely to result from borrower-specific or idiosyncratic factors. In the case of QREs, the asset correlation approaches an upper bound value of 11 percent for very low PD values and approaches a lower bound value 
of 2 percent for very high PD values. The specific formula for determining the asset correlation parameter for QREs is as follows:

Where

$$
\mathrm{R}=0.02 *(1-\operatorname{EXP}(-50 * \mathrm{PD}))+0.11 *[1-(1-\operatorname{EXP}(-50 * \mathrm{PD}))]
$$

$\mathrm{R}$ denotes asset correlation;

EXP denotes the natural exponential function; and

PD denotes probability of default.

The second step in the A-IRB capital calculation for QREs would be the calculation of the capital requirement assuming no FMI offset. The specific formula to calculate this amount is as follows:

Where

$$
\mathrm{K}_{\mathrm{No} \mathrm{FMI}}=\mathrm{EAD} * \mathrm{LGD} * \mathrm{~N}\left[(1-\mathrm{R})^{\wedge}-0.5 * \mathrm{G}(\mathrm{PD})+(\mathrm{R} /(1-\mathrm{R}))^{\wedge} 0.5 * \mathrm{G}(0.999)\right]
$$

$\mathrm{K}_{\mathrm{NoFMI}}$ denotes the capital requirement assuming no FMI offset;

EAD denotes exposure at default;

LGD denotes loss given default;

$\mathrm{N}(\mathrm{x})$ denotes the standard normal cumulative distribution function;

$\mathrm{R}$ denotes asset correlation;

$\mathrm{G}(\mathrm{x})$ denotes the inverse of the standard normal cumulative distribution function; and PD denotes probability of default.

\section{$\underline{\text { Future Margin Income Adjustment }}$}

The result of this calculation effectively includes both an EL and a UL component. As already discussed, for QREs only, the Agencies are considering the possibility of allowing institutions to offset a portion of the EL portion of the capital requirement using eligible FMI. Up to 75 percent of the EL portion of the capital requirement could potentially be offset in this fashion. The specific calculation for determining the capital requirement (K) after application of the potential offset for eligible FMI is as follows.

Where

$$
\mathrm{K}=\mathrm{K}_{\mathrm{No} \text { FMI }}-\text { eligible FMI offset }
$$

$\mathrm{K}$ denotes the capital requirement after application of an offset for eligible FMI;

$\mathrm{K}_{\mathrm{NoFMI}}$ denotes the capital requirement assuming no FMI offset;

Eligible FMI offset equals:

$0.75 *$ EL if estimated FMI equals or exceeds the expected 12-month loss amount plus two standard deviations of the annualized loss rate, or zero otherwise;

EL denotes expected loss $(\mathrm{EL}=\mathrm{EAD} * \mathrm{PD} * \mathrm{LGD})$;

FMI denotes future margin income;

EAD denotes exposure at default;

PD denotes probability of default; and

LGD denotes loss given default. 
If eligible FMI did not exceed the required minimum, then recognition of eligible FMI would be disallowed.

The Agencies are interested in views on whether partial recognition of FMI should be permitted in cases where the amount of eligible FMI fails to meet the required minimum. The Agencies also are interested in views on the level of portfolio segmentation at which it would be appropriate to perform the FMI calculation. Would a requirement that FMI eligibility calculations be performed separately for each portfolio segment effectively allow FMI to offset EL capital requirements for QREs?

The following table depicts a range of representative capital requirements $(\mathrm{K})$ for QREs based on these formulas. In each case, it is assumed that the maximum offset for eligible FMI has been applied. The LGD is assumed to equal 90 percent, consistent with recovery rates for credit card portfolios. The table shows capital requirements with recognition of FMI and without recognition of FMI but using the same formula in other respects. As PDs increase, the proportion of total required capital held against EL after deducting the 75 percent offset rises at an increasing rate and the proportion held against UL declines at an increasing rate. Offsets from EL, as considered in this ANPR, would therefore have a proportionally greater impact on reducing required capital charges as default probabilities increase. For comparison purposes, the current capital requirement on drawn credit card exposures is 8 percent and is zero for undrawn credit lines.

Capital Requirement (in percentage points)

\begin{tabular}{|c|c|c|}
\hline PD & With FMI & Without FMI \\
\hline & Capital 8\% & Capital 8\% \\
\hline 0.05 & 0.68 & 0.72 \\
\hline 0.10 & 1.17 & 1.23 \\
\hline 0.25 & 2.24 & 2.41 \\
\hline 0.50 & 3.44 & 3.78 \\
\hline 1.00 & 4.87 & 5.55 \\
\hline 2.00 & 6.21 & 7.56 \\
\hline 5.00 & 7.89 & 11.27 \\
\hline 10.0 & 11.12 & 17.87 \\
\hline 20.0 & 17.23 & 30.73 \\
\hline
\end{tabular}

Subject to the same qualifications mentioned earlier, the QIS3 results estimated an increase in credit risk capital requirements for QREs of about 16 percent.

\section{Other Retail Exposures}

The third and final sub-category of retail A-IRB exposures is other retail exposures. This sub-category encompasses a wide variety of different exposures including auto loans, student loans, consumer installment loans, and some SME loans. Two steps would be required to calculate the A-IRB capital requirement for other retail exposures: (1) calculating the relevant asset correlation parameter, and (2) calculating the capital requirement. Both of these steps 
would be done separately for each portfolio segment included within the other retail subcategory.

As for wholesale exposures and QREs, the asset correlation parameter for other retail exposures declines as PD rises. In the case of other retail exposures, the asset correlation parameter approaches an upper bound value of 17 percent for very low PD values and approaches a lower bound value of 2 percent for very high PD values. The specific formula for determining the asset correlation for other retail exposures is as follows:

Where

$$
\mathrm{R}=0.02 *(1-\mathrm{EXP}(-35 * \mathrm{PD}))+0.17 *[1-(1-\operatorname{EXP}(-35 * \mathrm{PD}))]
$$

$\mathrm{R}$ denotes asset correlation;

EXP denotes the natural exponential function; and

PD denotes probability of default.

The second step in the A-IRB capital calculation for other retail exposures would be the calculation of the capital requirement $(\mathrm{K})$. The specific formula to calculate this amount is as follows:

Where

$$
\mathrm{K}=\mathrm{EAD} * \mathrm{LGD} * \mathrm{~N}\left[(1-\mathrm{R})^{\wedge}-0.5 * \mathrm{G}(\mathrm{PD})+(\mathrm{R} /(1-\mathrm{R}))^{\wedge} 0.5 * \mathrm{G}(0.999)\right]
$$

$\mathrm{K}$ denotes the capital requirement;

EAD denotes exposure at default;

LGD denotes loss given default;

PD denotes probability of default;

$\mathrm{N}(\mathrm{x})$ denotes the standard normal cumulative distribution function;

$\mathrm{G}(\mathrm{x})$ denotes the inverse of the standard normal cumulative distribution function; and $\mathrm{R}$ denotes asset correlation.

The following table depicts a range of representative capital requirements $(\mathrm{K})$ for other retail exposures based on this formula. Three different LGD assumptions are shown -- 25 percent, 50 percent, and 75 percent -- in order to depict a range of potential outcomes depending on the characteristics of the underlying retail exposure. For comparison purposes, the current capital requirement on most of the exposures likely to be included in the other retail sub-category is 8 percent.

Capital Requirements (in percentage points)

\begin{tabular}{|c|c|c|c|}
\hline & \multicolumn{3}{|c|}{ LGD } \\
\hline PD & 25 percent & 50 percent & 75 percent \\
\hline 0.05 percent & 0.33 & 0.66 & 0.99 \\
\hline 0.10 percent & 0.56 & 1.11 & 1.67 \\
\hline 0.25 percent & 1.06 & 2.13 & 3.19 \\
\hline 0.50 percent & 1.64 & 3.28 & 4.92 \\
\hline 1.00 percent & 2.35 & 4.70 & 7.05 \\
\hline 2.00 percent & 3.08 & 6.15 & 9.23 \\
\hline 5.00 percent & 3.94 & 7.87 & 11.81 \\
\hline
\end{tabular}




\begin{tabular}{|l|l|l|l|}
\hline 10.00 percent & 5.24 & 10.48 & 15.73 \\
\hline 20.00 percent & 8.55 & 17.10 & 25.64 \\
\hline
\end{tabular}

Subject to the qualifications described earlier, QIS3 estimated a 25 percent reduction in credit risk-based capital requirements for the other retail category.

The Agencies are seeking comment on the retail A-IRB capital formulas and the resulting capital requirements, including the specific issues mentioned. Are there particular retail product lines or retail activities for which the resulting A-IRB capital requirements would not be appropriate, either because of a misalignment with underlying risks or because of other potential consequences?

\section{A-IRB: Other Considerations}

As described earlier, the A-IRB capital requirement includes components to cover both EL and UL. Because banking organizations have resources other than capital to cover EL, the Agencies proposes to recognize certain of these measures as potential offsets to the A-IRB capital requirement, subject to the limitations set forth below. The use of eligible FMI for QREs is one such potential mechanism that has already been discussed.

\section{$\underline{\text { Loan Loss Reserves }}$}

A second important mechanism involves the allowance for loan and lease losses (ALLL), also referred to as general loan loss reserves. Under the general risk-based capital rules, an amount of the ALLL is eligible for inclusion as an element of Tier 2 capital, up to a limit equal to 1.25 percent of gross risk-weighted assets. Loan loss reserves above this limit are deducted from risk-weighted assets, on a dollar-for-dollar basis. The New Accord proposes to retain the 1.25 percent limit on the eligibility of loan loss reserves as an element of Tier 2 capital. However, the New Accord also contains, and the Agencies are proposing for comment, a feature that would allow the amount of the ALLL (net of associated deferred tax) above this 1.25 percent limit to be used to offset the EL portion of A-IRB capital requirements in certain circumstances.

The offset would be limited to that amount of EL that exceeds the 1.25 percent limit. For example, if the 1.25 percent limit equals $\$ 100$, the ALLL equals $\$ 125$, and the EL portion of the A-IRB capital requirement equals $\$ 110$, then $\$ 10$ of the capital requirement may be directly offset (\$110 - \$100). The additional amount of the ALLL not included in Tier 2 capital and not included as a direct offset against the A-IRB capital requirement $(\$ 125-\$ 110=\$ 15$ in the example) would continue to be deducted from risk-weighted assets.

It is important to recognize that this treatment would likely result in a significantly more favorable treatment of such excess ALLL amounts than simply deducting them from riskweighted assets. Under the proposal, banking organizations would be allowed to multiply the eligible excess ALLL by a factor of 12.5 because the minimum total capital requirement is 8 percent of risk-weighted assets. In effect, this treatment is 12.5 times more favorable than the treatment contained in the general risk-based capital rules, which allow only a deduction against risk-weighted assets on a dollar-for-dollar basis. In addition, it is important to note that a dollar- 
for-dollar offset against the A-IRB capital requirement is also more favorable than the inclusion of ALLL below the 1.25 percent limit in Tier 2 capital, because the latter has no impact on Tier 1 capital ratios, while the former does.

The Agencies recognize the existence of various issues in regard to the proposed treatment of ALLL amounts in excess of the 1.25 percent limit and are interested in views on these subjects, as well as related issues concerning the incorporation of expected losses in the A-IRB framework and the treatment of the ALLL generally. Specifically, the Agencies invite comment on the domestic competitive impact of the potential difference in the treatment of reserves described above.

Another issue the Agencies wish to highlight is the inclusion within the New Accord of the ability for banking organizations to make use of "general specific" provisions as a direct offset against EL capital requirements. Such provisions are not specific to particular exposures but are specific to particular categories of exposures and are not allowed as an element of Tier 2 capital. While several other countries make use of such provisions, the Agencies do not believe existing elements of the ALLL in the United States qualify for such treatment.

The Agencies seek views on this issue, including whether the proposed U.S. treatment has significant competitive implications. Feedback also is sought on whether there is an inconsistency in the treatment of general specific provisions (all of which may be used as an offset against the EL portion of the A-IRB capital requirement) in comparison to the treatment of the ALLL (for which only those amounts of general reserves exceeding the 1.25 percent limit may be used to offset the EL capital charge).

\section{$\underline{\text { Charge-Offs }}$}

Another potential offset to the EL portion of the A-IRB capital requirements is the use of partial charge-offs, where a portion of an individual exposure is written off. Given the A-IRB definition of default, a partial charge-off would cause an exposure to be classified as a defaulted exposure (that is, $\mathrm{PD}=100 \%$ ), in which case the A-IRB capital formulas ensure that the resulting capital requirement on the defaulted exposure is equal to EAD * LGD, where EAD is defined as the gross exposure amount prior to the partial charge-off. All of this capital requirement can be considered to be covering EL.

The New Accord proposes that for such partially charged-off exposures, the banking organization be allowed to use the amount of the partial charge-off to offset the EL component of that asset's capital charge on a dollar-for-dollar basis. In addition, to the extent that the partial charge-off on a defaulted exposure exceeds the EL capital charge on that exposure, the amount of this surplus could be used to offset the EL capital charges on other defaulted assets in the same portfolio (for example, corporates, banks, residential mortgages, etc.), but not for any other purpose.

An implication of this aspect of the New Accord is that if a defaulted loan's charge-off were at least equal to its expected loss, no additional capital requirement would be incurred on that exposure. For example, consider a $\$ 100$ defaulted exposure having an LGD of 40 percent, 
implying an expected loss of $\$ 40$, equal to the IRB capital charge. If the charge-off were equal to $\$ 40$, under the New Accord approach, there would be no additional capital required against the resultant $\$ 60$ net position. The Agencies do not believe this is a prudent or acceptable outcome, since this position is not riskless and a banking organization could be forced to recognize additional charge-offs if the recoveries turn out to be less than expected.

To prevent this possibility, the Agencies propose that, for defaulted exposures, the A-IRB capital charge (inclusive of any EL offsets for charge-offs) be calculated as the sum of (a) EAD*LGD less any charge-offs and (b) 8 percent of the carrying value of the loan (that is, the gross exposure amount (EAD) less any charge-offs)

Also, the charged off amounts in excess of the EAD*LGD product would not be permitted to offset the EL capital requirements for other exposures. In effect, the proposed AIRB capital charge on a defaulted exposure adds a buffer for defaulted assets and results in a floor equal to 8 percent of the remaining book value of the exposure if the banking organization has taken a charge-off equal to or greater than the EAD * LGD. Importantly, this treatment would not apply to a defaulted exposure that has been restructured and where the obligor has not yet defaulted on the restructured credit. Upon any restructuring, whether associated with a default or otherwise, the A-IRB capital charge would be based on the EAD, PD, LGD, and M applicable to the exposure after it has been restructured. The existence of any partial charge-offs associated with the pre-restructured credit would affect the A-IRB capital charge on the restructured exposure only through its impact on the post-restructured exposure's EAD, PD, and/or LGD.

\section{Purchased Receivables}

This section describes the A-IRB treatment for wholesale and retail credit exposures acquired from another institution (purchased receivables). The purchase of such receivables may expose the acquiring banking organisation to potential losses from two sources: credit losses attributable to defaults by the underlying receivables obligors, and losses attributable to dilution of the underlying receivables. ${ }^{22}$ The total A-IRB capital requirement for purchased receivables would be the sum of (a) a capital charge for credit risk, and (b) a separate capital charge for dilution risk, when dilution is a material factor.

\section{Capital Charge for Credit Risk}

The New Accord's proposed treatment of purchased loans would treat a purchase discount as equivalent to a partial charge-off, and for this reason it could imply a zero capital charge against certain exposures. In general, a zero capital charge would emerge whenever the difference between a loan's face value and purchase price (the purchase discount) was greater than or equal to its LGD, as might be the case with a secondary market purchase of deeply

\footnotetext{
${ }^{22}$ Dilution refers to the possibility that the contractual amounts payable by the receivables obligors may be reduced through future cash or non-cash credits to the accounts of these obligors. Examples include offsets or allowances arising from returns of goods sold, disputes regarding product quality, possible debts of the originator/seller to a receivables obligor, and any payment or promotional discounts offered by the originator/seller (for example, a credit for cash payments within 30 days).
} 
distressed debt. Again, the Agencies believe that a zero capital charge in such a circumstance is unwarranted because the position is not riskless.

The Agencies propose that for a credit exposure that is purchased or acquired from another party, the A-IRB capital charge would be calculated as if the exposure were a direct loan to the underlying obligor in the amount of the loan's carrying value to the purchasing banking organization with other attributes of the loan agreement (for example, maturity, collateral, covenants) and, hence, LGD, remaining unchanged. This treatment would apply regardless of whether the carrying value to the purchasing banking organization was less than, equal to, or greater than the underlying instrument's face value. Thus, if a loan having a principal amount equal to $\$ 100$ and associated PD and LGD of 10 percent and 40 percent was purchased for $\$ 80$, the capital charge against the purchased loan would be calculated as if that loan had an EAD equal to $\$ 80, \mathrm{PD}$ equal to 10 percent, and LGD equal to 40 percent.

In general, the same treatment would apply to pools of purchased receivables. However, under the conditions detailed below, an alternative top-down approach (similar to that used for retail exposures) may be applied to pools of purchased receivables if the purchasing banking organization can only estimate inputs to the capital function (PD, LGD, EAD, and M) on a pool or aggregate basis.

\section{Top-down method for pools of purchased receivables}

Under the top-down approach, required capital would be determined using the appropriate A-IRB capital formula (that is, for wholesale exposures, the wholesale capital function, and for retail exposures, the appropriate retail capital function) in combination with estimates of PD, LGD, EAD, and M developed for pools of receivables. In estimating the pool parameters, the banking organization first would determine EL for the purchased receivables pool, expressed (in decimal form) at an annual rate relative to the amount currently owed to the banking organization by the obligors in the receivables pool. The estimated EL would not take into account any assumptions of recourse or guarantees from the seller of the receivables or other parties. If the banking organization can decompose EL into PD and LGD components, then it would do so and use those components as inputs into the capital function. If the institution cannot decompose EL, then it would use the following split: PD would equal the estimated EL, and LGD would be 100 percent. Under the top-down approach, EAD would equal the carrying amount of the receivables and for wholesale exposures, $M$ would equal the exposure-weighted average effective maturity of the receivables in the pool. ${ }^{23}$

\section{$\underline{\text { Treatment of undrawn receivables purchase commitments }}$}

Capital charges against any undrawn portions of receivables purchase facilities ('undrawn purchase commitments') also would be calculated using the top-down methodology. The EL (and/or PD and LGD) parameters would be determined on the basis of the current pool of eligible receivables using the pool-level estimation methods described above. For undrawn commitments under revolving purchase facilities, the New Accord specifies that the EAD would

\footnotetext{
${ }^{23}$ If a banking organization can estimate the exposure-weighted average size of the pool it also would use the firmsize adjustment $(\mathrm{S})$ in the wholesale framework.
} 
be set at 75 percent of the undrawn line. This treatment reflects a concern that relevant historical data for estimating such EADs reliably is not available at many banking organizations. For other undrawn purchase commitments, EAD would be estimated by the banking organization providing the facility and would be subject to the same operational standards that are applicable to undrawn wholesale credit lines. The level of $\mathrm{M}$ associated with undrawn purchase commitments would be the average effective maturity of receivables eligible for purchase from that seller, so long as the facility contains effective arrangements for protecting the banking organization against an unanticipated deterioration. In the absence of such protections, the $\mathrm{M}$ for an undrawn commitment would be calculated as the sum of (a) the longest-dated potential receivable under the purchase agreement, and (b) the remaining maturity of the facility.

The Agencies seek comment on the proposed methods for calculating credit risk capital charges for purchased receivables. Are the proposals reasonable and practicable?

For committed revolving purchase facilities, is the assumption of a fixed 75 percent conversion factor for undrawn lines reasonable? Do banking organizations have the ability (including relevant data) to develop their own estimate of EADs for such facilities? Should banking organizations be permitted to employ their own estimated EADs, subject to supervisory approval?

A banking organization may only use the top-down approach with approval of its primary Federal supervisor. In addition, the purchased receivables would have to have been purchased from unrelated, third party sellers and the organization may not have originated the credit exposures either directly or indirectly. The receivables must have been generated on an arm's length basis between the seller and the obligor (intercompany accounts receivable and receivables subject to contra-accounts between firms that buy and sell to each other would not qualify). Also, the receivables may not have a remaining maturity of greater than one year, unless they are fully secured. The Agencies propose that the bottom-up method would have to be used for receivables to any single obligor, or to any group of related obligors, that aggregate to more than $\$ 1$ million.

\section{Capital Charge for Dilution Risk}

When dilution is a material risk factor, ${ }^{24}$ purchased receivables would be subject to a separate capital charge for that risk. The dilution capital charge may be calculated at the level of each individual receivable and then aggregated, or, for a pool of receivables, at the level of the pool as a whole. The capital charge for dilution risk would be calculated using the wholesale AIRB formula and the following parameters: EAD would be equal to the gross amount of receivable(s) balance(s); LGD would be 100 percent; $M$ would be the (exposure weightedaverage) effective remaining maturity of the exposure(s); and PD would be the expected dilution loss rate, defined as total expected dilution losses over the remaining term of the receivable(s) divided by EAD. ${ }^{25}$ Expected dilution losses would be computed on a stand-alone basis; that is, under the assumption of no recourse or other support from the seller or third-party guarantors.

\footnotetext{
${ }^{24}$ If dilution risk is immaterial there would be no additional capital charge.

${ }^{25}$ If the remaining term exceeds one year, the expected dilution loss rate would be specified at an annual rate.
} 
The following table illustrates the dilution risk capital charges (per dollar of EAD) implied by this approach for a hypothetical pool of purchased receivables having a remaining maturity of one year or less. As can be seen, the proposal implies capital charges for dilution risk that are many multiples of expected dilution losses.

Capital Requirements (in percentage points)

\begin{tabular}{|c|c|}
\hline $\begin{array}{c}\text { Expected } \\
\text { Rate }\end{array}$ & $\begin{array}{c}\text { Dilution Risk Capital } \\
\text { Charge } \\
\text { (per dollar of EAD, } \\
\text { percent) }\end{array}$ \\
\hline 0.05 percent & 2.05 \\
\hline 0.10 percent & 3.42 \\
\hline 0.25 percent & 6.41 \\
\hline 0.50 percent & 9.77 \\
\hline 1.00 percent & 14.03 \\
\hline 2.00 percent & 19.03 \\
\hline 5.00 percent & 28.45 \\
\hline 10.00 percent & 41.24 \\
\hline
\end{tabular}

The Agencies seek comment on the proposed methods for calculating dilution risk capital requirements. Does this methodology produce capital charges for dilution risk that seem reasonable in light of available historical evidence? Is the wholesale A-IRB capital formula appropriate for computing capital charges for dilution risk?

In particular, is it reasonable to attribute the same asset correlations to dilution risk as are used in quantifying the credit risks of wholesale exposures within the A-IRB framework? Are there alternative method(s) for determining capital charges for dilution risk that would be superior to that set forth above?

\section{Minimum Requirements}

The Agencies propose to apply standards for the estimation of risk inputs and expected dilution losses and for the control and risk management systems associated with purchased receivables programs that are consistent with the general guidance contained in the New Accord. These standards will aim to ensure that risk input and expected dilution loss estimates are reliable and consistent over time, and reflect all relevant information that is available to the acquiring banking organization. The minimum operational requirements are intended to ensure that the acquiring banking organization has a valid legal claim to cash proceeds generated by the receivables pool, that the pool and cash proceeds are closely monitored and controlled, and that systems are in place to identify and address seller, servicer, and other potential risks. A more detailed discussion of these requirements will be provided when the Agencies release draft examination guidance dealing with purchased receivables programs. 
The Agencies seek comment on the appropriate eligibility requirements for using the top-down method. Are the proposed eligibility requirements, including the $\$ 1$ million limit for any single obligor, reasonable and sufficient?

The Agencies seek comment on the appropriate requirements for estimating expected dilution losses. Is the guidance set forth in the New Accord reasonable and sufficient?

\section{$\underline{\text { Risk Mitigation }}$}

For purposes of reducing the capital charges for credit risk or dilution risk with respect to purchased receivables, purchase discounts, guarantees, and other risk mitigants may be recognized through the same framework used elsewhere in the A-IRB approach.

\section{$\underline{\text { Credit Risk Mitigation Techniques }}$}

The New Accord takes account of the risk-mitigating effects of both financial and nonfinancial collateral, as well as guarantees, including credit derivatives. For these risk mitigants to be recognized for regulatory capital purposes, the banking organization must have in place operational procedures and risk management processes that ensure that all documentation used in collateralizing or guaranteeing a transaction is binding on all parties and legally enforceable in all relevant jurisdictions. The banking organization must have conducted sufficient legal review to verify this conclusion, must have a well-founded legal basis for the conclusion, and must reconduct such a review as necessary to ensure continuing enforceability.

\section{Adjusting LGD for the Effects of Collateral}

A banking organization would be able to take into account the risk-mitigating effect of collateral in its internal estimates of LGD, provided the organization has established internal requirements for collateral management, operational procedures, legal certainty, and risk management processes that ensure that:

(1) the legal mechanism under which the collateral is pledged or transferred ensures that the banking organization has the right to liquidate or take legal possession of the collateral in a timely manner in the event of the default, insolvency, or bankruptcy (or other defined credit event) of the obligor and, where applicable, the custodian holding the collateral;

(2) the banking organization has taken all steps necessary to fulfill legal requirements to secure the organization's interest in the collateral so that it has and maintains an enforceable security interest;

(3) the banking organization has clear and robust procedures for the timely liquidation of collateral to ensure observation of any legal conditions required for declaring the default of the borrower and prompt liquidation of the collateral in the event of default;

(4) the banking organization has established procedures and practices for (i) conservatively estimating, on a regular ongoing basis, the market value of the collateral, taking into account factors that could affect that value (for example, the liquidity of the market for the collateral and obsolescence or deterioration of the collateral), and (ii) where applicable, periodically verifying the collateral (for example, through physical inspection of collateral such as inventory and equipment); and 
(5) the banking organization has in place systems for requesting and receiving promptly additional collateral for transactions whose terms require maintenance of collateral values at specified thresholds.

In reflecting collateral in the LGD estimate, the banking organization would need to consider the extent of any dependence between the risk of the borrower and that of the collateral or collateral provider. The banking organization's assessment of LGD would have to address in a conservative way any significant degrees of dependence, as well as any currency mismatch between the underlying obligation and the collateral. The LGD estimates would have to be grounded in historical recovery rates on the collateral and could not be based solely upon the collateral's estimated market value.

\section{$\underline{\text { Repo-Style Transactions Subject to Master Netting Agreements }}$}

Repo-style transactions include reverse repurchase agreements and repurchase agreements and securities lending and borrowing transactions, including those executed on an indemnified agency basis. ${ }^{26}$ Many of these transactions are conducted under a bilateral master netting agreement or equivalent arrangement. The effects of netting arrangements generally would be recognized where the banking organization takes into account the risk-mitigating effect of collateral through an adjustment to EAD. To qualify for the EAD adjustment treatment, the repo-style transaction would have to be marked-to-market daily and be subject to a daily margin maintenance requirement. Further, the repo-style transaction would have to be documented under a qualifying master netting agreement that would have to:

(1) provide the non-defaulting party the right to terminate and close out promptly all transactions under the agreement upon an event of default, including in the event of insolvency or bankruptcy of the counterparty;

(2) provide for the netting of gains and losses on transactions (including the value of any collateral) terminated and closed out under the agreement so that a single net amount is owed by one party to the other;

(3) allow for the prompt liquidation or setoff of collateral upon the occurrence of an event of default; and

(4) be, together with the rights arising from the provisions required in 1) to 3) above, legally enforceable in each relevant jurisdiction upon the occurrence of an event of default and regardless of the counterparty's insolvency or bankruptcy.

Where a banking organization's repo-style transactions do not meet these requirements, it would not be able to use the EAD adjustment method. Rather, for each individual repo-style transaction it would estimate an LGD that takes into account the collateral received. It would use the notional amount of the transaction for EAD; it would not take into account netting effects for purposes of determining either EAD or LGD.

\footnotetext{
${ }^{26}$ Some banking organizations, particularly those that are custodians, lend, as agent, their customers' securities on a collateralized basis. Typically, the agent banking organization indemnifies the customer against risk of loss in the event the borrowing counterparty defaults. Where such indemnities are provided, the agent banking organization has the same risks it would have if it had entered into the transaction as principal.
} 
The method for determining EAD for repo-style transactions, described below, is essentially the determination of an unsecured loan equivalent exposure amount to the counterparty. Thus, no collateral effects for these transactions would be recognized through LGD; rather, the applicable LGD would be the one the banking organization would estimate for an unsecured exposure to the counterparty.

To determine EAD, the banking organization would add together its current exposure to the counterparty under the master netting arrangement and a measure for PFE to the counterparty under the master netting arrangement. The current exposure would be the sum of the market values of all securities and cash lent, sold subject to repurchase, or pledged as collateral to the counterparty under the master netting agreement, less the sum of the market values of all securities and cash lent, sold subject to repurchase, or pledged as collateral by the counterparty. The PFE calculation would be based on the market price volatilities of the securities delivered to, and the securities received from, the counterparty, as well as any foreign exchange rate volatilities associated with any cash or securities delivered or received.

Banking organizations would use a VaR-type measure for determining PFE for repo-style transactions subject to master netting agreements. Banking organizations would be required to use a $99^{\text {th }}$ percentile, one-tailed confidence interval for a five-day holding period using a minimum one-year historical observation period of price data. Banking organizations would have to update their data sets no less frequently than once every three months and reassess them whenever market prices are subject to material changes. The illiquidity of lower-quality instruments would have to be taken into account through an upward adjustment in the holding period where the five-day holding period would be inappropriate given the instrument's liquidity. No particular model would be prescribed for the VaR-based measure, but the model would have to capture all material risks for included transactions.

Banking organizations using a VaR-based approach to measuring PFE would be permitted to take into account correlations in the price volatilities among instruments delivered to the counterparty, among instruments received from the counterparty, as well as between the two sets of instruments. The VaR-based approach for calculating PFE for repo-style transactions would be available to all banking organizations that received supervisory approval for an internal market risk model under the market risk capital rules. Other banking organizations could apply separately for supervisory approval to use their internal VaR models for calculation of PFE for repo-style transactions.

A banking organization would use the following formula to determine EAD for each counterparty with which it has a master netting agreement for repo-style transactions.

$\mathrm{EAD}=\max \{0,[(\Sigma \mathrm{E}-\Sigma \mathrm{C})+(\mathrm{VaR}$ output from internal market risk model $\mathrm{x}$ multiplier $)]\}$ Where:

E denotes the current value of the exposure (that is, all securities and cash delivered to the counterparty); and

$\mathrm{C}$ denotes the current value of the collateral received (that is, all securities and cash received from the counterparty). 
The multiplier in the above formula would be determined based on the results of the banking organization's backtesting of the VaR output. To backtest the output, the banking organization would be required to identify on an annual basis twenty counterparties that include the ten largest as determined by the banking organization's own exposure measurement approach and ten others selected at random. For each day and for each of the twenty counterparties, the banking organization would compare the previous day's VaR estimate for the counterparty portfolio to the change in the current exposure of the previous day's portfolio. This change represents the difference between the net value of the previous day's portfolio using today's market prices and the net value of that portfolio using the previous day's market prices. Where this difference exceeds the previous day's VaR estimate, an exception would have occurred.

At the end of each quarter, the banking organization would identify the number of exceptions it has observed for its twenty counterparties over the most recent 250 business days, that is, the number of exceptions in the most recent 5000 observations. Depending on the number of exceptions, the output of the VaR model would be scaled up using a multiplier as provided in the table below.

\begin{tabular}{|l|c|c|}
\hline Zone & Number of Exceptions & Multiplier \\
\hline Green Zone & $0-99$ & None (=1) \\
\hline Yellow Zone & $100-119$ & 2.0 \\
& $120-139$ & 2.2 \\
& $140-159$ & 2.4 \\
& $160-179$ & 2.6 \\
& $180-199$ & 2.8 \\
\hline Red Zone & 200 or more & 3.0 \\
\hline
\end{tabular}

The Agencies seek comments on the methods set forth above for determining EAD, as well as on the proposed backtesting regime and possible alternatives banking organizations might find more consistent with their internal risk management processes for these transactions. The Agencies also request comment on whether banking organizations should be permitted to use the standard supervisory haircuts or own estimates haircuts methodologies that are proposed in the New Accord.

Guarantees and Credit Derivatives

The Agencies are proposing that banking organizations reflect the credit risk mitigating effects of guarantees and credit derivatives through adjusting the PD or the LGD estimate (but not both) of the underlying obligation that is protected. The banking organization would be required to assign the borrower and guarantor to an internal rating in accordance with the minimum requirements set out for unguaranteed (unhedged) exposures, both prior to the adjustments and on an ongoing basis. The organization also would be required to monitor regularly the guarantor's condition and ability and willingness to honor its obligation. For guarantees on retail exposures, these requirements would also apply to the assignment of an exposure to a pool and the estimation of the PD of the pool. 
For purposes of reflecting the effect of guarantees in regulatory capital requirements, the Agencies are proposing that a banking organization have clearly specified criteria for adjusting internal ratings or LGD estimates -- or, in the case of retail exposures, for allocating exposures to pools to reflect use of guarantees and credit derivatives -- that take account of all relevant information. The adjustment criteria would have to require a banking organization to (i) meet all minimum requirements for an unhedged exposure when assigning borrower or facility ratings to guaranteed/hedged exposures; (ii) be plausible and intuitive; (iii) consider the guarantor's ability and willingness to perform under the guarantee; (iv) consider the extent to which the guarantor's ability and willingness to perform and the borrower's ability to repay may be correlated (that is, the degree of wrong-way risk); and (v) consider the payout structure of the credit protection and conservatively assess its effect on the level and timing of recoveries. The banking organization also would be required to consider any residual risk to the borrower that may remain -- for example, a currency mismatch between the credit protection and the underlying exposure.

Banking organizations would be required to make adjustments to alter PD or LGD estimates in a consistent way for a given type of guarantee or credit derivative. In all cases, the adjusted risk weight for the hedged obligation could not be less than the risk weight associated with a comparable direct exposure on the protection provider. As a practical matter, this guarantor risk weight floor on the risk weight of the hedged obligation would require a banking organization first to determine the risk weight on the hedged obligation using the adjustment it has made to the PD or LGD estimate to reflect the hedge. The banking organization would then compare that risk weight to the risk weight assigned to a direct obligation of the guarantor. The higher of the two risk weights would then be used to determine the risk-weighted asset amount of the hedged obligation.

Notwithstanding the guarantor risk weight floor, the proposed approach gives institutions a great deal of flexibility in their methodology for recognizing the risk-reducing effects of guarantees and credit derivatives. At the same time, the approach does not differentiate between various types of guarantee structures, which may have widely varying characteristics, that a banking organization may use. For example, a company to company guarantee, such as a company's guarantee of an affiliate or a supplier, is fundamentally different from a guarantee obtained from an unrelated third party that is in the business of extending financial guarantees. Examples of the latter type of guarantee include standby letters of credit, financial guarantee insurance, and credit derivatives. These products tend to be standardized across institutions and, thus, arguably should be recognized for capital purposes in a consistent fashion across institutions. The problem of inconsistent treatment could be exacerbated in the case of protection in the form of credit derivatives, which are tradable and which further can be distinguished by their characteristic of allowing a banking organization to have a recovery claim on two parties, the obligor and the derivative counterparty, rather than just one.

Industry comment is sought on whether a more uniform method of adjusting PD or LGD estimates should be adopted for various types of guarantees to minimize inconsistencies in treatment across institutions and, if so, views on what methods would best reflect industry practices. In this regard, the Agencies would be particularly interested in information on how banking organizations are currently treating various 
forms of guarantees within their economic capital allocation systems and the methods used to adjust PD, LGD, EAD, and any combination thereof.

\section{$\underline{\text { Double Default Effects }}$}

The Agencies are proposing that neither the banking organization's criteria nor rating process for guaranteed/hedged exposures be allowed to take into account so-called "double default" effects -- that is, the joint probability of default of the borrower and guarantor. As a result of not being able to recognize double default probabilities, the adjusted risk weight for the hedged obligation could not be less than the risk weight associated with a direct exposure on the protection provider. The Agencies are seeking comment on the proposed nonrecognition of double default effects. On June 10, 2003, the Federal Reserve released a white paper on this issue entitled, "Treatment of Double Default and Double Recovery Effects for Hedged Exposures Under Pillar I of the Proposed New Basel Capital Accord.” Commenters are encouraged to take into account the white paper in formulating their responses to the ANPR.

The Agencies also are interested in obtaining commenters' views on alternative methods for giving recognition to double default effects in a manner that is operationally feasible and consistent with safety and soundness. With regard to the latter, commenters are requested to bear in mind the concerns outlined in the double default white paper, particularly in connection with concentrations, wrong-way risk (especially in stress periods), and the potential for regulatory capital arbitrage. In this regard, information is solicited on how banking organizations consider double default effects on credit protection arrangements in their economic capital calculations and for which types of credit protection arrangements they consider these effects.

\section{$\underline{\text { Requirements for recognized guarantees and credit derivatives }}$}

The Agencies are not proposing any restrictions on the types of eligible guarantors or credit derivative providers. Rather, a banking organization would be required to have clearly specified criteria for those guarantors they will accept as eligible for regulatory capital purposes. It is proposed that guarantees and credit derivatives recognized for regulatory capital purposes: (1) be required to represent a direct claim on the protection provider; (2) explicitly reference specific exposures or classes thereof; (3) be evidenced in writing through a contract that is irrevocable by the guarantor; (4) not have a clause that would (i) allow the protection provider unilaterally to cancel the credit protection (other than in the event of nonpayment or other default by the protection buying banking organization) or (ii) increase the effective cost of credit protection as the credit quality of the underlying obligor deteriorates; (5) be in force until the underlying obligation is satisfied in full (to the amount and tenor of the guarantee); and (6) be legally enforceable against the guarantor in a jurisdiction where the guarantor has assets to attach and enforce a judgement.

The Agencies view the risk mitigating benefits of conditional guarantees -- that is, guarantees that prescribe certain conditions under which the guarantor would not be obliged to perform -- as particularly difficult to quantify. The Agencies are proposing that as a general matter such guarantees would not be recognized under the A-IRB approach. In certain 
circumstances, however, conditional guarantees could be recognized where the banking organization can demonstrate that its assignment criteria fully reflect the reduction in credit risk mitigation arising from the conditionality and that the guarantee provides a meaningful degree of credit protection.

\section{$\underline{\text { Additional requirements for recognized credit derivatives }}$}

The Agencies are proposing that credit derivatives, whether in the form of credit default swaps or total return swaps, recognized for A-IRB risk-based capital purposes meet additional criteria. The credit events specified by the contracting parties would be required to include at a minimum: (i) failure to pay amounts due under the terms of the underlying obligation; (ii) bankruptcy, insolvency, or inability of the obligor to pay its debt; and (iii) restructuring of the underlying obligation that involves forgiveness or postponement of principal, interest, or fees that results in a credit loss.

With regard to restructuring events, the Agencies note that the New Accord suggests that a banking organization may not need to include restructuring credit events when it has complete control over the decision of whether or not there will be a restructuring of the underlying obligation. This would occur, for example, where the hedged obligation requires unanimous consent of the creditors for a restructuring. The Agencies have concerns that this approach could have the incidental effect of dictating terms in underlying obligations in ways that over time could diverge from creditors' business needs. The Agencies also question whether such clauses actually eliminate restructuring risk on the underlying obligation, particularly as many credit derivatives hedge only a small portion of a banking organization's exposure to the underlying obligation.

The Agencies invite comment on this issue, as well as consideration of an alternative approach whereby the notional amount of a credit derivative that does not include restructuring as a credit event would be discounted. Comment is sought on the appropriate level of discount and whether the level of discount should vary on the basis of, for example, whether the underlying obligor has publicly outstanding rated debt or whether the underlying obligor is an entity whose obligations have a relatively high likelihood of restructuring relative to default (for example, a sovereign or PSE). Another alternative that commenters may wish to discuss is elimination of the restructuring requirement for credit derivatives with a maturity that is considerably longer -- for example, two years -- than that of the hedged obligation.

Consistent with the New Accord, the Agencies are proposing not to recognize credit protection from total return swaps where the hedging banking organization records net payments received on the swap as net income, but does not record offsetting deterioration in the value of the hedged obligation either through reduction in fair value or by an addition to reserves. The Agencies are considering imposing similar non-recognition on credit default swaps where markto-market gains in value are recognized in income and, thus, in Tier 1 capital, but no offsetting deterioration in the hedged obligation is recorded. (This situation generally would not arise where both the hedged obligation and the credit default swap are recorded in the banking book 
because under GAAP increases in the swap's value are recorded in the Other Comprehensive Income account, which is not included in regulatory capital.)

Comment is sought on this matter, as well as on the possible alternative treatment of recognizing the hedge in these two cases for regulatory capital purposes but requiring that mark-to-market gains on the credit derivative that have been taken into income be deducted from Tier 1 capital.

Mismatches in credit derivatives between reference and underlying obligations

The Agencies are proposing to recognize credit derivative hedges for A-IRB capital purposes only where the reference obligation on which the protection is based is the same as the underlying obligation except where: 1) the reference obligation ranks pari passu with or is more junior than the underlying obligation, and 2) the underlying obligation and reference obligation share the same obligor and legally enforceable cross-default or cross-acceleration clauses are in place.

$\underline{\text { Treatment of maturity mismatch }}$

The Agencies are proposing to recognize on a discounted basis guarantees and credit derivatives that have a shorter maturity than the hedged obligation. A guarantee or credit derivative with less than one-year remaining maturity that does not have a matching maturity to the underlying obligation, however, would not be recognized. The formula for discounting the amount of a maturity-mismatched hedge that is recognized is proposed as follows:

Where:

$$
\mathrm{Pa}=\mathrm{P} * \mathrm{t} / \mathrm{T}
$$

Pa denotes the value of the credit protection adjusted for maturity mismatch;

$\mathrm{P}$ denotes the amount of the credit protection;

$\mathrm{t}$ denotes the lesser of $\mathrm{T}$ and the remaining maturity of the hedge arrangement, expressed in years; and

$\mathrm{T}$ denotes the lesser of five and the remaining maturity of the underlying obligation, expressed in years.

The Agencies have concerns that the proposed formulation does not appropriately reflect distinctions between bullet and amortizing underlying obligations. Comment is sought on the best way of making such a distinction, as well as more generally on alternative methods for dealing with the reduced credit risk coverage that results from a maturity mismatch.

$\underline{\text { Treatment of counterparty risk for credit derivative contracts }}$

The Agencies are proposing that the EAD for derivative contracts included in either the banking book or trading book be determined in accordance with the rules for calculating the credit equivalent amount for such contracts set forth under the general risk-based capital rules. The Agencies are proposing to include in the types of derivative contracts covered under these 
rules credit derivative contracts recorded in the trading book. Accordingly, where a banking organization buys or sells a credit derivative through its trading book, a counterparty credit risk capital charge would be imposed based on the replacement cost plus the following add-on factors for PFE:

\begin{tabular}{|l|c|c|}
\hline \multicolumn{1}{|c|}{$\begin{array}{c}\text { Total Return or Credit } \\
\text { Default Swap }\end{array}$} & Protection Buyer & Protection Seller \\
\hline $\begin{array}{l}\text { Qualifying Reference } \\
\text { Obligation* }\end{array}$ & $5 \%$ & $5 \% * *$ \\
\hline $\begin{array}{l}\text { Non-Qualifying Reference } \\
\text { Obligation* }\end{array}$ & $10 \%$ & $10 \% * *$ \\
\hline
\end{tabular}

* The definition of qualifying would be the same as for the "qualifying" category for the treatment of specific risk for covered debt positions under the market risk capital rules

** The protection seller of a credit default swap would only be subject to the add-on factor where the contract is subject to close-out upon the insolvency of the protection buyer while the underlying obligor is still solvent.

The Agencies also are considering applying a counterparty credit risk charge on all credit derivatives that are marked-to-market, including those recorded in the banking book. Such a treatment would promote consistency with other OTC derivatives, which are assessed the same counterparty credit risk charge regardless of where they are booked.

Further, the Agencies note that, if credit derivatives booked in the banking book are not assessed a counterparty credit risk charge, banking organizations would be required to exclude these derivatives from the net current exposure of their other derivative exposures to a counterparty for purposes of determining regulatory capital requirements. On balance, the Agencies believe a better approach would be to align the net derivative exposure used for capital purposes with that used for internal risk management purposes to manage counterparty risk exposure and collateralization thereof. This approach would suggest imposing a counterparty risk charge on all credit derivative exposures that are marked to market, regardless of where they are booked.

The Agencies are seeking industry views on the PFE add-ons proposed above and their applicability. Comment is also sought on whether different add-ons should apply for different remaining maturity buckets for credit derivatives and, if so, views on the appropriate percentage amounts for the add-ons in each bucket.

\section{$\underline{\text { Equity Exposures }}$}

Banking organizations using the A-IRB approach for any credit exposure would be required to use an internal models market-based approach to calculate regulatory capital charges for equity exposures. Minimum quantitative and qualitative requirements for using an internal model would have to be met on an ongoing basis. An advanced approach banking organization that is transitioning into an internal models approach to equity exposures or that fails to demonstrate compliance with the minimum operational requirements for using an internal models approach to equity exposures would be required to develop a plan for compliance, obtain approval of the plan from its primary Federal supervisor, and implement the plan in a timely 
fashion. In addition, a banking organization's primary Federal supervisor would have the authority to impose additional operational requirements on a case-by-case basis. Until it is fully compliant with all applicable requirements, the banking organization would apply a minimum 300 percent risk weight to all publicly traded equity investments (that is, equity investments that are traded on a nationally recognized securities exchange) and a minimum 400 percent risk weight to all other equity investments.

\section{$\underline{\text { Positions Covered }}$}

All equity exposures held in the banking book, along with any equity exposures in the trading book that are not currently subject to a market risk capital charge, would be subject to the A-IRB approach for equity exposures. In general, equity exposures are distinguished from other types of exposures based on the economic substance of the exposure. Equity exposures would include both direct and indirect ownership interests, whether voting or non-voting, in the assets or income of a commercial enterprise or financial institution that are not consolidated or deducted for regulatory capital purposes. Holdings in funds containing both equity investments and non-equity investments would be treated either as a single investment based on the majority of the fund's holdings or, where possible, as separate and distinct investments in the fund's component holdings based on a "look-through approach" (that is, based on the individual component holdings).

An instrument generally would be considered to be an equity exposure if it (1) would qualify as Tier 1 capital under the general risk-based capital rules if issued by a banking organization; (2) is irredeemable in the sense that the return of invested funds can be achieved only by the sale of the investment or sale of the rights to the investment or in the event of the liquidation of the issuer; (3) conveys a residual claim on the assets or income of the issuer; and (4) does not embody an obligation on the part of the issuer.

An instrument that embodies an obligation on the part of the issuer would be considered an equity exposure if the instrument meets any of the following conditions: (1) the issuer may defer indefinitely the settlement of the obligation; (2) the obligation requires, or permits at the issuer's discretion, settlement by the issuance of a fixed number of the issuer's equity interests; (3) the obligation requires, or permits at the issuer's discretion, settlement by the issuance of a variable number of the issuer's equity interests, and all things being equal, any change in the value of the obligation is attributable to, comparable to, and in the same direction as, the change in value of a fixed number of the issuer's equity shares; or (4) the holder has the option to require that the obligation be settled by issuance of the issuer's equity interests, unless the banking organization's primary Federal supervisor has opined in writing that the instrument should be treated as a debt position.

Debt obligations and other securities, derivatives, or other instruments structured with the intent of conveying the economic substance of equity ownership would be considered equity exposures for purposes of the A-IRB capital requirements. For example, options and warrants on equities and short positions in equity securities would be characterized as equity exposures. If a debt instrument is convertible into equity at the option of the holder, it would be deemed equity upon conversion. If such debt is convertible at the option of the issuer or automatically by the 
terms of the instrument, it would be deemed equity from inception. In addition, instruments with a return directly linked to equities would be characterized as equity exposures under most circumstances. A banking organization's primary Federal supervisor would have the discretion to allow a debt characterization of such an equity-linked instrument, however, if the instrument is directly hedged by an equity holding such that the net position does not involve material equity risk to the holder. Equity instruments that are structured with the intent of conveying the economic substance of debt holdings, or securitization exposures would not be considered equity exposures. For example, some issuances of term preferred stock may be more appropriately characterized as debt.

In all cases, the banking organization's primary Federal supervisor would have the discretion to recharacterize debt holdings as equity exposures or equity holdings as debt or securitization exposures for regulatory capital purposes.

The Agencies encourage comment on whether the definition of an equity exposure is sufficiently clear to allow banking organizations to make an appropriate determination as to the characterization of their assets.

\section{Materiality}

As noted above, a banking organization that is required or elects to use the A-IRB approach for any credit portfolio would also generally be required to use the A-IRB approach for its equity exposures. However, if the aggregate equity holdings of a banking organization are not material in amount, the organization would not be required to use the A-IRB approach to equity exposures. For this purpose, a banking organization's equity exposures generally would be considered material if their aggregate carrying value, including holdings subject to exclusions and transitional provisions (as described below), exceeds 10 percent of the organization's Tier 1 and Tier 2 capital on average during the prior calendar year. To address concentration concerns, however, the materiality threshold would be lowered to 5 percent of the banking organization's Tier 1 and Tier 2 capital if the organization's equity portfolio consists of less than ten individual holdings. Banking organizations would risk weight at 100 percent equity exposures exempted from the A-IRB equity treatment under a materiality threshold.

Comment is sought on whether the materiality thresholds set forth above are appropriate.

\section{Exclusions from the A-IRB Equity Capital Charge}

\section{Zero and low risk weight investments}

The New Accord provides that national supervisors may exclude from the A-IRB capital charge those equity exposures to entities whose debt obligations qualify for a zero risk weight under the New Accord's standardized approach for credit risk. Entities whose debt obligations qualify for a zero risk weight generally include (i) sovereigns rated AAA to AA-; (ii) the BIS; (iii) the IMF; (iv) the European Central Bank; (v) the European Community; and (vi) 
high-quality multilateral development banks (MDBs) with strong shareholder support. ${ }^{27}$ The Agencies intend to exclude from the A-IRB equity capital charge equity investments in these entities. Instead, these investments would be risk weighted at zero percent under the A-IRB approach.

In addition, the Agencies are proposing to exempt from the A-IRB equity capital charge investments in non-central government public-sector entities (PSEs) that are not traded publicly and generally are held as a condition of membership. Examples of such holdings include stock of a Federal Home Loan Bank or a Federal Reserve Bank. These investments would be riskweighted as they would be under the general risk-based capital rules -- 20 percent or zero percent, respectively, in the examples.

Comment is sought on whether other types of equity investments in PSEs should be exempted from the A-IRB capital charge on equity exposures, and if so, the appropriate criteria for determining which PSEs should be exempted.

Legislated program equity exposures

Under the New Accord, national supervisors may exclude from the A-IRB capital charge on equity exposures certain equity exposures made under legislated programs that involve government oversight and restrictions on the types or amounts of investments that may be made (legislated program equity exposures). Under the New Accord, a banking organization would be able to exclude from the A-IRB capital charge on equity exposures legislated program equity exposures in an amount up to 10 percent of the banking organization's Tier 1 plus Tier 2 capital.

The Agencies propose that equity investments by a banking organization in a small business investment company (SBIC) under section 302(b) of the Small Business Investment Act of 1958 would be legislated program equity exposures eligible for the exclusion from the A-IRB equity capital charge in an amount up to 10 percent of the banking organization's Tier 1 plus Tier 2 capital. A banking organization would be required to risk weight at 100 percent any amounts of legislated program equity exposures that qualify for this exclusion from the A-IRB equity capital charge.

The Agencies seek comment on what conditions might be appropriate for this partial exclusion from the A-IRB equity capital charge. Such conditions could include limitations on the size and types of businesses in which the banking organization invests, geographical limitations, or limitations on the size of individual investments.

U.S. banking organizations also make investments in community development corporations (CDCs) or community and economic development entities (CEDEs) that promote the public welfare. These investments receive favorable tax treatment and investment subsidies

\footnotetext{
27 These are, at present, the World Bank group comprised of the International Bank for Reconstruction and Development and the International Finance Corporation, the Asian Development Bank, the African Development Bank, the European Bank for Reconstruction and Development, the Inter-American Development Bank, the European Investment Bank, the Islamic Development Bank, the Nordic Investment Bank, the Caribbean Development Bank, and the Council of Europe Development Bank.
} 
that make their risk and return characteristics markedly different (and more favorable to investors) than equity investments in general. Recognizing this more favorable risk-return structure and the importance of these investments to promoting important public welfare goals, the Agencies are proposing the exclusion of all such investments from the A-IRB equity capital charge. Unlike the exclusion for SBIC exposures, the exclusion of CDC and CEDE investments would not be subject to a percentage of capital limit. All CDC and CEDE equity exposures would receive a 100 percent risk weight.

The Agencies seek comment on whether any conditions relating to the exclusion of CDC/CEDE investments from the A-IRB equity capital charge would be appropriate. These conditions could serve to limit the exclusion to investments in such entities that meet specific public welfare goals or to limit the amount of such investments that would qualify for the exclusion from the A-IRB equity capital charge. The Agencies also seek comment on whether any other classes of legislated program equity exposures should be excluded from the A-IRB equity capital charge.

\section{Grandfathered investments}

Equity exposures held as of the date of adoption of the final A-IRB capital rule governing equity exposures would be exempt from the A-IRB equity capital charge for a period of ten years from that date. A banking organization would be required to risk weight these holdings during the ten-year period at 100 percent. The investments that would be considered grandfathered would be equal to the number of shares held as of the date of the final rule, plus any shares that the holder acquires directly as a result of owning those shares, provided that any additional shares do not increase the holder's proportional ownership share in the company.

For example, if a banking organization owned 100 shares of a company on the date of adoption of the final rule, and the issuer thereafter declared a pro rata stock dividend of 5 percent, the entire post-dividend holdings of 105 shares would be exempt from the A-IRB equity capital charge for a period of ten years from the date of the adoption of the final rule. However, if additional shares are acquired such that the holder's proportional share of ownership increases, the additional shares would not be grandfathered. Thus, if a banking organization owned 100 shares of a company on the date of adoption of the final rule and subsequently acquired an additional 50 shares, the original 100 shares would be exempt from the A-IRB equity capital charge for the ten-year period from the date of adoption of the final rule, but the additional 50 shares would be immediately subject to the A-IRB equity capital charge.

\section{Description of Quantitative Principles}

The primary focus of the A-IRB approach to equity exposures is to assess capital based on an internal estimate of loss under extreme market conditions on an institution's portfolio of equity holdings or, in simpler forms, its individual equity investments. The methodology or methodologies used to compute the banking organization's estimated loss should be those used by the institution for internal risk management purposes. The model should be fully integrated into the banking organization's risk management infrastructure. 
A banking organization's use of internal models would be subject to supervisory approval and ongoing review by the institution's primary Federal supervisor. Given the unique nature of equity portfolios and differences in modeling techniques, the supervisory model review process would be, in many respects, institution-specific. The sophistication and nature of the modeling technique used for a particular type of equity exposure should correspond to the banking organization's exposure, concentration in individual equity issues of that type, and the particular risk of the holding (including any optionality). Institutions would have to use an internal model that is appropriate for the risk characteristics and complexity of their equity portfolios. The model would have to be able to capture adequately all of the material risks embodied in equity returns, including both general market risk and idiosyncratic (that is, specific) risk of the institution's equity portfolio.

In their evaluations of institutions' internal models, the Agencies would consider, among other factors, (a) the nature of equity holdings, including the number and types of equities (for example, public, private, long, short); (b) the risk characteristics and makeup of institutions' equity portfolio holdings, including the extent to which publicly available price information is obtainable on the exposures; and (c) the level and degree of concentration. Institutions with equity portfolios containing holdings with values that are highly nonlinear in nature (for example, equity derivatives or convertibles) would have to employ an internal model designed to appropriately capture the risks associated with these instruments.

The Agencies recognize that the type and sophistication of internal modeling systems will vary across institutions due to differences in the nature and complexity of business lines in general and equity exposures in particular. Although the Agencies intend to use a VaR methodology as a benchmark for the internal model approach, the Agencies recognize that some institutions employ models for internal risk management and capital allocation purposes that, given the nature of their equity holdings, can be more risk-sensitive than some VaR models. For example, some institutions employ rigorous historical scenario analysis and other techniques in assessing the risk of their equity portfolios. It is not the Agencies' intention to dictate the form or operational details of banking organizations' risk measurement and management practices for their equity exposures. Accordingly, the Agencies do not expect to prescribe any particular type of model for computing A-IRB capital charges for equity exposures.

For purposes of evaluating the A-IRB equity capital charges produced by a banking organization's selected methodology, the Agencies would expect to use as a benchmark a VaR methodology using a 99.0 percent (one-tailed) confidence level of estimated maximum loss over a quarterly time horizon using a long-term sample period. Moreover, A-IRB equity capital charges would have to produce risk weights for equity exposures that are at least equal to a 200 percent risk weight for publicly traded equity exposures, and a 300 percent risk weight for all other equity exposures.

VaR-based internal models must use a historical observation period that includes a sufficient amount of data points to ensure statistically reliable and robust loss estimates relevant to the long-term risk profile of the institution's specific holdings. The data used to represent return distributions should reflect the longest sample period for which data are available and should meaningfully represent the risk profile of the banking organization's specific equity 
holdings. The data sample should be long-term in nature and, at a minimum, should encompass at least one complete equity market cycle relevant to the institution's holdings, including both increases and decreases in relevant equity values over a long-term data period. The data used should be sufficient to provide conservative, statistically reliable, and robust loss estimates that are not based purely on subjective or judgmental considerations.

The parameters and assumptions used in a VaR model must be subject to a rigorous and comprehensive regime of stress-testing. Banking organizations utilizing VaR models would be required to subject their internal model and estimation procedures, including volatility computations, to either hypothetical or historical scenarios that reflect worst-case losses given underlying positions in both public and private equities. At a minimum, banking organizations that use a VaR model would be required to employ stress tests to provide information about the effect of tail events beyond the level of confidence assumed in the internal models approach.

Banking organizations using non-VaR internal models that are based on stress tests or scenario analyses would have to estimate losses under worst-case modeled scenarios. These scenarios would have to reflect the composition of the organization's equity portfolio and should produce capital charges at least as large as those that would be required to be held against a representative market index under a VaR approach. For example, for a portfolio consisting primarily of publicly held equity securities that are actively traded, capital charges produced using historical scenario analyses would have to be greater than or equal to capital charges produced by a baseline VaR approach for a major index that is representative of the institution's holdings.

The measure of an equity exposure on which A-IRB capital requirements would be based would be the value of the equity presented in a banking organization's financial statements. For investments held at fair value, the exposure amount would be equal to the fair value presented in the balance sheet. For investments held at the lower of cost or market value, the exposure amount would be equal to the cost or market value presented in the balance sheet.

The loss estimate derived from the internal model would constitute the A-IRB capital charge to be assessed against the equity exposure. The A-IRB equity capital charge would be incorporated into an institution's risk-based capital ratio through the calculation of risk-weighted equivalent assets. To convert the A-IRB equity capital charge into risk-weighted equivalent assets, a banking organization would multiply the capital charge by a factor of 12.5.

Consistent with the general risk-based capital rules, 45 percent of the positive change in value held in the tax-adjusted separate component of equity - that is, 45 percent of revaluation gains on available-for-sale (AFS) equity securities - would be includable in Tier 2 capital under the A-IRB framework.

Comment is specifically sought on whether the measure of an equity exposure under AFS accounting continues to be appropriate or whether a different rule for the inclusion of revaluation gains should be proposed. 


\section{Supervisory Assessment of A-IRB Framework}

A banking organization would have to satisfy all the A-IRB infrastructure requirements and supervisory standards before it would be able to use the A-IRB approach for calculating capital requirements for credit risk. This section describes key elements of the framework on which the Agencies propose to base the A-IRB qualifying requirements for U.S. banking organizations. The Agencies intend to provide more detailed implementation guidance in regard to these issues for wholesale and retail exposures, as well as for equity and securitization exposures. As noted earlier, draft guidance for corporate exposures that identifies associated supervisory standards was published elsewhere in today's Federal Register.

\section{Overview of Supervisory Framework}

Many of the supervisory standards are focused on requirements for a banking organization's internal risk rating system. Emphasis is placed on a banking organization's ability to rank order and quantify risk in a consistent, reliable and valid manner. In sum, a banking organization's internal risk rating system would have to provide for a meaningful differentiation of the riskiness of borrowers, as well as the risks inherent in individual transactions. To ensure the reliability of these estimates, internal risk rating systems would need to be subject to review by independent control units. Data sources and estimation methods used by banking organizations would need to be sufficiently robust to support the production of consistent quantitative assessments of risk over time. Finally, to ensure that ratings are not derived solely for regulatory capital purposes, internal risk rating systems and quantification methods would need to form an integral part of the management of the institution, as outlined below.

It is important to emphasize that the Agencies believe that meeting the A-IRB infrastructure requirements and supervisory standards will require significant efforts by banking organizations. The A-IRB supervisory standards will effectively "raise the bar" in regard to sound credit risk management practices.

\section{$\underline{\text { Rating System Design }}$}

The design of an internal risk rating system is key to its effectiveness. By definition, a rating system comprises all of the processes that support the assessment of credit risk, the assignment of internal risk ratings, and the quantification of default and loss estimates. Banking organizations would be able to rely on one or more systems for assessing their credit risk exposures. When this is the case, the banking organization would have to demonstrate that each system used for A-IRB capital purposes complies with the supervisory standards.

The Agencies believe that banking organizations' internal rating systems should accurately and consistently differentiate degrees of risk. For wholesale exposures, banking organizations would need to have a two-dimensional rating system that separately assesses the risk of borrower default, as well as transaction-specific factors that focus on the amount that would likely be collected in the event of default. Such factors may include whether an exposure is collateralized, its seniority, and the product type. In contrast to the individual evaluation required for wholesale exposures, retail exposures would be assessed on a pool basis. Banking organizations would need to group their retail exposures into portfolio segments based on the 
risk characteristics that they consider relevant -- for example borrower characteristics such as credit scores or transaction characteristics such as product or collateral type. Delinquent or defaulted exposures would need to be separated from those that are current.

Banking organizations would be required to define clearly their wholesale rating categories and retail portfolio segments. The clarity and transparency of the ratings criteria are critical to ensuring that ratings are assigned in a consistent and reliable manner. The Agencies believe it is important for banking organizations to document the operating procedures for their internal risk rating system in writing. For example, the documentation should describe which parties within the organization would have the authority to approve exceptions. Further, the documentation would have to clearly specify the frequency of review, as well as describe the oversight to be provided by management of the ratings process.

Banking organizations using the A-IRB approach would need to be able to generate sound measurements of the key risk inputs to the A-IRB capital formulas. Banking organizations would be able to rely on data based either on internal experience or generated by an external source, as long as the banking organization can demonstrate the relevance of external data to its own experience.

In assigning a rating to an obligor, a banking organization must assess the risk of default, taking into account possible adverse events that might increase the obligor's likelihood of default. The A-IRB supervisory standards in the supervisory guidance provide banking organizations with a degree of flexibility in determining precisely how to reflect adverse events in obligor ratings. However, banking organizations are required to clearly articulate the approach chosen, and to articulate the implications for capital planning and for capital adequacy during times of systematic economic stress. The Agencies recognize that banking organizations' internal risk rating systems may include a range of statistical models or other methods to assign borrower or facility ratings or to estimate key inputs. The burden of proof would remain on the banking organization as to whether a specific model or procedure satisfies the supervisory standards.

\section{$\underline{\text { Risk Rating System Operations }}$}

The risk rating system would have to form an integral part of the loan approval process wherein ratings are assigned to all borrowers, guarantors, or facilities depending upon whether the extension of credit is wholesale or retail in nature. Any deviations from policies that govern the assignment of ratings must be clearly documented and monitored.

Data maintenance is another key aspect of risk rating system operations. Banking organizations would be expected to collect and store data on key borrower and facility characteristics. The data would have to be sufficiently detailed to allow for future reconsideration of the way in which obligors and facilities have been allocated to grades. Furthermore, banking organizations would have to collect, retain, and disclose data on aspects of their internal ratings as described under the disclosure section of this proposal. 
Banking organizations would be required to have in place sound stress testing processes for use in the assessment of capital adequacy. Stress testing would have to involve identifying possible events or future changes in economic conditions that could have unfavorable effects on a banking organization's credit exposures. Specifically, institutions would need to assess the effect of certain specific conditions on their A-IRB regulatory capital requirements. The choice of test to be employed would remain with the individual banking organization provided the method selected is meaningful and reasonably conservative.

\section{Corporate Governance and Oversight}

The Agencies view the involvement of the board of directors and management as critical to the successful implementation of the A-IRB approach. The board of directors and management would be responsible for maintaining effective internal controls over the banking organization's information systems and processes for assessing adequacy of regulatory capital and determining regulatory capital charges consistent with this ANPR. All significant aspects of the rating and estimation processes would have to be approved by the banking organization's board of directors or a designated committee thereof and senior management. These parties would need to be fully aware of whether the system complies with the supervisory standards, makes use of the necessary data, and produces reliable quantitative estimates. Ongoing management reports would have to accurately capture the performance of the rating system.

Oversight would also need to involve independent credit risk control units responsible for ensuring the performance of the rating system, the accuracy of the ratings and parameter estimates, and overall compliance with supervisory standards and capital regulations. The Agencies believe it is critical that such units remain functionally independent from the personnel and management responsible for originating credit exposures. Among other responsibilities, the control units should be charged with testing and monitoring the appropriateness of the rating scale, verifying the consistent use of ratings for a given exposure type across the organization, and reviewing and documenting any changes to be made to the system.

\section{$\underline{\text { Use of Internal Ratings }}$}

To qualify to use the A-IRB framework, a banking organization's rating systems would have to form an integral part of its day-to-day credit risk management process. The Agencies expect that banking organizations would rely on their internal risk rating systems when making decisions about whether to extend credit as well as in their ongoing monitoring of credit exposures. For example, ratings information would have to be incorporated into other key processes, such as reserving determinations and when allocating economic capital internally.

\section{$\underline{\text { Risk Quantification }}$}

Ratings quantification is the process of assigning values to the key risk components of the A-IRB approach: PD, LGD, EAD and $\mathrm{M}$. With the exception of $\mathrm{M}$, the risk components are unobservable and must be estimated. The estimates would have to be consistent with sound practice and supervisory standards. Banking organizations' rating system review and internal audit functions would need to serve as control mechanisms that ensure the process of rating 
assignments and quantification are functioning according to policy and that non-compliance or weaknesses are identified.

$\underline{\text { Validation of Internal Estimates }}$

An equally important element would be a robust system for validating the accuracy and consistency of a banking organization's rating system, as well as the estimation of risk components. The standards in the supervisory guidance require that banking organizations use a broad range of validation tools, including evaluation of developmental evidence, ongoing monitoring of rating and quantification processes, benchmarking against alternative approaches, and comparison of outcomes with estimates. Details of the validation process would have to be consistent with the operation of the banking organization's rating system and data would have to be maintained and updated to support oversight and validation work. Banking organizations would have to have well-articulated standards for situations where deviations of realized values from expectations become significant enough to call the validity of the estimates into question. Rating systems with appropriate data and oversight feedback mechanisms should create an environment that promotes integrity and improvements in the rating system over time.

\section{$\underline{\text { U.S. Supervisory Review }}$}

The primary Federal supervisor would be responsible for evaluating an institution's initial and ongoing compliance with the infrastructure requirements and supervisory standards for approval to use the A-IRB approach for regulatory capital purposes. As noted, the Agencies will be developing and issuing specific implementation guidance describing the supervisory standards for wholesale, retail, equity and securitization exposures. The Agencies will issue the draft implementation guidance for each portfolio for public comment to ensure that there is an opportunity for banking organizations and others to provide feedback on the Agencies' expectations in regard to A-IRB systems.

The Agencies seek comment on the extent to which an appropriate balance has been struck between flexibility and comparability for the A-IRB requirements. If this balance is not appropriate, what are the specific areas of imbalance, and what is the potential impact of the identified imbalance? Are there alternatives that would provide greater flexibility, while meeting the overall objectives of producing accurate and consistent ratings?

The Agencies also seek comment on the supervisory standards contained in the draft guidance on internal ratings-based systems for corporate exposures. Do the standards cover all of the key elements of an A-IRB framework? Are there specific practices that appear to meet the objectives of accurate and consistent ratings but that would be ruled out by the supervisory standards related to controls and oversight? Are there particular elements from the corporate guidance that should be modified or reconsidered as the Agencies draft guidance for other types of credit?

In addition, the Agencies seek comment on the extent to which these proposed requirements are consistent with the ongoing improvements banking organizations are making in credit-risk management processes. 


\section{Securitization}

\section{A. General Framework}

This section describes the calculation of A-IRB capital requirements for securitization exposures. A securitization exposure is any on- or off-balance-sheet position created by aggregating and then tranching the risks of a pool of assets, commitments, or other instruments (underlying exposures) into multiple financial interests where, typically, the pooled risks are not shared pro rata. The pool may include one or more underlying exposures. Examples include all exposures arising from traditional and synthetic securitizations, as well as partial guarantee arrangements where credit losses are not divided proportionately among the parties (often referred to as tranched cover). Asset- and mortgage-backed securities (including those privately issued and those issued by GSEs such as Fannie Mae and Freddie Mac), credit enhancements, liquidity facilities, and credit derivatives that have the characteristics noted above would be considered securitization exposures.

With ongoing advances in financial engineering, the Agencies recognize that securitization exposures having similar risks can take different legal forms. For this reason, both the designation of positions as securitization exposures and the calculation of A-IRB capital requirements for securitization exposures would be guided by the economic substance of a given transaction, rather than by its legal form.

\section{$\underline{\text { Operational Criteria }}$}

Banking organizations would have to satisfy certain operational criteria to be eligible to use the A-IRB approach to securitization exposures. Moreover, all banking organizations that use the A-IRB approach for the underlying exposures that have been securitized would have to apply the A-IRB treatment for securitization exposures. Minimum operational criteria would apply to traditional and synthetic securitizations. The Agencies propose to establish supervisory criteria for determining when, for risk-based capital purposes, a banking organization may treat exposures that it has originated directly or indirectly as having been securitized and, hence, not subject to the same capital charge as if the banking organization continued to hold the assets. The Agencies anticipate these supervisory criteria will be substantially equivalent to the criteria contained in the New Accord (paragraphs 516-520). Broadly, these criteria are intended to ensure that securitization transactions transfer significant credit risk to third parties and, in the case of traditional securitizations, that each transaction qualifies as a true sale under applicable accounting standards.

The supervisory criteria also would describe the types of clean-up calls that may be incorporated within transactions qualifying for the A-IRB securitization treatment. ${ }^{28}$ Specifically, any clean-up call would have to meet the following conditions: (a) its exercise is at the discretion of the originating banking organization; (b) it does not serve as a credit

\footnotetext{
${ }^{28}$ In general terms, a clean-up call is an option that permits an originating banking organization to call the securitization exposures (for example, asset- or mortgage-backed securities) before all of the underlying exposures have been repaid.
} 
enhancement; and (c) it is only exercisable when 10 percent or less of the original underlying portfolio or reference portfolio value remains. If a clean-up call does not meet all of these criteria, the originating banking organization would have to treat the underlying exposures as if they had not been securitized.

The Agencies seek comment on the proposed operational requirements for securitizations. Are the proposed criteria for risk transference and clean-up calls consistent with existing market practices?

\section{Differences Between General A-IRB Approach and the A-IRB Approach for Securitization Exposures}

In contrast to the proposed A-IRB framework for traditional loans and commitments, the A-IRB securitization framework does not rely on a banking organization's own internal assessments of the PD and LGD of a securitization exposure. For securitization exposures backed by pools of multiple assets, such assessments require implicit or explicit estimates of correlations among the losses on those assets. Such correlations are extremely difficult to estimate and validate in an objective manner and on a going-forward basis. For this reason, the A-IRB framework generally would not permit a banking organization to use its internal risk assessments of PD or LGD when such assessments depend, implicitly or explicitly, on estimates of correlation effects. The A-IRB treatment of securitization exposures would rely principally on two sources of information, when available: (i) an assessment of the securitization exposure's credit risk made by an external rating agency; and (ii) the A-IRB capital charge that would have been assessed against the underlying exposures had the exposures not been securitized (the pool's A-IRB capital charge), along with other information about the transaction.

\section{B. Determining Capital Requirements}

\section{$\underline{\text { General Considerations }}$}

Because the information available to a banking organization about a securitization exposure often reflects the organization's role in a securitization transaction, the Agencies are proposing that the method of calculating the A-IRB capital requirement for a securitization exposure may depend on whether a banking organization is an originator or a third-party investor in the securitization transaction. In general, a banking organization would be considered an originator of a securitization if the organization directly or indirectly originated the underlying exposures or serves as the sponsor of an asset-backed commercial paper (ABCP) conduit or similar program. ${ }^{29}$ If a banking organization is not deemed an originator of a securitization transaction, then it would be considered an investor in the securitization.

There are several methods for determining the A-IRB capital requirement for a securitization exposure: the Ratings-Based Approach (RBA), the Alternative RBA, the Supervisory Formula Approach (SFA), the Look-Through Approach, deduction from Tier 1

\footnotetext{
${ }^{29}$ A banking organization is generally considered a sponsor of an $\mathrm{ABCP}$ conduit or similar program if, in fact or in substance, it manages or advises the conduit program, places securities into the market for the program, or provides liquidity support or credit enhancements to the program.
} 
capital, and deduction from total capital. The following table summarizes conditions under which a banking organization would apply each of these methods. In this table, KIRB denotes the ratio of (a) the pool's A-IRB capital charge to (b) the notional or loan equivalent amount of underlying exposures in the pool.

\section{Steps for Determining A-IRB \\ Capital Requirements for Securitization Exposures}

For an investing banking organization:

1. Deduct from total capital any credit-enhancing interest-only strips

2. When an external or inferred rating exists, apply the RBA

3. When an external or inferred rating does not exist, do the following:
a. Subject to supervisory review and approval, if the investing banking organization can determine KIRB, then calculate required capital as would an originating banking organization using the steps described in 2.a. below
b. Otherwise, deduct the exposure from total capital

For an originating banking organization:*

1. Deduct from Tier 1 capital any increase in capital resulting from the securitization transaction and deduct from total capital any credit-enhancing interest-only strips (net of deductions from Tier 1 capital due to increases in capital)

2. When an A-IRB approach exists for the underlying exposures do the following:

a. If KIRB can be determined:

i. For a securitization exposure (or portion thereof) that is at or below KIRB, deduct the exposure from total capital

ii. For a securitization exposure (or portion thereof) that is above KIRB:

1. Apply the RBA whenever an external or inferred rating is available

2. Otherwise, apply the SFA

b. If KIRB cannot be determined:

i. Apply the Look-Through Approach if the exposure is an eligible liquidity facility, subject to supervisory approval

ii. Otherwise, deduct the exposure from total capital

3. When an A-IRB approach does not exist for the underlying exposures do the following:

a. Apply the Look-Through Approach if the exposure is an eligible liquidity facility, subject to supervisory approval

b. Otherwise, apply the Alternative RBA

*In addition to the capital treatments delineated, an originating banking organization's total A-IRB capital charge with regard to any single securitization transaction is subject to a maximum or ceiling, as described later in this section.

Deductions of Gain-on-Sale or Other Accounting Elements that Result in Increases in Equity $\underline{\text { Capital }}$

Any increase in equity capital resulting from a securitization transaction (for example, a gain resulting from FAS 140 accounting treatment of the sale of assets) would be deducted from Tier 1 capital. Such deductions are intended to offset any gain on sale or other accounting 
treatments ("gain on sale") that result in an increase in an originating banking organization's shareholders' equity and Tier 1 capital. Over time, as banking organizations, from an accounting perspective, realize the increase in equity that was booked at origination of a securitization transaction through actual receipt of cash flows, the amount of the required deduction would be reduced accordingly.

Banking organizations would have to deduct from total capital any on-balance-sheet credit-enhancing interest-only strips (net of any increase in the shareholders' equity deducted from Tier 1 capital as described in the previous paragraph). ${ }^{30}$ Credit-enhancing interest-only strips are defined in the general risk-based capital rules and include items, such as excess spread, that represent subordinated cash flows of future margin income.

\section{$\underline{\text { Maximum Capital Requirement }}$}

Where an A-IRB approach exists for the underlying exposures, an originating banking organization's total A-IRB capital charge for exposures associated with a given securitization transaction would be subject to a maximum or ceiling. This maximum A-IRB capital charge would equal the pool's A-IRB capital charge plus any required deductions, as described in the preceding paragraphs. The aim of this treatment is to ensure that an institution's effective A-IRB capital charge generally would not be greater after securitization than before, while also addressing the Agencies' safety and soundness concerns with respect to credit-enhancing interest-only strips and other capitalized assets. ${ }^{31}$

The proposed maximum A-IRB capital requirement effectively would reverse one aspect of the general risk-based capital rules for securitization exposures referred to as residual interests. Under the general risk-based capital rules, banking organizations are required to hold a dollar in capital for every dollar in residual interest, regardless of the capital requirement on the underlying exposures. One of the reasons the Agencies adopted the "dollar-for-dollar" capital treatment for residual interests is that in many instances the relative size of the exposure retained by the originating banking organization reveals additional market information about the quality of the underlying exposures and deal structure that may not have been captured in the capital requirement on the underlying exposures, had those exposures remained on the banking organization's balance sheet. The Agencies will continue to review the proposal for safety and soundness considerations and may consider retaining the current dollar-for-dollar capital treatment for residual interests, especially in those instances where an originator retains first loss and other deeply subordinated interests in amounts that significantly exceed the pool's A-IRB capital charge plus required deductions.

Comments are invited on the circumstances under which the retention of the treatment in the general risk-based capital rules for residual interests for banking organizations using the A-IRB approach to securitization would be appropriate.

\footnotetext{
${ }^{30}$ Deductions other than of increases in equity capital are to be taken 50 percent from Tier 1 capital and 50 percent from Tier 2 capital.

31 The maximum capital requirement also applies to investing banking organizations that receive approval to use the SFA.
} 
Should the Agencies require originators to hold dollar-for-dollar capital against all retained securitization exposures, even if this treatment would result in an aggregate amount of capital required of the originator that exceeded the pool's A-IRB capital charge plus any applicable deductions? Please provide the underlying rationale.

\section{$\underline{\text { Investors }}$}

Third-party investors generally do not have access to detailed, ongoing information about the credit quality of the underlying exposures in a securitization. In such cases, investors often rely upon credit assessments made by external rating agencies. For a securitization exposure held by an investing banking organization, and where an A-IRB treatment for the underlying exposures exists, the institution would use the Ratings-Based Approach (RBA) described below if the securitization exposure is externally rated or if an inferred rating is available (as defined in the RBA discussion below). When neither an external rating nor an inferred rating is available, an investing banking organization would compute the A-IRB capital charge for the exposure using the methodology described below for originating institutions (subject to supervisory review and approval). Otherwise, the securitization exposure would be deducted 50 percent from Tier 1 capital and 50 percent from Tier 2 capital. The Agencies anticipate that investing banking organizations would apply the RBA in the vast majority of situations.

\section{$\underline{\text { Originators }}$}

This section presumes that an A-IRB approach exists for the underlying exposures. If no A-IRB treatment exists for the underlying exposures, then an originating banking organization (originator) would use the Alternative RBA discussed below.

In contrast to third-party investors, banking organizations that originate securitizations are presumed to have much greater access to information about the current credit quality of the underlying exposures. In general, when an originator retains a securitization exposure, the AIRB securitization framework would require the institution to calculate, on an ongoing basis, the underlying exposure pool's A-IRB capital requirement had the underlying exposures not been securitized (the pool's A-IRB capital charge), which would be based on the notional dollar amount of underlying exposures (the size of the pool). The pool's A-IRB capital charge would be calculated using the top-down or bottom-up method applicable to the type(s) of underlying exposure(s). ${ }^{32}$ As noted above, the pool's A-IRB capital charge divided by the size of the pool is denoted KIRB.

An originator also would be expected to know: (a) its retained securitization exposure's nominal size relative to the size of the pool (the exposure's "thickness," denoted T); and (b) the notional amount of all more junior securitization exposures relative to the size of the pool (the exposure's "credit enhancement level," denoted L). The retained securitization exposure's A-IRB capital requirement depends on the relationship between KIRB, $\mathrm{T}$, and $\mathrm{L}$. If an originator cannot determine KIRB, any retained securitization exposure would be deducted from capital. For eligible liquidity facilities (defined below in the Look Through Approach) provided to ABCP

\footnotetext{
${ }^{32}$ For the purpose of determining the A-IRB capital requirement for a securitization exposure, the top-down method could be used regardless of the maturity of the underlying exposures, provided the other eligibility criteria for employing the top-down approach are satisfied.
} 
programs where a banking organization lacks the information necessary to calculate KIRB, the Look-Through Approach described below would be applied on a temporary basis and subject to supervisory approval.

\section{$\underline{\text { Positions Below KIRB }}$}

An originating banking organization would deduct from capital any retained securitization exposure (or part thereof) that absorbs losses at or below the level of KIRB (that is, an exposure for which $\mathrm{L}+\mathrm{T} \leq \mathrm{KIRB}){ }^{33}$ This means that an originating banking organization would be given no risk-based capital relief unless it sheds at least some exposures below KIRB. Deduction from capital would be required regardless of the securitization exposure's external rating. This deduction treatment is in contrast to the A-IRB capital treatment for investors, who would be able to look to the external (or inferred) rating of a securitization exposure regardless of whether the exposure was below KIRB.

While this disparate treatment of originators and investors may be viewed as inconsistent with the principle of equal capital for equal risk, the Agencies believe it is appropriate in order to provide incentives for originating banks to shed highly subordinated securitization exposures. Such exposures contain the greatest credit risks. Moreover, these risks are difficult to evaluate, and risk quantifications tend to be highly sensitive to modeling assumptions that are difficult to validate objectively. The proposal to prevent an originator from using the RBA for securitization exposures below KIRB reflects, in part, a concern by the Agencies that the market discipline underpinning an external credit rating may be less effective when the rating applies to a retained, non-traded securitization exposure and is sought by an originator primarily for regulatory capital purposes.

The Agencies note that the specific securitization exposures retained by an originator that are subject to deduction treatment could change over time in response to variations in the credit quality of the underlying exposures. For example, if the pool's A-IRB capital charge were to increase after the inception of a securitization, additional portions of securitization exposures held by an originator may fall below KIRB and, thus, become subject to deduction. Therefore, when an originator retains a first-loss securitization exposure well in excess of KIRB, the originator's A-IRB capital requirement on the exposure could climb rapidly in the event of any marked deterioration of the underlying exposures. In general, an originator could minimize variability in future capital charges by minimizing the size of any retained first-loss securitization exposures.

\section{$\underline{\text { Positions Above KIRB }}$}

When an originating banking organization retains a securitization exposure, or part thereof, that absorbs losses above the KIRB amount (that is, an exposure for which $\mathrm{L}+\mathrm{T}>$ KIRB) and the banking organization has not already met the maximum capital requirement for securitization exposures described previously, the A-IRB capital requirement for the exposure would be calculated as follows. For securitization exposures having an external or inferred

\footnotetext{
${ }^{33}$ If an originator holds a securitization exposure that straddles KIRB, the exposure must be decomposed into two separate positions - one that is above KIRB and another that is at or below KIRB.
} 
rating, the organization would calculate its A-IRB capital requirement using the RBA. However, if neither an external rating nor an inferred rating is available, an originator would be able to use the SFA, subject to supervisory review and approval. Otherwise, the organization would deduct the securitization exposure from total capital.

The Agencies seek comment on the proposed treatment of securitization exposures held by originators. In particular, the Agencies seek comment on whether originating banking organizations should be permitted to calculate A-IRB capital charges for securitizations exposures below the KIRB threshold based on an external or inferred rating, when available.

The Agencies seek comment on whether deduction should be required for all nonrated positions above KIRB. What are the advantages and disadvantages of the SFA approach versus the deduction approach?

\section{Capital Calculation Approaches}

The Ratings-Based Approach (RBA)

The RBA builds upon the widespread acceptance of external ratings by third-party investors as objective assessments of a securitization exposure's stand-alone credit risk. Certain minimum requirements would have to be satisfied in order for a banking organization to rely on an external credit rating for determining its A-IRB capital charge for a securitization exposure. To be recognized for regulatory capital purposes, the external credit rating on a securitization exposure would have to be public and reflect the entire amount of credit risk exposure the banking organization has with regard to all payments owed to it under the exposure. In particular, if a banking organization is owed both principal and interest on a securitization exposure, the external rating on the exposure would have to fully reflect the credit risk associated with both payment streams. The Agencies propose to establish criteria to ensure the integrity of external ratings processes and banking organizations' use of these ratings under the RBA. These criteria are expected to be consistent with the proposed guidance provided in the New Accord (paragraph 525).

In certain circumstances, an "inferred rating" may be used for risk weighting a non-rated securitization exposure. Similar to the general risk-based capital rules, to qualify for use of an inferred rating, a non-rated securitization exposure would have to be senior in all respects to a subordinate rated position within the same securitization transaction. Further, the junior rated tranche would have to have an equivalent or longer remaining maturity than the non-rated exposure. Where these conditions are met, the non-rated exposure would be treated as if it had the same rating (an "inferred rating") as that of the junior rated tranche. External and inferred ratings would be treated equivalently.

Under the RBA, the capital charge per dollar of a securitization exposure would depend on: (i) the external rating (or inferred rating) of the exposure, (ii) whether the rating reflects a long-term or short-term assessment of the exposure's credit risk, and (iii) a measure of the 
effective number -- or granularity -- of the underlying exposures $(\mathrm{N}) .^{34}$ For a securitization exposure rated AA or AAA, the RBA capital charge also would depend on a measure of the exposure's relative seniority in the overall transaction $(\mathrm{Q}){ }^{35}$

Tables 1 and 2 below present the risk weights that would result from the RBA when a securitization exposure's external rating (or inferred rating) represents a long-term or short-term credit rating, respectively. In both tables, the risk weights in column 2 would apply to AA and AAA-rated securitization exposures when the effective number of exposures $(\mathrm{N})$ is 100 or more, and the exposure's relative seniority (Q) is greater than or equal to $0.1+25 / \mathrm{N}$. If the underlying exposures are retail exposures, $\mathrm{N}$ would be treated as infinite and the minimum qualifying value of Q would be 0.10 . The Agencies anticipate that these risk weights would apply to AA and AAA-rated tranches of most retail securitizations. Column 4 would apply only to securitizations involving non-retail exposures for which $\mathrm{N}$ is less than 6 , and column 3 would apply in all other situations.

Within each table, risk weights increase as external rating grades decline. Under the Base Case (column 3), for example, the risk weights range from 12 percent for AAA-rated exposures to 650 percent for exposures rated BB-. This pattern of risk weights is broadly consistent with analyses employing standard credit risk models and a range of assumptions regarding correlation effects and the types of exposures being securitized. ${ }^{36}$ These analyses imply that, compared with a corporate bond having a given level of stand-alone credit risk (for example, as measured by its expected loss rate), a securitization tranche having the same level of stand-alone risk -- but backed by a reasonably granular and diversified pool -- will tend to exhibit more systematic risk. $^{37}$ This effect is most pronounced for below-investment grade tranches, and is the primary reason why the RBA risk weights increase rapidly as ratings deteriorate over this range -- much more rapidly than for similarly rated corporate bonds. Similarly, for highly granular pools, the risk weights expected to apply to most AA and AAA-rated securitization exposures ( 7 percent and 10 percent, respectively) decline steeply relative to the risk weight applicable to A-rated exposures (20 percent, column 3 ) -- again, more so than might be the case for similarly rated corporate bonds. The decline in risk weights as ratings improve over the investment grade range is less pronounced for the Base Case and for tranches backed by non-granular pools (column 4).

For securitization exposures rated below BB-, the proposed A-IRB treatment -- deduction from capital -- would be somewhat more conservative than suggested by credit risk modeling analyses. However, the Agencies believe this more conservative treatment would be appropriate in light of modeling uncertainties and the tendency for securitization exposures in this range, at

\footnotetext{
${ }^{34} \mathrm{~N}$ is defined more formally in the discussion below of the Supervisory Formula Approach.

${ }^{35} \mathrm{Q}$ is defined as the total size of all securitization exposures rated at least AA- that are pari passu or junior to the exposure of interest, measured relative to the size of the pool and expressed as a decimal. Thus, for a securitization transaction having an AAA-rated tranche in the amount of 70 percent of the pool, an AA-rated tranche of 10 percent, a BBB-rated tranche of 10 percent, and a non-rated tranche of 10 percent, the values of $Q$ associated with these positions would be $0.80,0.10,0$, and 0 , respectively.

${ }^{36}$ See Vladislav Peretyatkin and William Perraudin, "Capital for Asset-Backed Securities," Bank of England, February 2003.

37 See, for example, Michael Pykhtin and Ashish Dev, "Credit Risk in Asset Securitizations: Analytical Model," Risk (May 2002) S16-S20.
} 
least at the inception of the securitization transaction, to be non-traded positions retained by an originator because they cannot be sold at a reasonable price.

Table 1: ABS risk weights based on long-term external credit assessments

\begin{tabular}{c|c|c|c}
\hline $\begin{array}{c}\text { External } \\
\text { Rating } \\
\text { (Illustrative) }\end{array}$ & $\begin{array}{c}\text { Thick Tranches } \\
\text { Backed by } \\
\text { Highly Granular } \\
\text { Pools }\end{array}$ & Base Case & $\begin{array}{c}\text { Tranches } \\
\text { Backed by } \\
\text { Non-granular } \\
\text { Pools }\end{array}$ \\
\hline AAA & $7 \%$ & $12 \%$ & $20 \%$ \\
\hline AA & $10 \%$ & $15 \%$ & $25 \%$ \\
\hline A & N/A & $20 \%$ & $35 \%$ \\
\hline BBB+ & N/A & $50 \%$ & $50 \%$ \\
\hline BBB & N/A & $75 \%$ & $75 \%$ \\
\hline BBB- & N/A & $100 \%$ & $100 \%$ \\
\hline BB+ & N/A & $250 \%$ & $250 \%$ \\
\hline BB & N/A & $425 \%$ & $425 \%$ \\
\hline BB- & N/A & $650 \%$ & $650 \%$ \\
\hline Below BB- & N/A & Deduction & Deduction \\
\hline
\end{tabular}

Table 2: ABS risk weights based on short-term external credit assessments

\begin{tabular}{c|c|c|c}
\hline $\begin{array}{c}\text { External Rating } \\
\text { (Illustrative) }\end{array}$ & $\begin{array}{c}\text { Thick Tranches } \\
\text { Backed by } \\
\text { Highly Granular } \\
\text { Pools }\end{array}$ & Base Case & $\begin{array}{c}\text { Tranches } \\
\text { Backed by } \\
\text { Non-granular } \\
\text { Pools }\end{array}$ \\
\hline A-1/P-1 & $7 \%$ & $12 \%$ & $20 \%$ \\
\hline A-2/P-2 & N/A & $20 \%$ & $35 \%$ \\
\hline A-3/P-3 & N/A & $75 \%$ & $75 \%$ \\
\hline All other ratings & N/A & Deduction & Deduction \\
\hline
\end{tabular}

The Agencies seek comment on the proposed treatment of securitization exposures under the RBA. For rated securitization exposures, is it appropriate to differentiate risk weights based on tranche thickness and pool granularity?

For non-retail securitizations, will investors generally have sufficient information to calculate the effective number of underlying exposures $(\mathrm{N})$

What are views on the thresholds, based on $\mathrm{N}$ and $\mathrm{Q}$, for determining when the different risk weights apply in the RBA?

Are there concerns regarding the reliability of external ratings and their use in determining regulatory capital? How might the Agencies address any such potential concerns?

Unlike the A-IRB framework for wholesale exposures, there is no maturity adjustment within the proposed RBA. Is this reasonable in light of the criteria to assign external ratings? 


\section{The Supervisory Formula Approach (SFA)}

As noted above, when an explicit A-IRB approach exists for the underlying exposures, originating and investing banking organizations would be able to apply the SFA to non-rated exposures above the KIRB threshold, subject to supervisory approval and review. The Agencies anticipate that, in addition to its application to liquidity facilities and to other traditional and synthetic securitization exposures, the SFA would be used when calculating A-IRB capital requirements for tranched guarantees (for example, a loan for which a guarantor assumes a firstloss position that is less than the full amount of the loan).

Under the SFA, the A-IRB capital charge for a securitization tranche would depend on six institution-supplied inputs: $:^{38}$ the notional amount of underlying exposures that have been securitized (E), the A-IRB capital charge had the underlying exposures not been securitized (KIRB); the tranche's credit enhancement level (L); the tranche's thickness (T); the pool's effective number of exposures $(\mathrm{N})$; and the pool's exposure-weighted average loss-given-default (LGD). In general, the estimates of $\mathrm{N}$ and LGD would be developed as a by-product of the process used to determine KIRB.

The SFA capital charge for a given securitization tranche would be calculated as the notional amount of underlying exposures that have been securitized (E), multiplied by the greater of: (i) $0.0056 * \mathrm{~T}$ or (ii) the following expression: ${ }^{39}$

$$
K[L+T]-K[L]+\left\{\left(0.05 * d * K I R B * e^{-20(L-K I R B) / K I R B}\right) *\left(1-e^{-20 T / K I R B}\right)\right\},
$$
where, ${ }^{40}$

\footnotetext{
${ }^{38}$ When the banking organization holds only a proportional interest in the tranche, that position's A-IRB capital charge equals the prorated share of the capital charge for the entire tranche.

${ }^{39}$ The SFA applies only to exposures above KIRB. When a securitization tranche straddles KIRB, for the purpose of applying the SFA the tranche should be decomposed into a position at or below KIRB and another above KIRB. The latter would be the position to which the SFA is actually applied.

${ }^{40}$ In these expressions, Beta[X; $\left.a, b\right]$ refers to the cumulative beta distribution with parameters a and $b$ evaluated at $\mathrm{X}$. The cumulative beta distribution function is available in Excel as the function BETADIST.
} 


$$
\begin{aligned}
h & =(1-\text { KIRB /LGD })^{N} \\
c & =\text { KIRB /(1-h) } \\
v & =\frac{(L G D-K I R B) \text { KIRB }+0.25(1-L G D) \text { KIRB }}{N} \\
f & =\left(\frac{v+K I R B^{2}}{1-h}-c^{2}\right)+\frac{(1-\text { KIRB }) \text { KIRB }-v}{(1-h)^{*} 1000} \\
g & =\frac{(1-c) c}{f}-1 \\
a & =g * c \\
b & =g *(1-c) \\
d & =1-(1-h) *(1-\operatorname{Beta}[K I R B ; a, b]) \\
K[x] & =(1-h) *(x *(1-\operatorname{Beta}[x ; a, b])+c * \text { Beta }[x ; a+1, b]) .
\end{aligned}
$$

Although visually daunting, the above supervisory formula is easily programmable within standard spreadsheet packages, and its various components have intuitive interpretations.

Part (i), noted above, of the SFA effectively imposes a 56 basis point minimum or floor A-IRB capital charge per dollar of tranche exposure. While acknowledging that such a floor is not risk-sensitive, the Agencies believe that some minimum prudential capital charge is nevertheless appropriate. The floor has been proposed at 56 basis points partly on the basis of empirical analyses suggesting that, across a broad range of modeling assumptions and exposure types, this level provides a reasonable lower bound on the capital charges implied by standard credit risk models for securitization tranches meeting the standards for an external rating of AAA. ${ }^{41}$ This floor also is consistent with the lowest capital charge available under the RBA.

Part (ii) of the SFA also is a blend of credit risk modeling results and supervisory judgment. The function denoted $\mathrm{K}[\mathrm{x}]$ represents a pure model-based estimate of the pool's aggregate systematic or non-diversifiable credit risk that is attributable to a first-loss position covering pool losses up to and including $\underline{\mathrm{x}}$. Because the tranche of interest (defined in terms of a credit enhancement level $\mathrm{L}$, and thickness $\mathrm{T}$ ) covers losses between $\mathrm{L}$ and $\mathrm{L}+\mathrm{T}$, its total systematic risk can be represented as K[L + T] - K[L], which are the first two terms in (1). The term in braces within (1) represents a supervisory add-on to the pure model-based result. This add-on is intended primarily to avoid potential behavioral distortions associated with what would otherwise be a discontinuity in capital charges for relatively thin mezzanine tranches lying just below and just above KIRB: all tranches at or below KIRB would be deducted from capital, whereas a very thin tranche just above KIRB would incur a pure model-based capital charge that could vary between zero and one, depending upon the number of effective underlying exposures in the pool (N). The add-on would apply primarily to positions just above KIRB, and its quantitative effect would diminish rapidly as the distance from KIRB widens.

\footnotetext{
${ }^{41}$ See Vladislav Peretyatkin and William Perraudin, "Capital for Asset-Backed Securities," Bank of England, February 2003.
} 
Most of the complexity of the supervisory formula is a consequence of attempting to make $\mathrm{K}[\underline{\mathrm{x}}]$ as consistent as possible with the parameters and assumptions of the A-IRB framework that would apply to the underlying exposures if held directly by a banking organization. ${ }^{42}$ The specification of $\mathrm{K}[\mathrm{x}]$ assumes that KIRB is an accurate measure of the pool's total systematic credit risk, and that a securitization merely redistributes this systematic risk among its various tranches. In this way, $\mathrm{K}[\underline{\mathrm{x}}]$ embodies precisely the same asset correlations as are assumed elsewhere within the A-IRB framework. In addition, this specification embodies the well-known result that a pool's total systematic risk (that is, KIRB) tends to be redistributed toward more senior tranches as the effective number of underlying exposures in the pool $(\mathrm{N})$ declines. ${ }^{43}$ The importance of pool granularity depends on the pool's average loss-rate-givendefault, as increases in LGD also tend to shift systematic risk toward senior tranches when $\mathrm{N}$ is small. For highly granular pools, such as securitizations of retail exposures, LGD would have no influence on the SFA capital charge.

The Agencies propose to establish criteria for determining E, KIRB, L, T, N, and LGD that are consistent with those suggested in the New Accord. A summary of these requirements is presented below.

E. This input would be measured (in dollars) as the A-IRB estimate of the exposures in the underlying pool of securitized exposures, as if they were held directly by the banking organization, rather than securitized. This amount would reflect only those underlying exposures that have actually been securitized to date. Thus, for example, E would exclude undrawn lines associated with revolving credit facilities (for example, credit card accounts).

$\underline{\text { KIRB }}$. This input would be measured (in decimal form) as the ratio of (a) the pool's AIRB capital requirement to (b) the notional or loan equivalent amount of the underlying exposures in the pool (E). The pool's A-IRB capital requirement would be calculated in accordance with the applicable A-IRB standard for the type of underlying exposure. This calculation would incorporate the effect of any credit risk mitigant that is applied to the underlying exposures (either individually or to the entire pool), and hence benefits all of the securitization exposures. Consistent with the measurement of $\mathrm{E}$, the estimate of KIRB would reflect only the underlying exposures that have been securitized. For example, KIRB generally would exclude the A-IRB capital charges against the undrawn portions of revolving credit facilities.

Credit enhancement level (L). This input would be measured (in decimal form) as the ratio of (a) the notional amount of all securitization exposures subordinate to the tranche of interest to (b) the notional or loan equivalent amount of underlying exposures in the pool (E). L would incorporate any funded reserve account (for example, spread account or overcollateralization) that provides credit enhancement to the tranche of interest. Creditenhancing interest-only strips would not be included in the calculation of L.

\footnotetext{
${ }^{42}$ The conceptual basis for specification of $\mathrm{K}[\underline{\mathrm{x}}]$ is developed in Michael B. Gordy and David Jones, "Random Tranches," Risk (March 2003) 78-83.

${ }^{43}$ See Michael Pykhtin and Ashish Dev, "Coarse-grained CDOs," Risk (January 2003) 113-116.
} 
Thickness (T). This input would be measured (in decimal form) as the ratio of (a) the notional amount of the tranche of interest to (b) the notional or loan equivalent amount of underlying exposures in the pool (E).

Effective number of exposures $(\mathrm{N})$. This input would be calculated as

$$
N=\frac{\left(\sum_{i} E A D_{i}\right)^{2}}{\sum_{i} E A D_{i}^{2}}
$$

where $\mathrm{EAD}_{\mathrm{i}}$ represents the exposure-at-default associated with the $\mathrm{i}$-th underlying exposure in the pool. Multiple underlying exposures to the same obligor would be consolidated (that is, treated as a single exposure). If the pool contains any underlying exposures that are themselves securitization exposures (for example, one or more asset-backed securities), each of these would be treated as a single exposure for the purpose of measuring $\mathrm{N} .{ }^{44}$

Exposure-weighted average LGD. This input would be calculated (in decimal form) as

$$
L G D=\frac{\sum_{i} L G D_{i} \cdot E A D_{i}}{\sum_{i} E A D_{i}}
$$

where $\mathrm{LGD}_{\mathrm{i}}$ represents the average LGD associated with all underlying exposures to the $\mathrm{i}$-th obligor. In the case of re-securitization (a securitization of securitization exposures), an LGD of 100 percent would be assumed for any underlying exposure that was itself a securitization exposure. $^{45}$

Simplified method for computing N and LGD. Under the conditions provided below, banking organizations would be able to employ simplified methods for calculating $\mathrm{N}$ and the exposure-weighted average LGD. When the underlying exposures are retail exposures, the SFA may be implemented by setting $\mathrm{h}=0$ and $\mathrm{v}=0$, subject to supervisory approval and review. When the share of the pool associated with the largest exposure, $\mathrm{C}_{1}$, is no more than 0.03 (or 3 percent of the pool), the banking organization would be able to set LGD $=0.50$ and $\mathrm{N}$ equal to:

${ }^{44}$ Within the supervisory formula, the probability distribution of credit losses associated with the pool of underlying exposures is approximated by treating the pool as if it consisted of $\mathrm{N}$ homogeneous exposures, each having an AIRB capital charge of KIRB/N. The proposed treatment of $\mathrm{N}$ implies, for example, that a pool containing one ABS tranche backed by 1 million effective loans behaves more like a single loan having an A-IRB capital charge of KIRB than a pool of 1 million loans, each having an A-IRB capital charge of KIRB/1,000,000.

${ }^{45}$ As noted above, the A-IRB securitization framework does not permit banking organizations to use their own internal estimates of LGDs (and PDs) for securitization exposures because such quantification requires implicit or explicit estimates of loss correlations among the underlying exposures. Recall that LGDs should be measured as the loss rates expected to prevail when default rates are high. While setting LGDs equal to 100 percent is reasonable for certain types of ABSs, such as highly subordinated or thin tranches, this level of LGD may be conservative for other types of ABSs. However, the Agencies believe that the complexity and burden associated with a more refined treatment of LGDs would outweigh any improvement in the overall risk sensitivity of A-IRB capital charges for originators, owing to the combined effects of (a) the dollar-for-dollar A-IRB capital charge on positions at or below KIRB, and (b) the maximum or cap on an originator's total A-IRB capital charge. 


$$
N=\left(C_{1} C_{m}+\left(\frac{C_{m}-C_{1}}{m-1}\right) \max \left\{1-m C_{1}, 0\right\}\right)^{-1},
$$

provided that the banking organization can measure $C_{m}$, which denotes the share of the pool corresponding to the largest " $\mathrm{m}$ " exposures (for example, a 15 percent share corresponds to a value of 0.15$){ }^{46}$ Alternatively, when only $\mathrm{C}_{1}$ is available and this amount is no more than 0.03 , then the banking organization would be able to set $\mathrm{LGD}=0.50$ and $\mathrm{N}=1 / \mathrm{C}_{1}$.

The Agencies seek comment on the proposed SFA. How might it be simplified without sacrificing significant risk sensitivity? How useful are the alternative simplified computation methodologies for $\mathrm{N}$ and LGD

The Look-Through Approach for Eligible Liquidity Facilities

ABCP conduits and similar programs sponsored by U.S. banking organizations are major sources of funding for financial and non-financial companies. Liquidity facilities supporting these programs are considered to be securitization exposures of the banking organizations providing the liquidity, and generally would be treated under the rules proposed for originators. As a general matter, the Agencies expect that banking organizations using the A-IRB approach would apply the SFA when determining the A-IRB capital requirement for liquidity facilities provided to $\mathrm{ABCP}$ conduits and similar programs. However, if it would not be practical for a banking organization to calculate KIRB for the underlying exposures using a top-down or a bottom-up approach, the banking organization may be allowed to use the Look-Through Approach, described below, for determining the A-IRB capital requirement, subject to supervisory approval and only for a temporary period of time to be determined in consultation with the organization's primary Federal supervisor.

Because the Look-Through Approach has limited risk sensitivity, the Agencies propose that its applicability be restricted to liquidity facilities that are structured to minimize the extent to which the facilities provide credit support to the conduit. The Look-Through Approach would only be available to liquidity facilities that meet the following criteria:

(a) the facility documentation clearly identifies and limits the circumstances under which it may be drawn. In particular, the facility must not be able to cover losses already sustained by the pool of underlying exposures (for example, to acquire assets from the pool at above fair value) or be structured such that draw-down is highly probable (as indicated by regular or continuous draws);

(b) the facility is subject to an asset quality test that prevents it from being drawn to cover underlying exposures that are in default;

(c) the facility cannot be drawn after all applicable (specific and program-wide) credit enhancements from which the liquidity facility would benefit have been exhausted;

(d) repayment of any draws on the facility (that is, assets acquired under a purchase agreement or loans made under a lending agreement) may not represent a subordinated obligation of the pool or be subject to deferral or waiver; and

(e) reduction in the maximum drawn amount, or early termination of the facility, occurs if the quality of the pool falls below investment grade.

\footnotetext{
${ }^{46}$ The level of $\mathrm{m}$ is to be set by each banking organization.
} 
Under the Look-Through Approach, the liquidity facility's A-IRB capital charge would be computed as the product of (a) 8 percent, (b) the maximum potential drawdown under the facility, (c) the applicable credit conversion factor (CCF), and (d) the applicable risk weight. The CCF would be set at 50 percent if the liquidity facility's original maturity is one year or less, and at 100 percent if the original maturity is more than one year. The Agencies propose that the risk weight be set equal to the risk weight applicable under the general risk-based capital rules for banking organizations not using the A-IRB approach (that is, to the underlying assets or obligors after consideration of collateral or guarantees or, if applicable, external ratings).

The Agencies seek comment on the proposed treatment of eligible liquidity facilities, including the qualifying criteria for such facilities. Does the proposed LookThrough Approach -- to be available as a temporary measure -- satisfactorily address concerns that, in some cases, it may be impractical for providers of liquidity facilities to apply either the "bottom-up" or "top-down" approach for calculating KIRB? It would be helpful to understand the degree to which any potential obstacles are likely to persist.

Feedback also is sought on whether liquidity providers should be permitted to calculate A-IRB capital charges based on their internal risk ratings for such facilities in combination with the appropriate RBA risk weight. What are the advantages and disadvantages of such an approach, and how might the Agencies address concerns that the supervisory validation of such internal ratings would be difficult and burdensome? Under such an approach, would the lack of any maturity adjustment with the RBA be problematic for assigning reasonable risk weights to liquidity facilities backed by relatively short-term receivables, such as trade credit?

\section{Other Considerations}

\section{Capital Treatment Absent an A-IRB Approach - The Alternative RBA}

For originating banking organizations when there is not a specific A-IRB treatment for an underlying exposure or group of underlying exposures, the Agencies propose that a securitization exposure's A-IRB capital charge be based exclusively on the exposure's external or inferred credit rating using the Alternative RBA. ${ }^{47}$ Under the Alternative RBA, a risk weight of 20 percent is applied to exposures rated $A A A$ to $A A-, 50$ percent to exposures rated $\mathrm{A}+$ to $\mathrm{A}-$, and 100 percent to exposures rated $\mathrm{BBB}+$ to $\mathrm{BBB}-$. Securitization exposures having ratings below investment grade, or that are non-rated, would be deducted from risk-based capital on a dollarfor-dollar basis.

Should the A-IRB capital treatment for securitization exposures that do not have a specific A-IRB treatment be the same for investors and originators? If so, which treatment should be applied - that used for investors (the RBA) or originators (the Alternative RBA)? The rationale for the response would be helpful.

\footnotetext{
${ }^{47}$ The Alternative RBA does not apply to eligible liquidity facilities, which may use the Look-Through Approach as described above. Additionally, the securitization exposures subject to the Alternative RBA are not limited by the maximum capital requirement discussed above.
} 
$\underline{\text { Structures with Early Amortization Provisions }}$

Many securitizations of revolving credit facilities (for example, credit card accounts) contain provisions that call for the securitization to be wound down if the excess spread falls below a certain threshold. ${ }^{48}$ This decrease in excess spread can, in some cases, be caused by deterioration in the credit quality of the underlying exposures. An early amortization event can increase a banking organization's capital needs if any new draws on the revolving facilities would need to be financed by the banking organization itself using on-balance-sheet sources of funding. The payment allocations used to distribute principal and finance charge collections during the amortization phase of these structures also can expose a banking organization to greater risk of loss than in other securitization structures. To account for the risks that early amortization structures pose to originating banking organizations, the capital treatment described below would apply to securitizations of revolving credit facilities containing such features.

In addition to the A-IRB capital charge an originating banking organization would incur on the securitization exposures it retains, an originator would be required to hold capital against all or a portion of the investors' interest in a securitization when (i) the organization sells exposures into a securitization that contains an early amortization feature, and (ii) the underlying exposures sold are of a revolving nature. The A-IRB capital charge attributed to the originator that is associated with the investors' interest is calculated as the product of (a) the A-IRB capital charge that would be imposed on the entire investors' interest if it were held by the originating banking organization, and (b) an applicable CCF.

In general, the CCF would depend on whether the early amortization feature repays investors through a controlled or non-controlled mechanism, and whether the underlying exposures represent uncommitted revolving retail facilities that are unconditionally cancellable without prior notice (for example, credit card receivables) or other credit lines (for example, revolving corporate facilities).

An early amortization provision would be considered controlled if, throughout the duration of the securitization transaction, including the amortization period, there is a pro rata sharing of interest, principal, expenses, losses, and recoveries based on the balances of receivables outstanding at the beginning of each month. Further, the pace of repayment may not be any more rapid than would be allowed through straight-line amortization over a period sufficient for 90 percent of the total debt outstanding at the beginning of the early amortization period to have been repaid or recognized as in default. In addition to these criteria, banking organizations with structures containing controlled early amortization features would also have to have appropriate plans in place to ensure that there is sufficient capital and liquidity available in the event of an early amortization. When these conditions are not met, the early amortization provision would be treated as non-controlled.

\footnotetext{
${ }^{48}$ Excess spread is defined as gross finance charge collections and other income received by the trust or special purpose entity (SPE) minus certificate interest, servicing fees, charge-offs, and other senior trust or SPE expenses.
} 


\section{Determination of CCFs for controlled early amortization structures}

The following method for determining CCFs applies to a securitization of revolving credit facilities containing a controlled early amortization mechanism. When the pool of underlying exposures includes uncommitted retail credit lines (for example, credit card receivables), an originator would first compare the securitization's three-month average excess spread against the following two reference levels:

A. The point at which the banking organization would be required to trap excess spread under the terms of the securitization; and

B. The excess spread level at which an early amortization would be triggered. In cases where a transaction does not require excess spread to be trapped, the first trapping point would be deemed to be 4.5 percentage points greater than the excess spread level at which an early amortization is triggered.

The banking organization would divide the distance between the two points described above into four equal segments. For example if the spread trapping point is 4.5 percent and the early amortization trigger is zero percent, then 4.5 percent would be divided into four equal segments of 112.5 basis points each. The following conversion factors, based on illustrative segments, would apply to the investors' interest.

\section{Controlled Early Amortization of Uncommitted Retail Credit Lines

3-month average excess spread Credit Conversion Factor (CCF)

$\begin{array}{ll}450 \text { basis points (bp) or more } & 0 \% \\ \text { Less than } 450 \text { bp to } 337.5 \text { bp } & 1 \% \\ \text { Less than } 337.5 \text { bp to } 225 \text { bp } & 2 \% \\ \text { Less than } 225 \text { bp to } 112.5 \text { bp } & 20 \% \\ \text { Less than } 112.5 \text { bp } & 40 \%\end{array}$

All other securitizations of revolving facilities (that is, those containing underlying exposures that are committed or non-retail) having controlled early amortization features would be subject to a CCF of 90 percent.

\section{Determination of CCFs for non-controlled early amortization structures}

The process for determining CCFs when a securitization of revolving credit facilities contains a non-controlled early amortization mechanism would be the same as that described above for controlled early amortization structures, except that different CCFs would apply to the various excess spread segments. For non-controlled structures, the following conversion factors, based on illustrative segments, would apply:

\section{Non-Controlled Early Amortization of Uncommitted Retail Credit Lines 3-month average excess spread Credit Conversion Factor (CCF) 450 basis points (bp) or more $0 \%$ Less than 450 bp to 337.5 bp $\quad 5 \%$ Less than 337.5 bp to 225 bp $\quad 10 \%$}


All other securitizations of revolving credit facilities (that is, those containing underlying exposures that are committed or non-retail) having non-controlled early amortization mechanisms would be subject to a CCF of 100 percent. In other words, no risk transference would be recognized for these structures; an originator's A-IRB capital charge would be the same as if the underlying exposures had not been securitized.

The Agencies seek comment on the proposed treatment of securitization of revolving credit facilities containing early amortization mechanisms. Does the proposal satisfactorily address the potential risks such transactions pose to originators?

Comments are invited on the interplay between the A-IRB capital charge for securitization structures containing early amortization features and that for undrawn lines that have not been securitized. Are there common elements that the Agencies should consider? Specific examples would be helpful.

Are proposed differences in CCFs for controlled and non-controlled amortization mechanisms appropriate? Are there other factors that the Agencies should consider?

\section{Market-Disruption Eligible Liquidity Facilities}

A banking organization would be able to apply a 20 percent CCF to an eligible liquidity facility that can be drawn only in the event of a general market disruption (that is, where a capital market instrument cannot be issued at any price), provided that any advance under the facility represents a senior secured claim on the assets in the pool. A banking organization using this treatment would recognize 20 percent of the A-IRB capital charge required for the facility through use of the SFA. If the market disruption eligible liquidity facility is externally rated, a banking organization would be able to rely on the external rating under the RBA for determining the A-IRB capital requirement provided the organization assigns a 100 percent CCF rather than a 20 percent CCF to the facility.

\section{Overlapping Credit Enhancements or Liquidity Facilities}

In some $\mathrm{ABCP}$ or similar programs, a banking organization may provide multiple facilities that may be drawn under varying circumstances. The Agencies do not intend that a banking organization incur duplicative capital requirements against these multiple exposures as long as, in the aggregate, multiple advances are not permitted against the same collateral. Rather, a banking organization would be required to hold capital only once for the exposure covered by the overlapping facilities (whether they are general liquidity facilities, eligible liquidity facilities, or the facilities serve as credit enhancements). Where the overlapping facilities are subject to different conversion factors, the banking organization would attribute the overlapping part to the facility with the highest conversion factor. However, if different banking organizations provide overlapping facilities, each institution would hold capital against the entire 
maximum amount of its facility. That is, there may be some duplication of capital charges for overlapping facilities provided by multiple banking organizations.

\section{$\underline{\text { Servicer Cash Advances }}$}

Subject to supervisory approval, servicer cash advances that are recoverable would receive a zero percent CCF. This treatment would apply when servicers, as part of their contracts, may advance cash to the pool to ensure an uninterrupted flow of payments to investors, provided the servicer is entitled to full reimbursement and this right is senior to other claims on cash flows from the pool of underlying exposures.

When providing servicer cash advances, are banking organizations obligated to advance funds up to a specified recoverable amount? If so, does the practice differ by asset type? Please provide a rationale for the response given.

\section{$\underline{\text { Credit Risk Mitigation }}$}

For securitization exposures covered by collateral or guarantees, the credit risk mitigation rules discussed earlier would apply. For example, a banking organization may reduce the A-IRB capital charge when a credit risk mitigant covers first losses or losses on a proportional basis. For all other cases, a banking organization would assume that the credit risk mitigant covers the most senior portion of the securitization exposure (that is, that the most junior portion of the securitization exposure is uncovered).

\section{AMA Framework for Operational Risk}

This section describes features of the proposed AMA framework for measuring the regulatory capital requirement for operational risk. Under this framework, a banking organization meeting the AMA supervisory standards would use its internal operational risk measurement system to calculate its regulatory capital requirement for operational risk. The discussion below provides background information on operational risk and the conceptual underpinnings of the AMA, followed by a discussion of the AMA supervisory standards. ${ }^{49}$

The Agencies' general risk-based capital rules do not currently include an explicit capital charge for operational risk, which is defined as the risk of loss resulting from inadequate or failed processes, people, and systems or from external events. When developing the general risk-based capital rules, the Agencies recognized that institutions were exposed to non-credit related risks, including operational risk. Consequently, the Agencies built a "buffer" into the general risk-based capital rules to implicitly cover other risks such as operational risk. With the introduction of the A-IRB framework for credit risk in this ANPR, which results in a more risksensitive treatment of credit risk, there is no longer an implicit capital buffer for other risks.

\footnotetext{
49 For a more detailed discussion of the concepts set forth in this ANPR and definitions of relevant terms, see the accompanying interagency "Supervisory Guidance on Operational Risk Advanced Measurement Approaches for Regulatory Capital” (supervisory guidance) published elsewhere in today's Federal Register.
} 
The Agencies recognize that operational risk is a key risk in financial institutions, and evidence indicates that a number of factors are driving increases in operational risk. These include the recent experience of a number of high-profile, high-severity losses across the banking industry highlighting operational risk as a major source of unexpected losses. Because the regulatory capital buffer for operational risk would be removed under the proposal, the Agencies are now seeking comment on a risk-sensitive capital framework for the largest, most complex institutions that would include an explicit risk-based capital requirement for operational risk. The Agencies propose to require banking organizations using the A-IRB approach for credit risk also to use the AMA to compute capital charges for operational risk.

The Agencies are proposing the AMA to address operational risk for regulatory capital purposes. The Agencies are interested, however, in possible alternatives. Are there alternative concepts or approaches that might be equally or more effective in addressing operational risk? If so, please provide some discussion on possible alternatives.

\section{A. AMA Capital Calculation}

The AMA capital requirement would be based on the measure of operational risk exposure generated by a banking organization's internal operational risk measurement system. In calculating the operational risk exposure, an AMA-qualified institution would be expected to estimate the aggregate operational risk loss that it faces over a one-year period at a soundness standard consistent with a 99.9 percent confidence level. The institution's AMA capital requirement for operational risk would be the sum of EL and UL, unless the institution can demonstrate that an EL offset would meet the supervisory standards for operational risk. The institution would have to use a combination of internal loss event data, relevant external loss event data, business environment and internal control factors, and scenario analysis in calculating its operational risk exposure. The institution also would be allowed to recognize the effect of risk dependency (for example, correlation) and, to a limited extent, the effect of insurance as a risk mitigant.

As with the proposed A-IRB capital requirement for credit risk, the operational risk exposure would be converted to an equivalent amount of risk-weighted assets for the calculation of an institution's risk-based capital ratios. An AMA-qualified institution would multiply the operational risk exposure generated by its analytical framework by a factor of 12.5 to convert the exposure to a risk-weighted assets equivalent. The resulting figure would be added to the comparable figures for credit and market risk in calculating the institution's risk-based capital denominator.

Does the broad structure that the Agencies have outlined incorporate all the key elements that should be factored into the operational risk framework for regulatory capital? If not, what other issues should be addressed? Are any elements included not directly relevant for operational risk measurement or management? The Agencies have not included indirect losses (for example, opportunity costs) in the definition of operational risk against which institutions would have to hold capital; because such losses can be substantial, should they be included in the definition of operational risk? 


\section{Overview of the Supervisory Criteria}

Use of the AMA would be subject to supervisory approval. A banking organization would have to demonstrate that it has satisfied all supervisory standards before it would be able to use the AMA for risk-based capital purposes. The supervisory standards are briefly described below. Because an institution would have significant flexibility to develop its own methodology for calculating its risk-based capital requirement for operational risk, it would be necessary for supervisors to ensure that the institution's methodology is fundamentally sound. In addition, because different institutions may adopt different methodologies for assessing operational risk, the requirement to satisfy supervisory standards offers some assurance to institutions and their supervisors that all AMA-qualified institutions would be subject to a common set of standards.

While the supervisory standards are rigorous, institutions would have substantial flexibility in terms of how they satisfy the standards in practice. This flexibility is intended to encourage an institution to adopt a system that is responsive to its unique risk profile, foster improved risk management, and allow for future innovation. The Agencies recognize that operational risk measurement is evolving rapidly and wish to encourage continued evolution and innovation. Nevertheless, the Agencies also acknowledge that this flexibility would make crossinstitution comparisons more difficult than if a single supervisory approach were to be mandated for all institutions. The supervisory standards outlined below are intended to allow flexibility while also being sufficiently objective to ensure consistent supervisory assessment and enforcement of standards across institutions.

The Agencies seek comment on the extent to which an appropriate balance has been struck between flexibility and comparability for the operational risk requirement. If this balance is not appropriate, what are the specific areas of imbalance and what is the potential impact of the identified imbalance?

The Agencies are considering additional measures to facilitate consistency in both the supervisory assessment of AMA frameworks and the enforcement of AMA standards across institutions. Specifically, the Agencies are considering enhancements to existing interagency operational and managerial standards to directly address operational risk and to articulate supervisory expectations for AMA frameworks. The Agencies seek comment on the need for and effectiveness of these additional measures.

The Agencies also seek comment on the supervisory standards. Do the standards cover the key elements of an operational risk framework?

An institution's operational risk framework would have to include an independent operational risk management function, line of business oversight, and independent testing and verification. Both the institution's board of directors and management would have to have responsibilities in establishing and overseeing this framework. The institution would have to have clear policies and procedures in place for identifying, measuring, monitoring, and controlling operational risk. 
An institution would have to establish an analytical framework that incorporates internal operational loss event data, relevant external loss event data, assessments of the business environment and internal control factors, and scenario analysis. The institution would have to have standards in place to capture all of these elements. The combination of these elements would determine the institution's quantification of operational risk and related regulatory capital requirement.

The supervisory standards for the AMA have both quantitative and qualitative elements. Effective operational risk quantification is critical to the objective of a risk-sensitive capital requirement. Consequently, a number of the supervisory standards are aimed at ensuring the integrity of the process by which an institution arrives at its estimated operational risk exposure.

It is not sufficient, however, to focus solely on operational risk measurement. If the Agencies are to rely on institutions to determine their risk-based capital requirements for operational risk, there would have to be assurances that institutions have in place sound operational risk management infrastructures. In addition, risk management elements would be critical inputs into the quantification of operational risk exposure, that is, operational risk quantification would have to take into account such risk management elements as the quality of an institution's internal controls. Likewise, the AMA capital requirement derived from an institution's quantification methodology would need to offer incentives for an institution to improve its operational risk management practices. Ultimately, the Agencies believe that better operational risk management will enhance operational risk measurement, and vice versa.

\section{Corporate Governance}

An institution's operational risk framework would have to include an independent firmwide operational risk management function, line of business management oversight, and independent testing and verification functions. While no specific management structure would be mandated, all three components would have to be evident.

The institution's board of directors would have to oversee the development of the firmwide operational risk framework, as well as major changes to the framework. Management roles and accountability would have to be clearly established. The board and management would have to ensure that appropriate resources have been allocated to support the operational risk framework.

The independent firm-wide operational risk management function would be responsible for overseeing the operational risk framework at the firm level to ensure the development and consistent application of operational risk policies, processes, and procedures throughout the institution. This function would have to be independent from line of business management and the testing and verification functions. The firm-wide operational risk management function would have to ensure appropriate reporting of operational risk exposures and loss data to the board and management.

Lines of business would be responsible for the day-to-day management of operational risk within each business unit. Line of business management would have to ensure that internal 
controls and practices within their lines of business are consistent with firm-wide policies and procedures that support the management and measurement of the institution's operational risk.

The Agencies are introducing the concept of an operational risk management function, while emphasizing the importance of the roles played by the board, management, lines of business, and audit. Are the responsibilities delineated for each of these functions sufficiently clear and would they result in a satisfactory process for managing the operational risk framework?

\section{Operational Risk Management Elements}

An institution would have to have policies and procedures that clearly describe the major elements of its operational risk framework, including identifying, measuring, monitoring, and controlling operational risk. Management reports would need to be developed to address both firm-wide and line of business results. These reports would summarize operational risk exposure, operational loss experience, and relevant assessments of business environment and internal control factors, and would have to be produced at least quarterly. Operational risk reports, which summarize relevant firm-wide operational risk information, would also have to be provided periodically to senior management and the board. An institution's internal control system and practice would have to be adequate in view of the complexity and scope of its operations. In addition, an institution would be expected to meet or exceed minimum supervisory standards as set forth in the Agencies' supervisory policy statements and other guidance.

\section{B. Elements of an AMA Framework}

An institution would have to demonstrate that it has adequate internal loss event data, relevant external loss event data, assessments of business environments and internal control factors, and scenario analysis to support its operational risk management and quantification framework. These inputs would need to be consistent with the regulatory definition of operational risk. The institution would have to have clear standards for the collection and modification of operational risk inputs.

There are a number of standards that banking organizations would have to meet with respect to internal operational loss data. Institutions would have to have at least five years of internal operational risk loss data captured across all material business lines, events, product types, and geographic locations. ${ }^{50}$ An institution would have to establish thresholds above which all internal operational losses would be captured. The New Accord introduces seven loss event type classifications; the Agencies are not proposing that an institution would be required to internally manage its operational risk according to these specific loss event type classifications, but nevertheless it would have to be able to map its internal loss data to these loss event categories. The institution would have to provide consistent treatment for the timing of reporting an operational loss in its internal data systems. As highlighted earlier in this ANPR, credit losses

\footnotetext{
${ }^{50}$ With supervisory approval, a shorter initial observation period may be acceptable for institutions that are newly authorized to use an AMA methodology.
} 
caused or exacerbated by operational risk events would be treated as credit losses for regulatory capital purposes; these would include fraud-related credit losses.

An institution would have to establish and adhere to policies and procedures that provide for the use of relevant external loss data in the operational risk framework. External data would be particularly relevant where an institution's internal loss history is not sufficient to generate an estimate of major unexpected losses. Management would have to systematically review external data to ensure an understanding of industry experience. The Agencies seek comment on the use of external data and its optimal function in the operational risk framework.

While internal and external data provide an important historic picture of an institution's operational risk profile, it is important that institutions take a forward-looking view as well. Consequently, an institution would have to incorporate assessments of the business environment and internal control factors (for example, audit scores, risk and control assessments, risk indicators, etc.) into its AMA capital assessment. In addition, an institution would have to periodically compare its assessment of these factors with actual operational loss experience.

Another element of the AMA framework is scenario analysis. Scenario analysis is a systematic process of obtaining expert opinions from business managers and risk management experts to derive reasoned assessments of the likelihood and impact of plausible operational losses consistent with the regulatory soundness standard. While scenario analysis may rely, to a large extent, on internal or, especially, external data (for example, where an institution looks to industry experience to generate plausible loss scenarios), it is particularly useful where internal and external data do not generate a sufficient assessment of the institution's operational risk profile.

An institution would be required to have a comprehensive analytical framework that provides an estimate of the aggregate operational loss that it faces over a one-year period at a soundness standard consistent with a 99.9 percent confidence level. The institution would have to document the rationale for all assumptions underpinning its chosen analytical framework, including the choice of inputs, distributional assumptions, and weighting of quantitative and qualitative elements. The institution would also have to document and justify any subsequent changes to these assumptions.

An institution's operational risk analytical framework would have to use a combination of internal operational loss event data, relevant external operational loss event data, business environment and control factors, as well as scenario analysis. The institution would have to combine these elements in the manner that most effectively enables it to quantify its operational risk exposure. The institution would have to develop an analytical framework that is appropriate to its business model and risk profile.

Regulatory capital for operational risk would be based on the sum of EL and UL. There may be instances where an EL offset could be recognized, but the Agencies believe that this is likely to be difficult given existing supervisory and accounting standards. The Agencies have considered both reserving and budgeting as potential mechanisms for EL offsets. The use of reserves may be hampered by accounting standards, while budgeting raises concerns about 
availability over a one-year time horizon to act as a capital replacement mechanism. The Agencies are interested in specific examples of how business practices might be used to offset EL in the operational risk framework.

An institution would have to document how its chosen analytical framework accounts for dependence (for example, correlation) among operational losses across and within business lines. The institution would have to demonstrate that its explicit and embedded dependence assumptions are appropriate, and where dependence assumptions are uncertain, the institution would have to use conservative estimates.

An institution would be able to reduce its operational risk exposure by no more than 20 percent to reflect the impact of risk mitigants such as insurance. Institutions would have to demonstrate that qualifying risk mitigants meet a series of criteria (described in the supervisory guidance) to assess whether the risk mitigants are sufficiently capital-like to warrant a reduction of the operational risk exposure.

The Agencies seek comment on the reasonableness of the criteria for recognition of risk mitigants in reducing an institution's operational risk exposure. In particular, do the criteria allow for recognition of common insurance policies? If not, what criteria are most binding against current insurance products? Other than insurance, are there additional risk mitigation products that should be considered for operational risk?

An institution using an AMA for regulatory capital purposes would have to use advanced data management practices to produce credible and reliable operational risk estimates. These practices are comparable to the data maintenance requirements set forth under the A-IRB approach for credit risk.

The institution would have to test and verify the accuracy and appropriateness of the operational risk framework and results. Testing and verification would have to be done independently of the firm-wide risk management function and the lines of business.

\section{Disclosure}

Market discipline is a key component of the New Accord. The disclosure requirements summarized below seek to enhance the public disclosure practices, and thereby the transparency, of advanced approach organizations. Commenters are encouraged to consult the New Accord for specifics on the disclosure requirements under consideration. The Agencies view enhanced market discipline as an important complement to the advanced approaches to calculating minimum regulatory capital requirements, which would be heavily based on internal methodologies. Increased disclosures, especially regarding a banking organization's use of the A-IRB approach for credit risk and the AMA for operational risk, would allow a banking organization's private sector investors to more fully evaluate the institution's financial condition, risk profile, and capital adequacy. Given better information, private shareholders and debt holders can better influence the funding and capital costs of a banking organization. Such actions would enhance market discipline and supplement supervisory oversight of the organization's risk-taking and management. 


\section{A. Overview}

Disclosure requirements would apply to the bank holding company representing the top consolidated level of the banking group. Individual banks within the holding company or consolidated group would not generally be required to fulfill the disclosure requirements set out below. An exception to the general rule would be that individual banks and thrifts within a group would still be required to disclose Tier 1 and total capital ratios and their components (that is, Tier 1, Tier 2, and Tier 3 capital), as is the case today. In addition, all banks and thrifts would continue to be required to submit appropriate information to regulatory authorities (for example, Report of Condition of Income (Call Reports) or Thrift Financial Reports). ${ }^{51}$

The Agencies are proposing a set of disclosure requirements that would allow market participants to assess key pieces of information regarding a banking group's capital structure, risk exposures, risk assessment processes, and ultimately, the capital adequacy of the institution. Failure to meet these minimum disclosure requirements, if not corrected, would render a banking organization ineligible to use the advanced approaches or would otherwise cause the banking organization to forgo potential capital benefits arising from the advanced approaches. In addition, other supervisory measures may be taken if appropriate.

Management would have some discretion to determine the appropriate medium and location of the required disclosure. Disclosures made in public financial reports (for example, in financial statements or Management's Discussion and Analysis included in periodic reports or SEC filings) or other regulatory reports (for example, FR Y-9C Reports), could fulfill the applicable disclosure requirements and would not need to be repeated elsewhere. For those disclosures that are not made under accounting or other requirements, the Agencies are seeking comment on the appropriate means of providing this data to market participants. Institutions would be encouraged to provide all related information in one location; at a minimum, institutions would be required to provide a cross reference to the location of the required disclosures.

The Agencies intend to maximize a banking organization's flexibility regarding where to make the required disclosures while ensuring that the information is readily available to market participants without unnecessary burden. To balance these contrasting objectives, the Agencies are considering requiring banking organizations to provide a summary table on their public websites that indicate where all disclosures may be found. Such an approach also would allow institutions to cross-reference other web addresses (for example, those containing public financial reports or regulatory reports or other risk-oriented disclosures) where certain of the disclosures are located.

Given longstanding requirements for robust quarterly disclosure in the United States, and recognizing the potential for rapid change in risk profiles, the Agencies intend to require that the disclosures be made on a quarterly basis. However, qualitative disclosures that provide a general summary of a banking organization's risk management objectives and policies, reporting system,

\footnotetext{
${ }^{51}$ In order to meet supervisory responsibilities, the Agencies plan to collect more detailed information through the supervisory process or regulatory reports. Much of this information may be proprietary and accordingly would not be made public.
} 
and definitions would be able to be published on an annual basis, provided any significant changes to these are disclosed in the interim. When significant events occur, banking organizations would be required to publish material information as soon as practicable rather than at the end of the quarter.

The risks to which banking organizations are exposed and the techniques that they use to identify, measure, monitor, and control those risks are important factors that market participants consider in their assessment of an institution. Accordingly, banking organizations would be required to have a formal disclosure policy approved by the board of directors that addresses the institution's approach for determining the disclosures it will make. The policy also would have to address the associated internal controls and disclosure controls and procedures. The board of directors and senior management would have to ensure that appropriate verification of the disclosures takes place and that effective internal controls and disclosure controls and procedures are maintained.

Consistent with sections 302 and 404 of the Sarbanes-Oxley Act of 2002, management would have to certify to the effectiveness of internal controls over financial reporting and disclosure controls and procedures, and the banking organization's external auditor would have to attest to management's assertions with respect to internal controls over financial reporting. The scope of these reports would need to include all information included in regulatory reports and the disclosures outlined in this ANPR. Section 36 of the Federal Deposit Insurance Act has similar requirements. Accordingly, banking organizations would have to implement a process for assessing the appropriateness of their disclosures, including validation and frequency. Unless otherwise required by accounting or auditing standards, or by other regulatory authorities, the proposed requirements do not mandate that the new disclosures be audited by an external auditor for purposes of opining on whether the financial statements are presented in accordance with GAAP.

\section{B. Disclosure Requirements}

Banking organizations would be required to provide disclosures related to scope of application, capital structure, capital adequacy, credit risk, equities in the banking book, credit risk mitigation, asset securitization, market risk, operational risk and interest rate risk in the banking book. The disclosure requirements are summarized below.

The required disclosures pertaining to the scope of application of the advanced approaches would include a description of the entities found in the consolidated banking group. Additionally, banking organizations would be required to disclose the methods used to consolidate them, any major impediments on the transfer of funds or regulatory capital within the banking group, and specific disclosures related to insurance subsidiaries.

Capital structure disclosures would provide summary information on the terms and conditions of the main features of capital instruments issued by the banking organization, especially in the case of innovative, complex, or hybrid capital instruments. Quantitative disclosures include the amount of Tier 1, Tier 2, and Tier 3 capital, deductions from capital, and total eligible capital. 
Capital adequacy disclosures would include a summary discussion of the banking organization's approach to assessing the adequacy of its capital to support current and future activities. These requirements also include a breakdown of the capital requirements for credit, equity, market, and operational risks. Banking organizations also would be required to disclose their Tier 1 and total capital ratios for the consolidated group, as well as those of significant bank or thrift subsidiaries.

For each separate risk area, a banking organization would describe its risk management objectives and policies. Such disclosures would include an explanation of the banking organization's strategies and processes; the structure and organization of the relevant risk management function; the scope and nature of risk reporting and/or measurement systems; and the policies for hedging and/or mitigating risk and strategies and processes for monitoring the continuing effectiveness of hedges/mitigants.

The credit risk disclosure regime is intended to enable market participants to assess the credit risk exposure of A-IRB banking organizations and the overall applicability of the A-IRB framework, without revealing proprietary information or duplicating the role of the supervisor in validating the framework the banking organization has put into place.

Credit risk disclosures would include breakdowns of the banking organization's exposures by type of credit exposure, geographic distribution, industry or counterparty type distribution, residual contractual maturity, amount and type of impaired and past due exposures, and reconciliation of changes in the allowances for exposure impairment.

Banking organizations would provide disclosures discussing the status of the regulatory acceptance process for the adoption of the A-IRB approach, including supervisory approval of such transition. The disclosures would provide an explanation and review of the structure of internal rating systems and relation between internal and external ratings; the use of internal estimates other than for A-IRB capital purposes; the process for managing and recognizing credit risk mitigation; and, the control mechanisms for the rating system including discussion of independence, accountability, and rating systems review. Required qualitative disclosures would include a description of the internal ratings process and separate disclosures pertaining to the banking organization's wholesale, retail and equity exposures.

There would be two categories of quantitative disclosures for credit risk: those that focus on the analysis of risk and those that focus on the actual results. Risk assessment disclosures would include the percentage of total credit exposures to which A-IRB disclosures relate. Also, for each portfolio except retail, the disclosures would have to provide (1) a presentation of exposures across a sufficient number of PD grades (including default) to allow for a meaningful differentiation of credit risk, ${ }^{52}$ and (2) the default weighted-average LGD for each PD, and the

\footnotetext{
${ }^{52}$ Where banking organizations are aggregating PD grades for the purposes of disclosure, this would be a representative breakdown of the distribution of PD grades used in the A-IRB approach.
} 
amount of undrawn commitments and weighted average EAD ${ }^{53}$ For retail portfolios, banking organization would provide either ${ }^{54}$ (a) disclosures outlined above on a pool basis (that is, the same as for non-retail portfolios), or (b) analysis of exposures on a pool basis against a sufficient number of EL grades to allow for a meaningful differentiation of credit risk.

Quantitative disclosures pertaining to historical results would include actual losses (for example, charge-offs and specific provisions) in the preceding period for each portfolio and how this differs from past experience and a discussion of the factors that affected the loss experience in the preceding period. In addition, disclosures would include banking organizations' estimates against actual outcomes over a longer period. ${ }^{55}$ At a minimum, this would include information on estimates of losses against actual losses in each portfolio over a period sufficient to allow for a meaningful assessment of the performance of the internal rating processes. Banking organizations would further be expected to decompose this to provide analysis of PD, LGD and EAD estimates against estimates provided in the quantitative risk assessment disclosures above. $^{56}$

Disclosures for banking book equity positions would include both balance sheet and fair values, and the types and nature of investments. The total cumulative realized gains or losses arising from sales and liquidations would be disclosed, together with total unrealized gains/losses and any amounts included in Tier 1 and/or Tier 2 capital. Details on the equity capital requirements would also be disclosed.

Disclosures relating to credit risk mitigation would include a description of the policies and processes for netting and collateral valuation and management, and the types of collateral accepted by the bank. Banking organizations would also be expected to include information about the main types of guarantor or credit derivative counterparties, and any risk concentrations arising from the use of a mitigation technique.

Securitization disclosures would summarize a banking organization's accounting policies for securitization activities and the current year's securitization activity. Further, banking organizations would be expected to disclose the names of the external credit rating providers

${ }^{53}$ Banking organizations need only provide one estimate of EAD for each portfolio. However, where banking organizations believe it is helpful, in order to give a more meaningful assessment of risk, they may also disclose EAD estimates across a number of EAD categories, against the undrawn exposures to which these relate.

${ }^{54}$ Banking organizations would normally be expected to follow the disclosures provided for the non-retail portfolios. However, banking organizations would be able to adopt EL grades as the basis of disclosure where they believe this can provide the reader with a meaningful differentiation of credit risk. Where banking organizations are aggregating internal grades (either PD/LGD or EL) for the purposes of disclosure, this should be a representative breakdown of the distribution of those grades used in the IRB approach.

${ }^{55}$ For banking organizations implementing the A-IRB and AMA in 2007, the disclosures would be required from year-end-2008; in the meantime, early adoption would be encouraged. The phased implementation is to allow banking organizations sufficient time to build up a longer run of data that will make these disclosures meaningful. For banking organizations that may adopt the advanced approaches at a later date, they would also be subject to a one-year phase in period after which the disclosures would be required.

${ }^{56}$ Banking organizations would have to provide this further decomposition where it would allow users greater insight into the reliability of the estimates provided in the quantitative disclosures: risk assessment. In particular, banking organizations should provide this information where there are material differences between the PD, LGD or EAD estimates given by banking organizations compared to actual outcomes over the long run. Banking organizations should also provide explanations for such differences. 
used for securitizations. They would also provide details of the outstanding exposures securitized by the banking organization and subject to the securitization framework, including impairments and losses, exposures retained or purchased broken down into risk weight bands, and aggregate outstanding amounts of securitized revolving exposures.

Disclosures for market risk would include a description of the models, stress testing, and backtesting used in assessing market risk, as well as information on the scope of supervisory acceptance. Quantitative disclosures would include the aggregate VaR, the high, mean, and low VaR values over the reporting period, and a comparison of VaR estimates with actual outcomes.

A key disclosure under the operational risk framework would be a description of the AMA the banking organization uses, including a discussion of relevant internal and external factors considered in the banking organization's measurement approach. In addition, the banking organization would disclose the operational risk charge before and after any reduction in capital resulting from the use of insurance or other potential risk mitigants.

Finally, disclosures relating to interest rate risk in the banking book would include the nature of that risk, key assumptions made, and the frequency of risk measurement. They would also include the increase or decline in earnings or economic value for upward and downward rate shocks according to management's method for measuring interest rate risk in the banking book.

The Agencies seek comment on the feasibility of such an approach to the disclosure of pertinent information and also whether commenters have any other suggestions regarding how best to present the required disclosures.

Comments are requested on whether the Agencies' description of the required formal disclosure policy is adequate, or whether additional guidance would be useful.

Comments are requested regarding whether any of the information sought by the Agencies to be disclosed raises any particular concerns regarding the disclosure of proprietary or confidential information. If a commenter believes certain of the required information would be proprietary or confidential, the Agencies seek comment on why that is so and alternatives that would meet the objectives of the required disclosure.

The Agencies also seek comment regarding the most efficient means for institutions to meet the disclosure requirements. Specifically, the Agencies are interested in comments about the feasibility of requiring institutions to provide all requested information in one location and also whether commenters have other suggestions on how to ensure that the requested information is readily available to market participants.

\section{REGULATORY ANALYSIS}

Federal agencies are required to consider the costs, benefits, or other effects of their regulations for various purposes described by statute or executive order. In particular, an 
executive order and several statutes may require the preparation of detailed analyses of the costs, benefits, or other effects of rules, depending on threshold determinations as to whether the rulemaking in question triggers the substantive requirements of the applicable statute or executive order.

For the reasons described above, the proposed and final rules that the Agencies may issue to implement the New Accord would represent a significant change to their current approach to the measurement of regulatory capital ratios, and the supervision of institutions' internal risk management processes with respect to capital allocations. First, in this ANPR, core and opt-in banks would rely on their own analyses to derive some of the principal inputs that would determine their regulatory capital requirements. Core and opt-in banks would incur new costs to create and refine their internal systems and to attract and train the staff expertise necessary to develop, oversee, manage and test those systems. Second, the measured regulatory capital ratios (although not the minimums) would likely change, perhaps substantially for core and opt-in banks. Third, the Agencies' approach to supervising capital adequacy would become bifurcated; that is, general banks would continue to use the general risk-based capital rules, either in their current form or as modified. As a result, there may be significant differences in the regulatory capital assigned to a particular type of asset depending on whether the bank is a core, opt-in, or general bank. To the extent that an institution's product mix would be directly affected by a change in the landscape of regulatory capital requirements, this might also affect the customers of those institutions due to the changes in pricing and market strategies.

The economic impact that would be created by these possibly unforeseen competitive effects is difficult to estimate, and the Agencies encourage comment. In particular, the Agencies are interested in comments on the competitive impact that a change in the regulatory capital regime applied to large institutions would have relative to the competitive position of smaller institutions that remain subject to the general risk-based capital rules. Conversely, if the regulatory burden of the more prescriptive A-IRB approach applied to core institutions were so large as to offset the potential for a lower measured capital requirement for certain exposures, then the competitive position of large institutions, with respect to both their domestic and international competitors, might be worsened. The Agencies are also interested in comments that address the competitive position of regulated institutions in the United States with respect to financial service providers, both domestic and foreign, that are not subject to the same degree of regulatory oversight.

None of the Agencies has yet made the threshold determinations required by executive order or statute with respect to this ANPR. Because the proposed approaches to assessing capital adequacy described in this ANPR are new, the Agencies currently lack information that is sufficiently specific or complete to permit those determinations to be made or to prepare any economic analysis that may ultimately be required. Therefore, this section of the ANPR describes the relevant executive order and statutes, and asks for comment and information that will assist in the determination of whether such analyses would be necessary before the Agencies published proposed or final rules.

Quantitative information would be the most useful to the Agencies. However, commenters may also provide estimates of costs, benefits, or other effects, or any other 
information they believe would be useful to the Agencies in making the determinations. In addition, commenters are asked to identify or estimate start-up, or non-recurring, costs separately from costs or effects they believe would be ongoing.

\section{A. Executive Order 12866}

Executive Order 12866 requires preparation of an economic analysis for agency actions that are "significant regulatory actions." "Significant regulatory actions" include, among other things, regulations that "have an annual effect on the economy of $\$ 100$ million or more or adversely affect in a material way the economy, a sector of the economy, productivity, competition, jobs, the environment, public health or safety, or state, local, or tribal governments or communities ...." ${ }^{57}$ Regulatory actions that satisfy one or more of these criteria are called "economically significant regulatory actions." E.O. 12866 applies to the OCC and the OTS, but not the Board or the FDIC. If the OCC or the OTS determines that the rules implementing the New Accord comprise an "economically significant regulatory action," then the agency making that determination would be required to prepare and submit to the Office of Management and Budget's (OMB) Office of Information and Regulatory Affairs (OIRA) an economic analysis that includes:

- a description of the need for the rules and an explanation of how they will meet the need;

- an assessment of the benefits anticipated from the rules (for example, the promotion of the efficient functioning of the economy and private markets) together with, to the extent feasible, a quantification of those benefits;

- an assessment of the costs anticipated from the rules (for example, the direct cost both to the government in administering the regulation and to businesses and others in complying with the regulation, and any adverse effects on the efficient functioning of the economy, private markets (including productivity, employment, and competitiveness)), together with, to the extent feasible, a quantification of those costs; and

- an assessment of the costs and benefits of potentially effective and reasonably feasible alternatives to the planned regulation (including improving the current regulation and reasonably viable nonregulatory actions), and an explanation why the planned regulatory action is preferable to the identified potential alternatives. $^{58}$

For purposes of determining whether this rulemaking would constitute an "economically significant regulatory action," as defined by E.O. 12866, and to assist any economic analysis that

\footnotetext{
${ }^{57}$ Executive Order 12866 (Sept. 30, 1993), 58 FR 51735 (Oct. 4, 1993), as amended by Executive Order 13258, 67 FR 9385 (referred to hereafter as E.O. 12866). For the complete text of the definition of "significant regulatory action," see E.O. 12866 at $\S 3(\mathrm{f})$. A "regulatory action" is "any substantive action by an agency (normally published in the Federal Register) that promulgates or is expected to lead to the promulgation of a final rule or regulation, including notices of inquiry, advance notices of proposed rulemaking, and notices of proposed rulemaking." E.O. 12866 at $\S(\mathrm{e})$.

${ }^{58}$ The components of the economic analysis are set forth in E.O. $12866 \S 6(\mathrm{a})(3)(\mathrm{C})(\mathrm{i})$-(iii). For a description of the methodology that OMB recommends for preparing an economic analysis, see Office of Management and Budget, "Economic Analysis of Federal Regulations Under Executive Order 12866" (January 11, 1996). This publication is available on OMB's website at www.whitehouse.gov/omb/inforeg/riaguide.html. OMB recently published revisions to this publication for comment. See 68 FR 5492 (February 3, 2003).
} 
E.O. 12866 may require, the OCC and the OTS encourage commenters to provide information about:

- the direct and indirect costs, for core banks and those banks who intend to qualify as optin banks, of compliance with the approach described in this ANPR and the related supervisory guidance;

- the costs, for general banks, of adopting the approach;

- the effects on regulatory capital requirements for core, opt-in, and general banks;

- the effects on competitiveness, in both domestic and international markets, for core, optin, and general banks. This would include the possible effects on the customers served by these U.S. institutions through changes in the mix of product offerings and prices;

- the economic benefits of the approach for core, opt-in, or general banks, as measured by lower regulatory capital ratios, and a potentially more efficient allocation of capital. This might also include estimates of savings associated with regulatory capital arbitrage transactions that are currently undertaken in order to optimize return on capital under the current capital regime. That is, what estimates might exist to quantify the improvements in market efficiency from no longer pursuing regulatory capital arbitrage transactions?

- the features of the A-IRB approach that provide an incentive for a bank to seek to qualify to use it, that is, to become an opt-in bank.

The OCC and the OTS also encourage comment on any alternatives to the regulatory approaches described in the ANPR that the Agencies should consider.

\section{B. Regulatory Flexibility Act}

The Regulatory Flexibility Act (RFA) generally requires agencies to prepare a "regulatory flexibility analysis" unless the head of the agency certifies that a regulation will not "have a significant economic impact on a substantial number of small entities." ${ }^{59}$ The RFA applies to all of the Agencies.

The Agencies understand that the RFA has been construed to require consideration only of the direct impact on small entities. ${ }^{60}$ The Small Business Administration (SBA) has said: "The courts have held that the RFA requires an agency to perform a regulatory flexibility analysis of small entity impacts only when a rule directly regulates them," that is, when it directly applies to them. ${ }^{61}$ Since the proposed approach would directly apply to only a limited number of large banking organizations, it would appear that the Agencies may certify that the issuance of this ANPR would not have significant economic impact on a substantial number of small entities.

\footnotetext{
${ }^{59}$ The RFA is codified at 5 U.S.C. 601 et seq.

${ }^{60}$ With respect to banks, the Small Business Administration (SBA) has defined a small entity to be a bank with total assets of $\$ 150$ million or less. 13 C.F.R. $\S 121.201$.

${ }^{61}$ SBA Office of Advocacy, A Guide for Government Agencies, "How to Comply with the Regulatory Flexibility Act (May 2003), at 20 (emphasis added). See also Mid-Tex Electric Cooperative, Inc. v. FERC, 773 F.2d 327 , 340-43 (D.C. Cir. 1985) ("[W]e conclude that an agency may properly certify that no regulatory flexibility analysis is necessary when it determines that the rule will not have a significant economic impact on a substantial number of small entities that are subject to the requirements of the rule.") (emphasis added) (construing language in the RFA that was unchanged by subsequent statutory amendments).
} 
Do the potential advantages of the A-IRB approach, as measured by the specific capital requirements on lower-risk loans, create a competitive inequality for small institutions, which are effectively precluded from adopting the A-IRB due to stringent qualification standards? Conversely, would small institutions that remain on the general risk-based capital rules be at a competitive advantage from specific capital requirements on higher risk assets vis-à-vis advanced approach institutions? How might the Agencies estimate the effect on credit availability to small businesses or retail customers of general banks?

\section{Unfunded Mandates Reform Act of $\mathbf{1 9 9 5}$}

The Unfunded Mandates Reform Act of 1995 (UMRA) requires preparation of a written budgetary impact statement before promulgation of any rule likely to result in a "Federal mandate" that "may result in the expenditure by State, local, and tribal governments, in the aggregate, or by the private sector, of $\$ 100,000,000$ or more (adjusted annually for inflation) in any 1 year." ${ }^{62}$ A "Federal mandate" includes any regulation "that would impose an enforceable duty upon the private sector. ..." If a budgetary impact statement is required, the UMRA further requires the agency to identify and consider a reasonable number of regulatory alternatives before promulgating the rule in question. The UMRA applies to the OCC and the OTS, but not the Board or the FDIC.

The OCC and the OTS have asked for comments and information from core and opt-in banks on compliance costs and, generally, on alternative regulatory approaches, for purposes of evaluating what actions they need to take in order to comply with E.O. 12866. That same information (with cost information adjusted annually for inflation) is relevant to those agencies' determination of whether a budgetary impact statement is necessary pursuant to the UMRA. Commenters are therefore asked to be mindful of the UMRA requirements when they provide information about compliance costs and in suggesting alternatives to the approach described in this ANPR.

\section{Paperwork Reduction Act}

Each of the Agencies is subject to the Paperwork Reduction Act of 1995 (PRA). ${ }^{63}$ The PRA requires burden estimates that will likely be based on some of the same information that is necessary to prepare an economic analysis under E.O. 12866 or an estimate of private sector expenditures pursuant to the UMRA.

In particular, an agency may not "conduct or sponsor" a collection of information without conducting an analysis that includes an estimate of the "burden" imposed by the collection. A collection of information includes, essentially, the eliciting of identical information - whether through questions, recordkeeping requirements, or reporting requirements - from ten or more persons. "Burden" means the "time, effort, or financial resources expended by persons to generate, maintain, or provide information" to the agency. The rulemaking initiated by this ANPR will likely impose requirements, either in the regulations themselves or as part of interagency implementation guidance, that are covered by the PRA. In order to estimate burden,

\footnotetext{
${ }^{62}$ The Unfunded Mandates Reform Act is codified at 2 U.S.C. 1532 et seq.

${ }^{63} 44$ U.S.C. $\S 3501$ et seq.
} 
the Agencies will need to know, for example, the cost - in terms of time and money - that mandatory and opt-in banks would have to expend to develop and maintain the systems, procedures, and personnel that compliance with the rules would require. With this in mind, to assist in their analysis of the treatment of retail portfolios and other exposures, the Agencies intend to request from U.S. institutions additional quantitative data for which confidential treatment may be requested in accordance with the Agencies' applicable rules.

While it will be difficult to identify those requirements with precision before a proposed rule is issued, this notice and the draft supervisory guidance published elsewhere in today's Federal Register generally describes aspects of the Agencies' implementation of the New Accord where new reporting and recordkeeping requirements would be likely. Commenters are asked to provide any estimates they can reasonably derive about the time, effort, and financial resources that will be required to provide the Agencies with the requisite plans, reports, and records that are described in this notice and in the supervisory guidance. Commenters also are requested to identify any activities that will be conducted as a result from the capital and methodological standards in the framework presented in this ANPR that would impose new recordkeeping or reporting burden. Commenters should specify whether certain capital and methodological standards would necessitate the acquisition or development of new compliance/ information systems or the significant modification of existing compliance/information systems.

\section{List of Acronyms}

$\begin{array}{ll}\text { ABCP } & \text { Asset-Backed Commercial Paper } \\ \text { ADC } & \text { Acquisition, Development, and Construction } \\ \text { AFS } & \text { Available-for-Sale (securities) } \\ \text { AIG } & \text { Accord Implementation Group } \\ \text { A-IRB } & \text { Advanced Internal Ratings-Based (approach for credit risk) } \\ \text { ALLL } & \text { Allowance for Loan and Lease Losses } \\ \text { AMA } & \text { Advanced Measurement Approach (for operational risk) } \\ \text { ANPR } & \text { Advance Notice of Proposed Rulemaking } \\ \text { BIS } & \text { Bank for International Settlements } \\ \text { BSC } & \text { Basel Committee on Banking Supervision } \\ \text { CCF } & \text { Credit Conversion Factor } \\ \text { CDC } & \text { Community Development Corporations } \\ \text { CEDE } & \text { Community and Economic Development Entity } \\ \text { CF } & \text { Commodities Finance } \\ \text { CRE } & \text { Commercial Real Estate } \\ \text { CRM } & \text { Credit Risk Mitigation } \\ \text { EAD } & \text { Exposure at Default } \\ \text { EL } & \text { Expected Loss } \\ \text { FFIEC } & \text { Federal Financial Institutions Examination Council } \\ \text { FMI } & \text { Future Margin Income } \\ \text { GAAP } & \text { Generally Accepted Accounting Principles } \\ \text { HVCRE } & \text { High Volatility Commercial Real Estate } \\ \text { IMF } & \text { International Monetary Fund } \\ \text { IRB } & \text { Internal Ratings-Based } \\ \text { KIRB } & \text { Capital for Underlying Pool of Exposures (securitizations) } \\ & \end{array}$




$\begin{array}{ll}\text { LGD } & \text { Loss Given Default } \\ \text { M } & \text { Maturity } \\ \text { MDB } & \text { Multilateral Development Bank } \\ \text { OF } & \text { Object Finance } \\ \text { OTC } & \text { Over-the-Counter (derivatives) } \\ \text { PCA } & \text { Prompt Corrective Action (regulation) } \\ \text { PD } & \text { Probability of Default } \\ \text { PDF } & \text { Probability Density Function } \\ \text { PF } & \text { Project Finance } \\ \text { PFE } & \text { Potential Future Exposure } \\ \text { PMI } & \text { Private Mortgage Insurance } \\ \text { PRA } & \text { Paperwork Reduction Act } \\ \text { PSE } & \text { Public-Sector Entity } \\ \text { QIS3 } & \text { Third Quantitative Impact Study } \\ \text { QRE } & \text { Qualifying Revolving Exposures } \\ \text { R } & \text { Asset Correlation } \\ \text { RBA } & \text { Ratings-Based Approach (securitizations) } \\ \text { RFA } & \text { Regulatory Flexibility Act } \\ \text { S } & \text { Borrower-Size } \\ \text { SBIC } & \text { Small Business Investment Company } \\ \text { SFA } & \text { Supervisory Formula Approach (securitizations) } \\ \text { SL } & \text { Specialized Lending } \\ \text { SME } & \text { Small- to Medium-Sized Enterprise } \\ \text { SPE } & \text { Special Purpose Entity } \\ \text { SSC } & \text { Supervisory Slotting Criteria } \\ \text { UL } & \text { Unexpected Loss } \\ \text { UMRA } & \text { Unfunded Mandates Reform Act } \\ \text { VaR } & \text { Value at Risk (model) } \\ \end{array}$


[THIS SIGNATURE PAGE RELATES TO THE JOINT ADVANCE NOTICE OF PROPOSED RULEMAKING ON "RISK-BASED CAPITAL GUIDELINES; IMPLEMENTATION OF THE NEW BASEL CAPITAL ACCORD”]

July 17,2003

Date (signed) John D. Hawke, Jr. John D. Hawke, Jr.

Comptroller of the Currency 
[THIS SIGNATURE PAGE RELATES TO THE JOINT ADVANCE NOTICE OF PROPOSED RULEMAKING ON "RISK-BASED CAPITAL GUIDELINES; IMPLEMENTATION OF THE NEW BASEL CAPITAL ACCORD]

By order of the Board of Governors of the Federal Reserve System, July 21, 2003.

(signed) Jennifer J. Johnson

Jennifer J. Johnson

Secretary of the Board 
[THIS SIGNATURE PAGE RELATES TO THE JOINT ADVANCE NOTICE OF PROPOSED RULEMAKING ON "RISK-BASED CAPITAL GUIDELINES; IMPLEMENTATION OF THE NEW BASEL CAPITAL ACCORD]

By order of the Board of Directors.

Dated at Washington, DC, this $11^{\text {th }}$ day of July, 2003.

Federal Deposit Insurance Corporation

(signed) Robert E. Feldman

Robert E. Feldman,

Executive Secretary.

$(\mathrm{SEAL})$ 
[THIS SIGNATURE PAGE RELATES TO THE JOINT ADVANCE NOTICE OF PROPOSED RULEMAKING ON "RISK-BASED CAPITAL GUIDELINES; IMPLEMENTATION OF THE NEW BASEL CAPITAL ACCORD]

Dated: July 18, 2003

By the Office of Thrift Supervision

(signed) James E. Gilleran

James E. Gilleran

Director 